\title{
AGR-3/4 TRISO Fuel Compact Ceramography
}

John Stempien

Jason Schulthess

March 2020

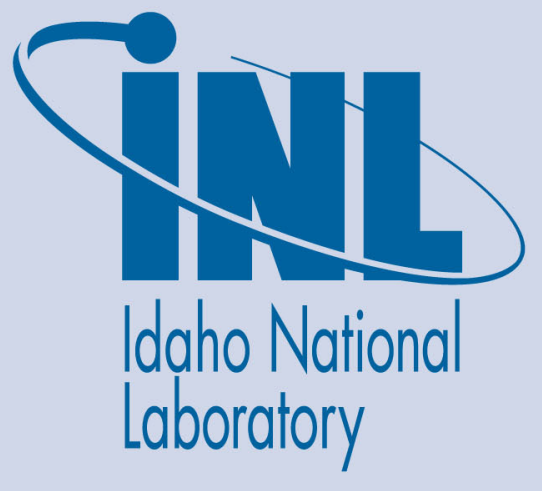

The INL is a U.S. Department of Energy National Laboratory operated by Battelle Energy Alliance 


\section{DISCLAIMER}

This information was prepared as an account of work sponsored by an agency of the U.S. Government. Neither the U.S. Government nor any agency thereof, nor any of their employees, makes any warranty, expressed or implied, or assumes any legal liability or responsibility for the accuracy, completeness, or usefulness, of any information, apparatus, product, or process disclosed, or represents that its use would not infringe privately owned rights. References herein to any specific commercial product, process, or service by trade name, trademark, manufacturer, or otherwise, does not necessarily constitute or imply its endorsement, recommendation, or favoring by the U.S. Government or any agency thereof. The views and opinions of authors expressed herein do not necessarily state or reflect those of the U.S. Government or any agency thereof. 
INL/EXT-20-57610

Revision 0

\title{
AGR-3/4 Fuel Compact Ceramography
}

\author{
John Stempien \\ Jason Schulthess
}

March 2020

\begin{abstract}
Idaho National Laboratory
INL ART Program

Idaho Falls, Idaho 83415
\end{abstract}

http://www.inl.gov

Prepared for the

U.S. Department of Energy

Office of Nuclear Energy

Under DOE Idaho Operations Office

Contract DE-AC07-05ID14517 

INL ART Program

\title{
AGR-3/4 Fuel Compact Ceramography
}

\author{
INL/EXT-20-57610 \\ Revision 0
}

March 2020

Prepared by:
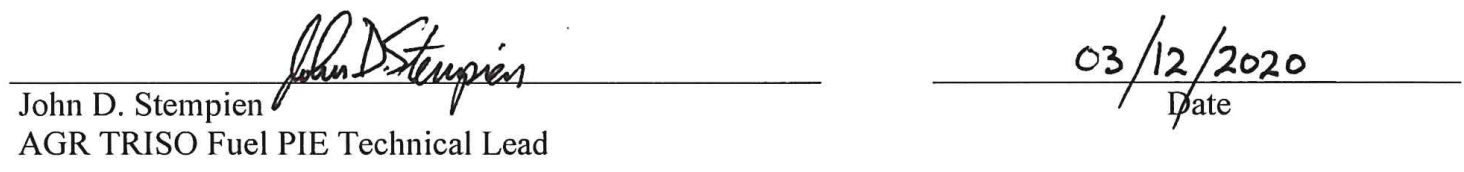

Approved by:

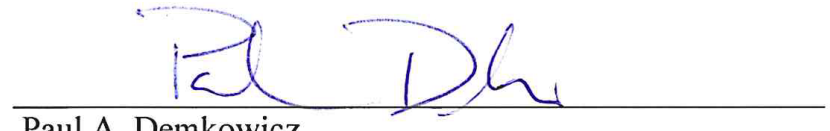

Paul A. Demkowicz

AGR TRISO Fuel Program Technical Director
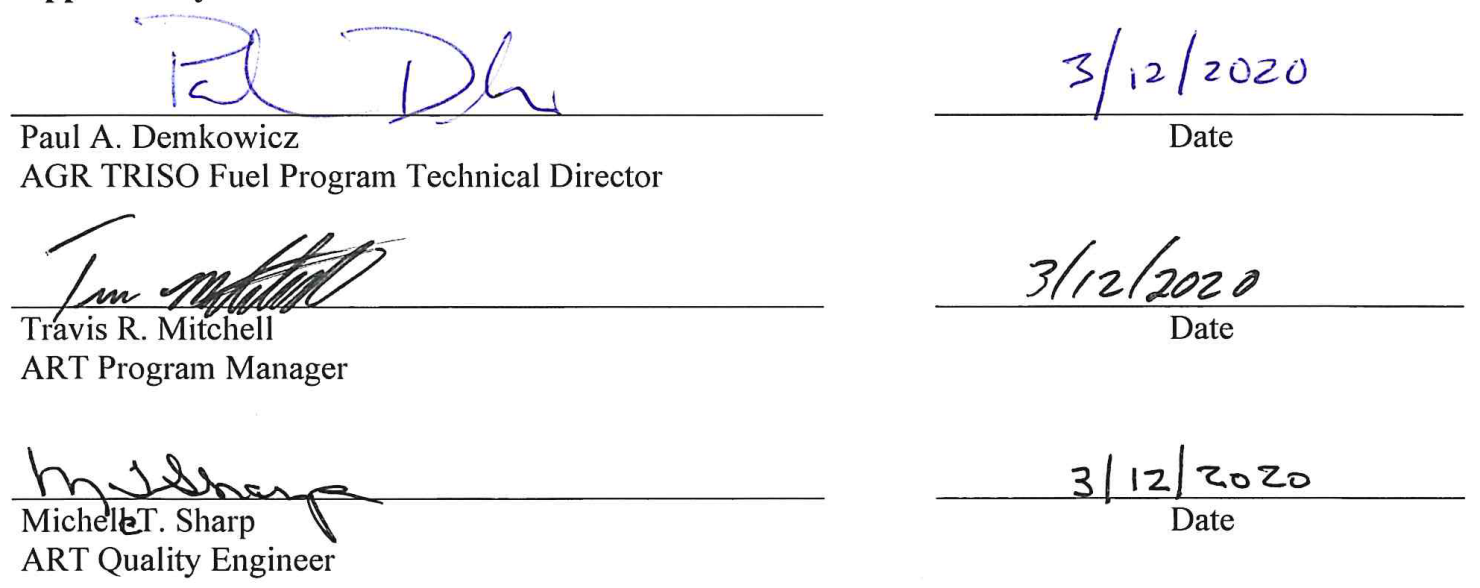


\section{SUMMARY}

The combined third and fourth irradiation in the Advanced Gas Reactor (AGR) program (AGR-3/4) contained tristructural isotropic (TRISO)-coated particle fuel and designed-to-fail (DTF) fuel particles. The DTF particles were only coated with highly anisotropic pyrocarbon (PyC) so they would purposely fail during the AGR-3/4 irradiation and provide a source of fission products for measurement.

To observe the post-irradiation morphology of these DTF particles and the TRISOcoated particles, three AGR-3/4 compacts were mounted in epoxy, sectioned above their centerlines, and ground/polished. Three rounds of grinding/polishing and optical microscopy were performed so that the particles could be observed at multiple planes. Each compact contained approximately 1,872 TRISO particles and exactly $20 \mathrm{DTF}$ particles. The three AGR-3/4 compacts examined covered a wide temperature range and featured both the hottest average irradiation temperature $\left(1375^{\circ} \mathrm{C}\right)$ and the coldest/lowest burnup $\left(872^{\circ} \mathrm{C}\right.$ and $5.5 \%$ fissions per initial metal atom) of any compacts to undergo post-irradiation examination (PIE) in the AGR program to date. A total of $29 \mathrm{DTF}$ particles were located and observed via microscopy across the three compacts. All the DTF particles observed via microscopy had completely failed PyC coatings.

Some different DTF kernel and PyC morphologies were observed that have been attributed to the differences in irradiation temperature and/or burnup. At low and medium irradiation temperatures (roughly 850 to $1050^{\circ} \mathrm{C}$ ), it appears irradiation-induced dimensional changes in the DTF PyC caused it to fracture and fold in on itself, and the kernel deformed to accommodate this PyC deformation. The extent of DTF kernel deformation to accommodate DTF PyC buckling tended to be greater for the mediumtemperature fuel compared to the cold fuel. In the high irradiation temperature compact $\left(1375^{\circ} \mathrm{C}\right)$, the DTF PyC layer appears to have completely reacted chemically with the kernel material. The only material surrounding the DTF particles in this hot compact resembles the compact matrix material.

Observations of the TRISO-coated driver fuel particles and fuel compact graphitic matrix were also made. The TRISO particle kernels in the medium-temperature compact $\left(1047^{\circ} \mathrm{C}\right)$, and many in the high-temperature compact $\left(1375^{\circ} \mathrm{C}\right)$, showed morphologies consistent with what was seen in AGR-1 and AGR-2. In other TRISO particles from the high-temperature compact, a spatial gradient in the kernel appearance was evident. Here the cool side of the kernel (away from the center of the compact) had a much darker appearance (like that of the buffer and pyrocarbon). This is the first observation of this kind of kernel spatial gradient in AGR fuel. It is believed that the high irradiation temperature of that compact (an average of $1375^{\circ} \mathrm{C}$ ) activates or accelerates an unidentified chemical reaction, and the temperature gradient within the fuel causes a sharp spatial gradient.

The low-temperature/low-burnup compact also showed unique kernel morphologies where the TRISO-coated particles had clearly distinguishable oxide and carbide phases at the center of the kernel, an oxide rind surrounding this, and remnants of a carbide skin surrounding the oxide rind. These are features observed in the as-fabricated fuel that are no longer present in higher burnup fuel.

Occasional gaps between the outer pyrolytic carbon $(\mathrm{OPyC})$ and graphitic matrix material were observed in all compacts. Gaps were most often found in the small, matrixfilled spaces between adjacent particles. 
Finally, buffer morphologies in AGR-3/4 TRISO particles were like those observed in AGR-1 and AGR-2, and the buffer fracture frequencies in AGR-3/4 and AGR-2 TRISO particles were plotted versus fast neutron fluence and irradiation temperature. In AGR-3/4 the buffer fracture rate was highest (23\%) for an irradiation temperature of $1047^{\circ} \mathrm{C}$ and a fast fluence of $5.18 \mathrm{E} 25 \mathrm{n} / \mathrm{m}^{2}$. Increasing the irradiation temperature to $1375^{\circ} \mathrm{C}$ reduced the buffer fracture rate to $14 \%$. Reducing the irradiation temperature to $872^{\circ} \mathrm{C}$ and the fast fluence by a factor of 3 reduced the buffer fracture rate to $7 \%$. The temperature and fluence dependencies observed for AGR-3/4 buffer fracture were consistent with those observed in AGR-2. Lower fluences and/or higher temperatures significantly reduced the buffer fracture frequencies. Lower buffer fracture frequencies were also observed at lower temperatures as long as the fluence was also significantly reduced. This is believed to be due to lower fluence resulting in less irradiation-induced dimensional change (shrinkage) of the buffer, and a higher temperature promoting enhanced creep relaxation of stresses within the buffer, leading to less buffer fracture. 


\section{ACKNOWLEDGEMENTS}

Critical contributions to this work were made by a number of people. Brian Frickey performed materialographic preparation of the irradiated and unirradiated fuel compacts. This included designing and fabricating the mounts, grinding, and polishing the mounts at the Hot Fuel Examination Facility at Idaho National Laboratory. Cassie Anderson-Thueson assisted in the mounting, grinding, polishing, and optical microscopy work. John Stanek and Francine Rice assisted in the mount design and provided valuable input to sample preparation and microscopy processes leading to acquisition of the images included in this report. Fuel burnup and fast neutron fluence were calculated by Dr. Jim Sterbentz. Fuel temperatures and temperature variations were calculated by Grant Hawkes. 


\section{CONTENTS}

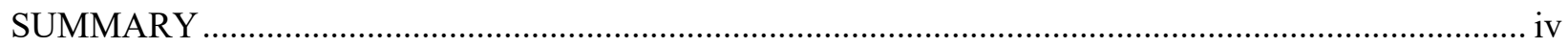

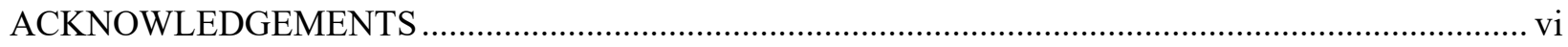

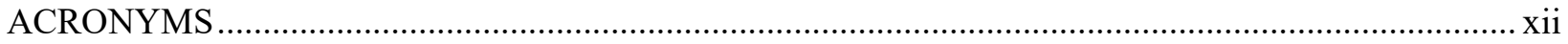

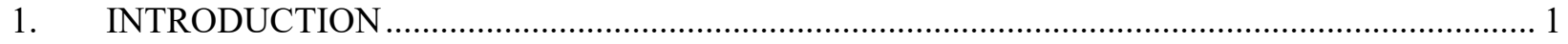

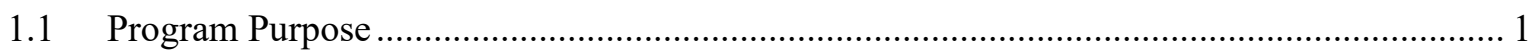

1.2 Status and Purpose of AGR Irradiation Experiments......................................................... 1

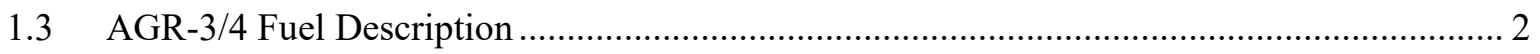

2. FUEL COMPACT CERAMOGRAPHY PURPOSE AND PROCESSES ..................................... 3

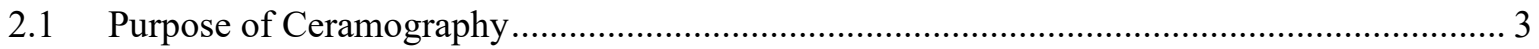

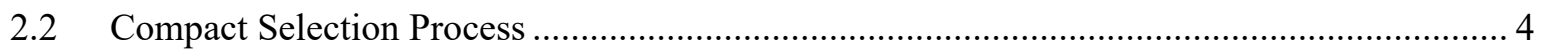

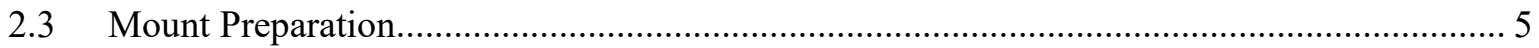

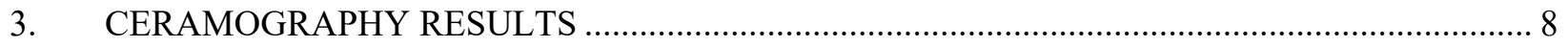

3.1 Unirradiated Compact Cross-Sections ......................................................................... 8

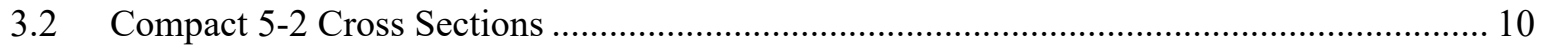

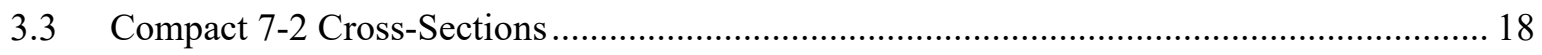

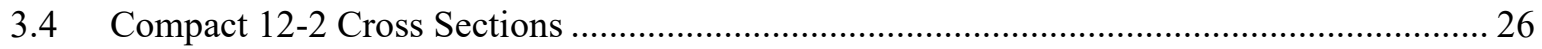

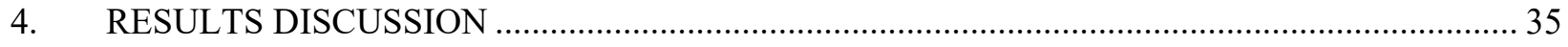

4.1 DTF Pyrocarbon Coating Integrity and Morphology ........................................................ 35

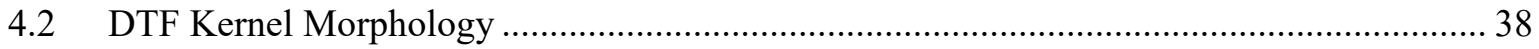

4.3 Driver Particle Buffer/Kernel and Matrix Morphologies..................................................... 39

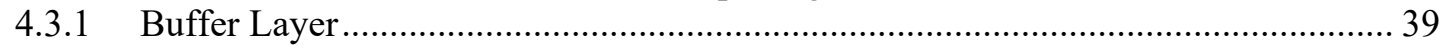

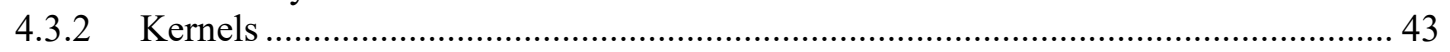

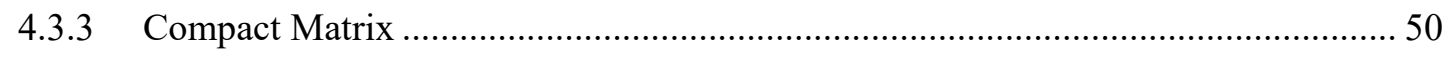

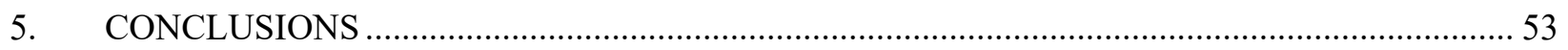

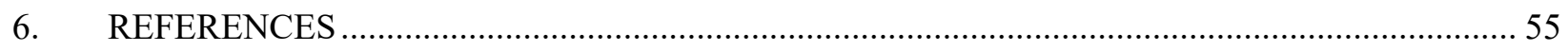




\section{FIGURES}

Figure 1. Image of an AGR-3/4 fuel compact (left) and x-ray side view image (right) (Hunn, Trammell, and Montgomery 2011). DTF particles are highlighted with red dots in the $\mathrm{x}$-ray image

Figure 2. Irradiation temperature and burnup for each US AGR compact. AGR-3/4 compacts selected for ceramography are highlighted. Burnups are from (Sterbentz 2013, Sterbentz 2014, and Sterbentz 2015), and temperatures are from (Hawkes 2014a, Hawkes 2014b, and Hawkes 2016).

Figure 3. Two representations of an AGR-3/4 compact in the specially fabricated mount. 6

Figure 4. Sample preparation equipment at Window 2M (also known as the "Containment Box") at HFEF.

Figure 5. X-ray radiograph of as-fabricated compact from Figure 1-8 of (Hunn et al. 2011).

Kernels farthest from compact centerline were estimated to be $1.4 \mathrm{~mm}$ from centerline. Red dots highlight DTF particles. Top purple bar denotes extent of compact diameter used to calibrate image. Lower purple bar shows maximum distance between DTF particles and compact center $(\sim 1.4 \mathrm{~mm})$.

Figure 6. Instruments in the "Met Box" located in Room 133 at HFEF. The Leica microscope was

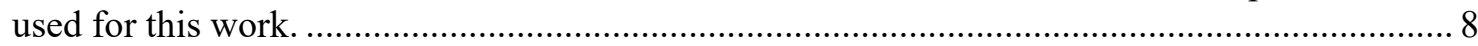

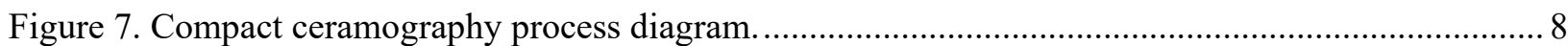

Figure 8. Montage of multiple micrographs of a unirradiated Compact Z138 (MNT78A) crosssection with five DTF particles visible. Kernel diameter measurements were also made on a three TRISO driver particles.

Figure 9. Cross-section of unirradiated DTF particle "1" from MNT78A (see Figure 8) in this work (left) and from work on a different, unirradiated compact in Hunn et al. 2011 Figure 1-13 (right).

Figure 10. Montages of optical micrographs of the cross-sections of AGR-3/4 Compact 5-2 after each of the three rounds of polishing/grinding.

Figure 11. Compact 5-2 cross-section after third polish. DTF particles are highlighted and labeled 1 through 11 .

Figure 12. Optical micrograph of DTF 1 from the first polished cross-section of Compact 5-2 _.............. 13

Figure 13. Optical micrograph of DTF 2 from the second polished cross-section of Compact 5-2 .......... 13

Figure 14. Optical micrograph of DTF 4 from the second polished cross-section of Compact 5-2 (left). Optical micrograph of the same particle from the third polished cross-section (right).

Figure 15. Optical micrograph of DTF 6 from the first polished cross-section of Compact 5-2.............. 14

Figure 16. Optical micrograph of DTF 7 from the second cross-section of Compact 5-2 _..................... 15

Figure 17. Optical micrograph of DTF 8 from the second cross-section of Compact 5-2 2..................... 15

Figure 18. Optical micrograph of DTF 11 from the second cross-section of Compact 5-2 (left) and from the third cross-section (right). 
Figure 19. Optical micrographs of five different TRISO-coated driver fuel particles from the third polished cross-section of Compact 5-2. The locations of these driver particles within the mount were indicated by red dots in the middle image in Figure 10.

Figure 20. Montages of optical micrographs of the cross-sections of AGR-3/4 Compact 7-2 after each of the three rounds of grinding/polishing.

Figure 21. Montage of optical micrographs from the third polish of Compact 7-2. Each DTF particle imaged from any of the three cross-sections is labeled and numbered.

Figure 22. Montage of optical micrographs of DTF 1 through DTF 3 and several TRISO-coated driver fuel particles after the first polish of Compact 7-2.

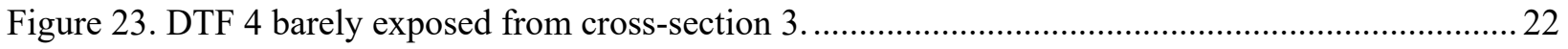

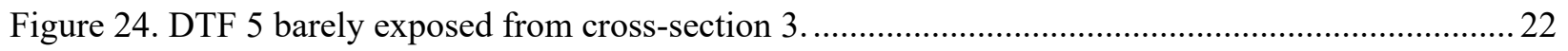

Figure 25. DTF 6 from first cross-section (top), second cross-section (middle), and third crosssection (bottom).

Figure 26. DTF 8 first cross-section (top), second cross-section (middle), third cross-section (bottom).

Figure 27. Montage of optical micrographs from the third cross-section of Compact 7-2. Driver particles and pairs of driver particles are highlighted and labeled A through G. These labels will be referenced in later sections of the report.

Figure 28. Montage of optical micrographs after each of three rounds of grinding and polishing of AGR-3/4 Compact 12-2.

Figure 29. Montage of optical micrographs from the third polished cross-section of Compact 12-

2. DTF particles are highlighted and numbered. 28

Figure 30. Optical micrograph of DTF 1 from the third polished cross-section of Compact 12-2 _...........29

Figure 31. Optical micrograph of DTF 2 from the third polished cross-section of Compact 12-2_...........29

Figure 32. Optical micrograph of DTF 3 from the third polished cross-section of Compact 12-2 2............ 30

Figure 33. Optical micrographs of DTF 4 after the second polish (left) and third polish (right). Scale applies to right image only. 30

Figure 34. Optical micrographs of DTF 5 after the second polish (left) and the third polish (right).

Scale applies to right image only

Figure 35. Optical micrograph of DTF 6 from the third polished cross-section of Compact 12-2 ….........31

Figure 36. Optical micrograph of DTF 7 from the third polish of Compact 12-2 .................................. 32

Figure 37. Optical micrograph of DTF 8 from the third polish of Compact 12-2 ................................ 32

Figure 38. Optical micrograph of TRISO-coated driver fuel particle from Compact 12-2 after first polish. Particle was located immediately to the left of DTF 8 in Figure 29. This figure is enlarged and annotated in Figure 49 in Section 4.3.2.

Figure 39. Montage of optical micrographs of driver particles from the first cross-section of Compact 12-2. These particles were located to the right of DTF 1, 2, and 3, in Figure 29.

Figure 40. Optical micrograph of a driver particle from the second cross-section of Compact 12-2 ........ 34

Figure 41. Optical micrograph of a driver particle from the third polish of Compact 12-2 2..................... 34 
Figure 42. Optical micrograph of DTF 6 from the first cross-section of Compact 7-2 after reducing brightness and contrast. Compare with top micrograph in Figure 25.

Figure 43. Optical micrographs from two DTF particles in HFR-B1 Capsule 1 Compact DC 012100 (Hanson 2006). Annotations added.

Figure 44. Montage of optical micrographs of a driver particle with fracture buffer layer and kernel extrusion. Particle from AGR-3/4 Compact 5-2.

Figure 45. Buffer fracture frequency for AGR-1 TRISO particles. ......................................................... 42

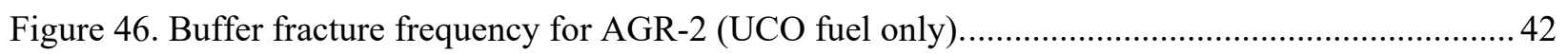

Figure 47. Buffer fracture frequency for AGR-3/4 TRISO particles.................................................... 43

Figure 48. Driver particle from Compact 5-2 (TAVA $1047^{\circ} \mathrm{C}$ ), cross-section 3. Image also shown

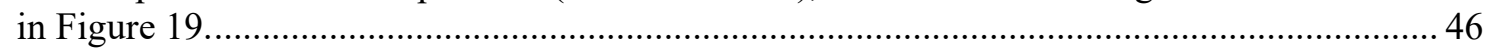

Figure 49. Driver particle from Compact 12-2 (TAVA $872^{\circ} \mathrm{C}$ ), cross-section 1. Image enlarged from Figure 38.

Figure 50. Optical micrograph of driver particle from the second cross-section of Compact 7-2. Particle was highlighted by the second-from-left-most red dot in the center micrograph in Figure 20.

Figure 51. Montage of optical micrographs of driver particles from Compact 7-3, cross-section 3. These particles were highlighted in Region B in Figure 27.

Figure 52. Particle 212-RS08 from $1800^{\circ} \mathrm{C}$-safety tested AGR-2 UCO Compact 2-1-2 (left) (Hunn et al. 2019b). Particle 642-RS27 from $1800^{\circ} \mathrm{C}$-safety tested AGR-2 UCO Compact 6-4-3 (right) (Hunn et al. 2019a).

Figure 53. Driver particle from Compact 5-2 (TAVA $1047^{\circ} \mathrm{C}$ ), cross-section 3. Image also shown in Figure 19 and Figure 48.

Figure 54. Image from the first cross-section from Compact 7-2 (MNT80A).

Figure 55. Montage of two images of the cross-section from the third polish of Compact 12-2 (MNT81A).

Figure 56. Montage of two images from the first cross-section of Compact 12-2 (MNT81A). OPyC barely exposed on particle. 


\section{TABLES}

Table 1. As-fabricated particle dimensions and standard deviations from Table A-2 of (Collin 2015)..... 3

Table 2. AGR-3/4 DTF particle failure count in each irradiation capsule (Collin et al. 2018). 5

Table 3. Compact properties and ceramographic mount identifiers for the three AGR-3/4 compacts. 5

Table 4. Observed DTF failures and probability that all 20 DTF particles in a compact had failed.......... 38

Table 5. Summary of irradiation temperature, fluence, and buffer fracture frequency for AGR-3/4 ........ 41 


\section{ACRONYMS}

AGR Advanced Gas Reactor

ART Advanced Reactor Technologies

ATR Advanced Test Reactor

DTF designed-to-fail

FIMA fissions per initial metal atom

HFEF Hot Fuel Examination Facility

HFR High Flux Reactor

HTGR high-temperature gas-cooled reactor

INL Idaho National Laboratory

IPyC inner pyrolytic carbon

OPyC outer pyrolytic carbon

PIE post-irradiation examination

PyC pyrolytic carbon (also called pyrocarbon)

$\mathrm{SiC} \quad$ silicon carbide

TA time-averaged

TAVA time-averaged, volume-averaged

TRISO tristructural isotropic 


\section{AGR-3/4 Fuel Compact Ceramography}

\section{INTRODUCTION \\ 1.1 Program Purpose}

The Advanced Gas Reactor (AGR) Fuel Development and Qualification Program was established to perform research and development on tristructural isotropic (TRISO)-coated particle fuel to support deployment of a high-temperature gas-cooled reactor (HTGR). This work continues as part of the Advanced Reactor Technologies (ART) Program. The overarching goal of the ART AGR program is to provide a baseline fuel qualification data set to support licensing and operation of an HTGR. To achieve these goals, the program includes the elements of fuel fabrication, irradiation, post-irradiation examination (PIE) and safety/heating testing, fuel performance modeling, and fission product transport (Idaho National Laboratory, 2019). Several fuel irradiation experiments have been performed at the Advanced Test Reactor (ATR) at Idaho National Laboratory (INL), and a fourth irradiation began in February 2018. These experiments are intended to provide data on fuel performance under irradiation, support fuel fabrication process development, qualify fuel for operating and accident conditions, provide irradiated fuel for accident testing, and support development of fuel performance and fission product transport models.

\subsection{Status and Purpose of AGR Irradiation Experiments}

The first two AGR fuel irradiation experiments (AGR-1 and AGR-2) had similar test train designs, and one objective was to test uranium oxycarbide (UCO) TRISO-coated particle fuel performance over a range of irradiation temperatures and burnups. UCO fuel kernels are a heterogeneous mixture of uranium carbide and uranium oxide. AGR-2 TRISO coatings were fabricated using conditions derived from the AGR-1 Variant 3 fuel, and while the AGR-1 coatings were produced at the lab-scale, AGR-2 coatings were produced in a 6-in. diameter, engineering-scale coater (INL 2019).

AGR-1 was irradiated in the B-10 position in ATR from December 2006 to November 2009 (Collin 2015a). In addition to AGR UCO fuel (in Capsules 2, 5, and 6), the AGR-2 experiment also had $\mathrm{UO}_{2}$ fuel (in Capsule 3) to compare the performance of $\mathrm{UCO}$ versus $\mathrm{UO}_{2}$ fuel and to compare to $\mathrm{UO}_{2}$ fuel performance observed historically in the German TRISO fuel program. ${ }^{a}$ AGR-2 was irradiated in the B12 position of ATR from June 2010 to October 2013 (Collin 2018a). The major elements of AGR-1 PIE are complete (Demkowicz et al. 2015). AGR-2 PIE began in July 2014, is still in-progress, and encompasses as-irradiated analyses, reirradiations, heating tests microscopy, and other activities.

The third irradiation experiment, AGR-3/4, was designed to investigate the migration of fission products in fuel compact graphitic matrix and reactor graphite components. The experiment consisted of fuel compacts containing TRISO-coated driver-fuel particles similar to AGR-1 baseline fuel (Collin 2015b; Hunn and Lowden 2007; Hunn et al. 2014) and designed-to-fail (DTF) particles that are designed to release fission products during irradiation to migrate through the surrounding cylindrical rings of graphitic matrix and nuclear-grade graphite. Following irradiation, PIE measurements of the fission product distributions in these rings and fuel compacts are critical components of the experiment. PIE will provide data to support refinement of fission product transport models and HTGR source-term analyses (Demkowicz 2017).

The fourth irradiation experiment, AGR-5/6/7 (Collin 2018b), started in ATR in February 2018 and serves as the fuel qualification irradiation.

a The AGR-2 irradiation had six irradiation capsules. Capsules 2, 3, 5, and 6 were US AGR capsules. Capsules 1 and 4 were French and South African fuel, respectively (Collin 2018a). Capsule 1 and 4 fuel compacts are not discussed. 


\subsection{AGR-3/4 Fuel Description}

The AGR-1 and AGR-2 experiments focused on the performance of high-quality TRISO fuel, and PIE focused on quantifying the very small rates of SiC and TRISO coating failures. In contrast, the AGR$3 / 4$ experiment was primarily a fission product transport experiment focused on observing the migration of fission products throughout fuel and nuclear-grade graphites in the presence of exposed fuel kernels. A feature of AGR-3/4 fuel that sets it apart from AGR-1 and AGR-2 was the incorporation of 20 DTF particles in each compact, in addition to the approximately 1,872 TRISO-coated "driver" fuel particles. DTF fuel kernels were coated only with a thin $(20-\mu \mathrm{m}$-thick) pyrocarbon layer. This layer was intentionally fabricated with high anisotropy, such that it would be likely to fail during the irradiation (Collin 2015b; Hunn and Miller 2009; and Kercher et al. 2011), resulting in up to 20 exposed fuel kernels per compact. As shown at right in Figure 1, the DTF particles (highlighted in red) were aligned roughly along the compact radial centerline. DTF particles provided a known source of fission products to migrate radially outward in the compacts and into the surrounding concentric rings of graphite and/or matrix material. It was expected that intact DTF particles would behave like TRISO particles with SiC layer failures (releasing substantial Cs, but retaining fission gases), and failed DTF particles (DTF particles with breached pyrocarbon layers) would behave like TRISO particles with failed TRISO coatings (releasing both Cs and fission gases).

The white particles in Figure 1 are the driver particles. AGR-3/4 driver particle fuel kernels were fully TRISO-coated with buffer layer, inner pyrolytic carbon layer (IPyC), silicon carbide layer (SiC), and outer pyrolytic carbon layer (OPyC) characteristics similar to the "baseline" variant from the AGR-1 experiment (Collin 2015c; Hunn and Lowden 2007). Both the AGR-3/4 driver and DTF fuel particles contain UCO fuel kernels (approximately $350 \mu \mathrm{m}$ in diameter) manufactured at BWX Technologies Nuclear Operations Group (Lynchburg, VA). The U-235 enrichment was 19.7 wt\%. The DTF pyrocarbon coating and the driver fuel TRISO coatings were applied to the kernels at Oak Ridge National Laboratory (ORNL). Driver particle and DTF particle properties are summarized in (Collin 2015b). Complete kernel and particle characterization and fabrication data are compiled in (Kercher and Hunn 2006; Hunn and Lowden 2007; Hunn and Miller 2009; Kercher et al., 2011). Driver fuel particles and DTF particles had average dimensions summarized in Table 1.

AGR-3/4 driver and DTF particles were over-coated with a precursor to graphitic matrix material and formed into cylindrical fuel compacts at ORNL. The compact graphitic matrix material is composed of multiple types of graphite and a carbonized phenolic resin. Compacts were nominally $12.3 \mathrm{~mm}$ in diameter and $12.5 \mathrm{~mm}$ long (in contrast to the AGR-1 and AGR-2 compacts, which were approximately $12.3 \mathrm{~mm}$ in diameter and $25 \mathrm{~mm}$ long). A summary of AGR-3/4 fuel compact properties is provided in the AGR-3/4 Final As-Run Report (Collin 2015b). Detailed characterization data of the as-fabricated compacts have been compiled in (Hunn, Trammel, and Montgomery 2011). 

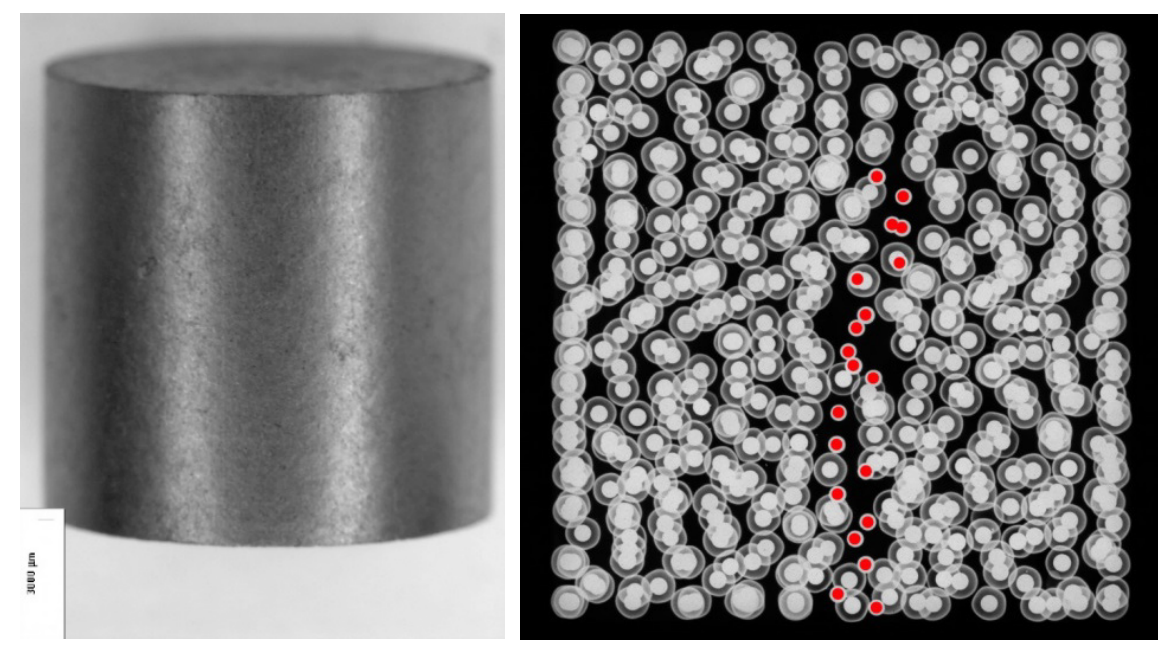

Figure 1. Image of an AGR-3/4 fuel compact (left) and x-ray side view image (right) (Hunn, Trammell, and Montgomery 2011). DTF particles are highlighted with red dots in the x-ray image.

Table 1. As-fabricated particle dimensions and standard deviations from Table A-2 of (Collin 2015).

\begin{tabular}{|l|c|}
\hline \multicolumn{2}{|c|}{ DTF Particle Properties } \\
\hline Kernel diameter $(\mu \mathrm{m})$ & $357.3 \pm 10.5$ \\
\hline DTF pyrocarbon thickness $(\mu \mathrm{m})$ & $20.0 \pm 9$ \\
\hline DTF particle overall diameter $(\mu \mathrm{m})$ & $400.0 \pm 9.2$ \\
\hline \multicolumn{2}{|c|}{ Driver Particle Properties } \\
\hline Kernel diameter $(\mu \mathrm{m})$ & $357.3 \pm 10.5$ \\
\hline Buffer thickness $(\mu \mathrm{m})$ & $109.7 \pm 7.7$ \\
\hline IPyC thickness $(\mu \mathrm{m})$ & $40.4 \pm 2.3$ \\
\hline SiC thickness $(\mu \mathrm{m})$ & $33.5 \pm 1.1$ \\
\hline OPyC thickness $(\mu \mathrm{m})$ & $41.3 \pm 2.1$ \\
\hline Driver particle overall diameter $(\mu \mathrm{m})$ & $818.9 \pm 14.2$ \\
\hline
\end{tabular}

\section{FUEL COMPACT CERAMOGRAPHY PURPOSE AND PROCESSES}

\subsection{Purpose of Ceramography}

In-pile measurements of fission gas release-to-birth ratios indicated a range of possible DTF particle failure rates. In some capsules, the upper bound of these measurements indicated that all the DTF particles likely failed, but the lower bound indicated that substantial numbers of DTF particles remained intact. It is important to know if any DTF particles remained intact throughout the irradiation in order to better interpret in-pile measurements of fission gas release, post-irradiation measurements of fission product inventories in fuel compacts and irradiation capsule components, and model predictions. One purpose of AGR-3/4 compact ceramography was to observe the cross-sections of some (though not necessarily all) DTF particles, observe the DTF pyrocarbon morphologies, and to determine if the DTF pyrocarbon layers were intact or if they failed (i.e. were breached). In that vein, the following phenomena were also of interest: DTF kernel morphology (e.g., porosity, shape, and chemical phases) and kernel chemical reactions with pyrocarbon or surrounding compact matrix material. Another purpose was to examine both the hottest fuel irradiated by the AGR program to date (compacts from AGR-3/4 Capsule 7) and the lowest-temperature/lowest-burnup fuel irradiated in AGR (AGR-3/4 Capsule 12). 


\subsection{Compact Selection Process}

The AGR-3/4 irradiation test train consisted of 12 separate capsules, each with four fuel compacts. Capsules and compacts were numbered from bottom to top. Thus, Capsule 1 was at the bottom and Capsule 12 was at the top. The compact naming convention begins with the capsule number and then denotes the level of the compact within its respective capsule. For example, Compact 10-2 was the second compact from the bottom of Capsule 10. The time-averaged, volume-averaged (TAVA) irradiation temperatures and burnups for all AGR-1, AGR-2, and AGR-3/4 compacts are plotted in Figure 2. Burnup in Figure 2 is expressed as percent fissions per initial metal atoms (FIMA).

Online fission gas monitoring was used for each capsule during the AGR-3/4 irradiation in ATR (Collin et al. 2018). Using fission gas measurements, estimates of the number of DTF particles to fail inpile (with broken pyrocarbon layers) in each of the 12 AGR-3/4 irradiation capsules were made (Collin et al. 2018). Given the similarity between AGR-3/4 and AGR-1 TRISO fuel, and based on experience from AGR-1, it was very unlikely that any AGR-3/4 driver particles failed during the irradiation. Therefore, all estimated in-pile particle failures were assumed to be DTF failures. Table 2 shows estimated numbers of failed DTF particles (meaning particles with breached pyrocarbon layers) in each of the 12 AGR-3/4 irradiation capsules. Challenges in assessing the occurrence of individual particle failures from spikes in the gamma spectrometry data explain why greater than 80 DTF particle failures are listed in some columns for some compacts.

Compacts 5-2 and 7-2 were chosen for ceramography because the fission gas measurements indicate that compacts from Capsules 5 and 7 may contain substantial numbers of both intact and failed DTF particles. Based on the "best-estimate" values in Table 2, an average compact in Capsules 5 and 7 would have about 13 failed DTF particles and seven intact DTF particles. Currently, there is no evidence that the number of failed DTF particles is the same for each compact within a capsule. Compact 12-2 was chosen because the estimates in Table 2 suggest Capsule 12 compacts are the most likely to have intact DTF particles for observation via ceramography. Looking at the "best-estimate" value for Capsule 12, and assuming that all compacts in Capsule 12 had the same number of failed DTF particles, a Capsule 12 compact would have between nine and 10 intact DTF particles. Based on the best available information from in-pile measurements, there was a good chance of observing both intact and failed DTF particles in all three Compacts 5-2, 7-2, and 12-2. Table 3 lists the compact irradiation properties and their mount IDs. The time-averaged (TA) peak irradiation temperatures are the average hottest temperatures within the compact. These generally occur at or near the compact centerline, where the DTF particles were located.

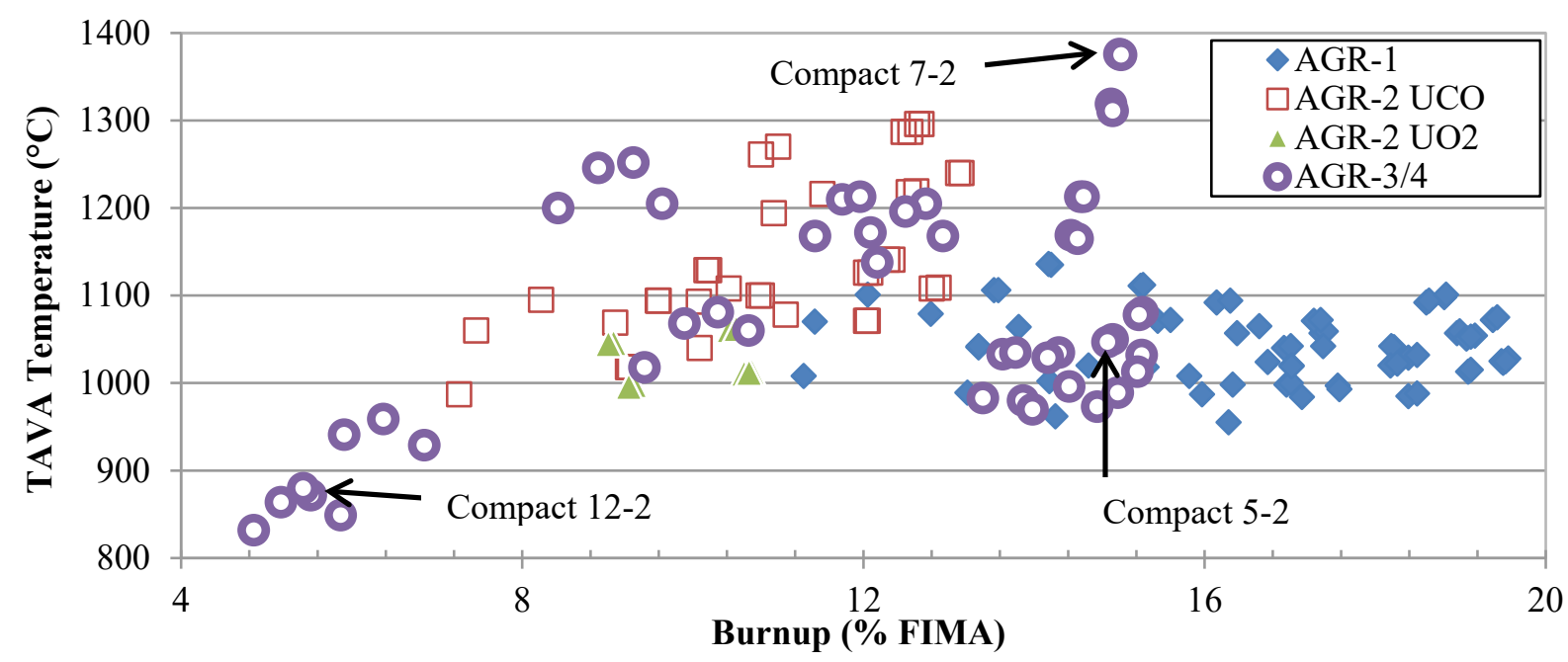

Figure 2. Irradiation temperature and burnup for each US AGR compact. AGR-3/4 compacts selected for 
ceramography are highlighted. Burnups are from (Sterbentz 2013, Sterbentz 2014, and Sterbentz 2015), and temperatures are from (Hawkes 2014a, Hawkes 2014b, and Hawkes 2016).

Table 2. AGR-3/4 DTF particle failure count in each irradiation capsule (Collin et al. 2018).

\begin{tabular}{|c|c|c|c|}
\hline Capsule & Best-estimate & Max & Min \\
\hline 1 & 41 & 81 & 21 \\
\hline 2 & 91 & 168 & 51 \\
\hline 3 & 96 & 164 & 53 \\
\hline 4 & 76 & 100 & 57 \\
\hline 5 & 54 & 92 & 36 \\
\hline 6 & 47 & 53 & 42 \\
\hline 7 & 52 & 75 & 38 \\
\hline 8 & 78 & 129 & 54 \\
\hline 9 & 90 & 99 & 88 \\
\hline 10 & 47 & 75 & 36 \\
\hline 11 & 69 & 92 & 48 \\
\hline 12 & 39 & 49 & 38 \\
\hline
\end{tabular}

Table 3. Compact properties and ceramographic mount identifiers for the three AGR-3/4 compacts.

\begin{tabular}{|c|c|c|c|c|c|}
\hline Compact & $\begin{array}{c}\text { Mount } \\
\text { ID }\end{array}$ & $\begin{array}{c}\text { TAVA } \\
\text { Irradiation } \\
\text { Temperature } \\
\left({ }^{\circ} \mathbf{C}\right)\end{array}$ & $\begin{array}{c}\text { TA Peak } \\
\text { Irradiation } \\
\text { Temperature } \\
\left({ }^{\circ} \mathbf{C}\right)\end{array}$ & $\begin{array}{c}\text { Burnup } \\
(\mathbf{\%} \text { FIMA) }\end{array}$ & $\begin{array}{c}\text { Fast Neutron } \\
\text { Fluence } \times \mathbf{1 0} \\
\left(\mathbf{n} / \mathbf{m}^{\mathbf{2}}, \mathbf{E}>\mathbf{0 . 1 8} \mathbf{M e V}\right)\end{array}$ \\
\hline $5-2$ & MNT79A & 1047 & 1101 & 14.86 & 5.18 \\
\hline $7-2$ & MNT80A & 1375 & 1417 & 15.02 & 5.29 \\
\hline $12-2$ & MNT81A & 872 & 888 & 5.52 & 1.6 \\
\hline
\end{tabular}

\subsection{Mount Preparation}

Mounts were fabricated for each compact that would give a 0.045 -in. offset from the center of the compact to the top of the mount surface (see Figure 3). This was based on the assumption that the DTF particles should all be within 1-mm (0.039-in.) of the compact centerline. The compacts were then fixed into the mounts via epoxy at Window 2M at the Hot Fuels Examination Facility (HFEF). Figure 4 shows the equipment used for this work located at Window 2M (also known as the "Containment Box"). Mounts were fabricated from Micarta, and the compacts were mounted to the Micarta using Buehler EpoHeat ${ }^{\mathrm{TM}}$ CLR epoxy and following the manufacturers recommendations for curing the epoxy. After reviewing additional x-ray radiographs of as-fabricated AGR-3/4 compacts (see Figure 5), it was determined that a greater initial offset was required. To accomplish this, a Micarta ring that was 0.020 -in. thick was fabricated and epoxied to the top of the mounts. This achieved an offset of 0.065 -in. Using the mount surface as a guide, the compact was then cut using the low-speed saw (see Figure 4) to remove the free portion of the compact that extended above the mount surface. The result was a cross-section of the compact at the level of the mount surface, offset approximately 0.065 -in. from the compact center. 
After the initial cut with the low-speed saw, the mount was backpotted with epoxy, ground, and polished (using the equipment shown in Figure 4), and imaged via the Leica optical microscope (see Figure 6). Grinding was performed using a 1200 grit grinding pad with $\sim 20 \mathrm{~N}$ of force during more aggressive grinding operations to rapidly remove material. As little as $\sim 5 \mathrm{~N}$ of force was used during more delicate/gradual grinding operations. After each round of grinding, the mounts were inspected via the Containment Box (Window 2M) periscope. Frequent vacuum backpotting was performed to fill voids made accessible via grinding and polishing and to aid in preservation of the fuel kernels, specifically the DTF pyrolytic carbon layer. Once an adequate amount of material was removed and DTF particles were identified, polishing was performed using a Struers MD-Mol pad and a 3- $\mu \mathrm{m}$ diamond suspension followed by a Struers MD-Nap pad and a 1- $\mu \mathrm{m}$ diamond suspension. Micrographs of the entire compact cross-section were taken so that a montage of the surface could be made that would include any DTF particles and all the driver TRISO fuel particles. If any DTF particles were visible, individual micrographs were taken of those particles.

No DTF particles were visible after the initial round of grinding and polishing, so additional rounds of grinding, polishing, and microscopy were performed until the DTF particles first became visible. Once the DTF particles had been uncovered, the mount surface was polished and imaged. Two additional rounds of grinding/polishing/imaging were performed so that the DTF particles could be observed at multiple planes and so that additional DTF particles could be uncovered. Figure 7 depicts the overall AGR-3/4 ceramography process. Not all DTF particles were at the same plane in the compact; therefore, at one plane, DTF Particle A may be visible, but DTF Particle B may still be below the polished surface of the cross-section. Additional grinding to reveal Particle B may have to remove enough material that Particle A has been ground through completely and is gone.
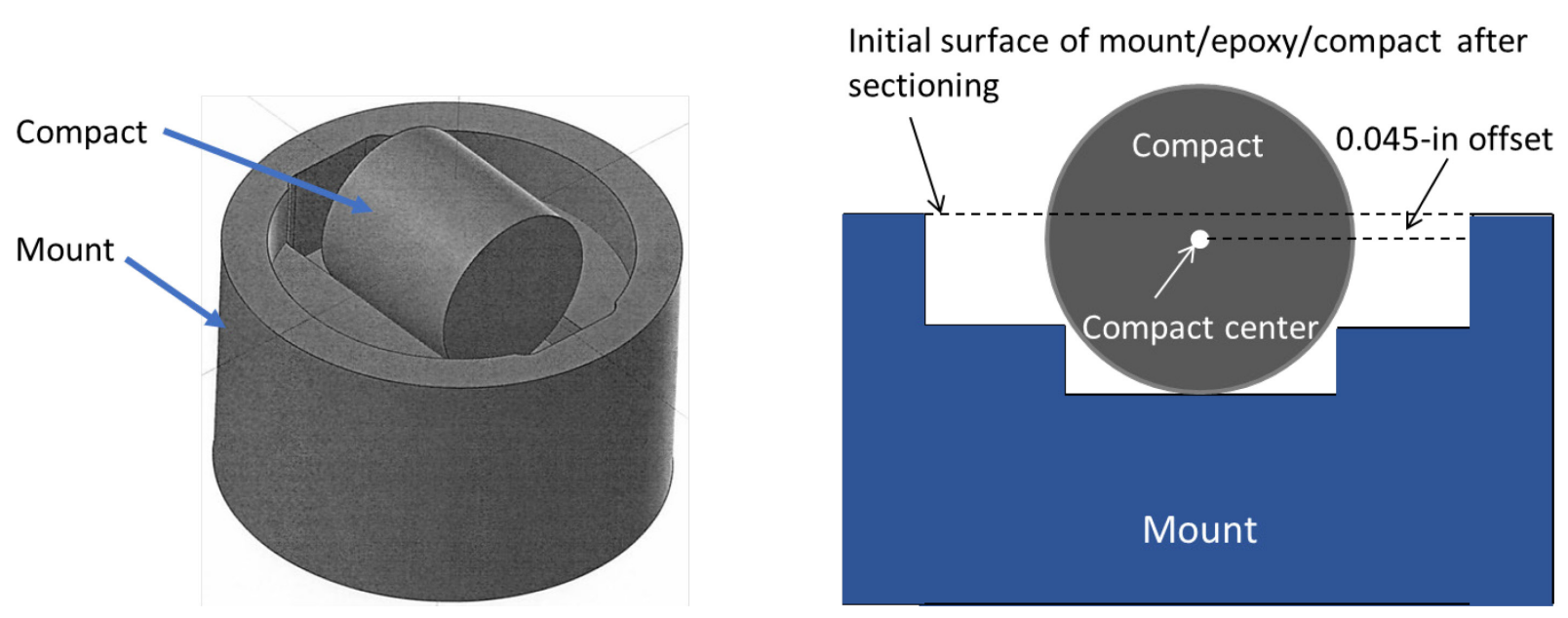

Figure 3. Two representations of an AGR-3/4 compact in the specially fabricated mount. 


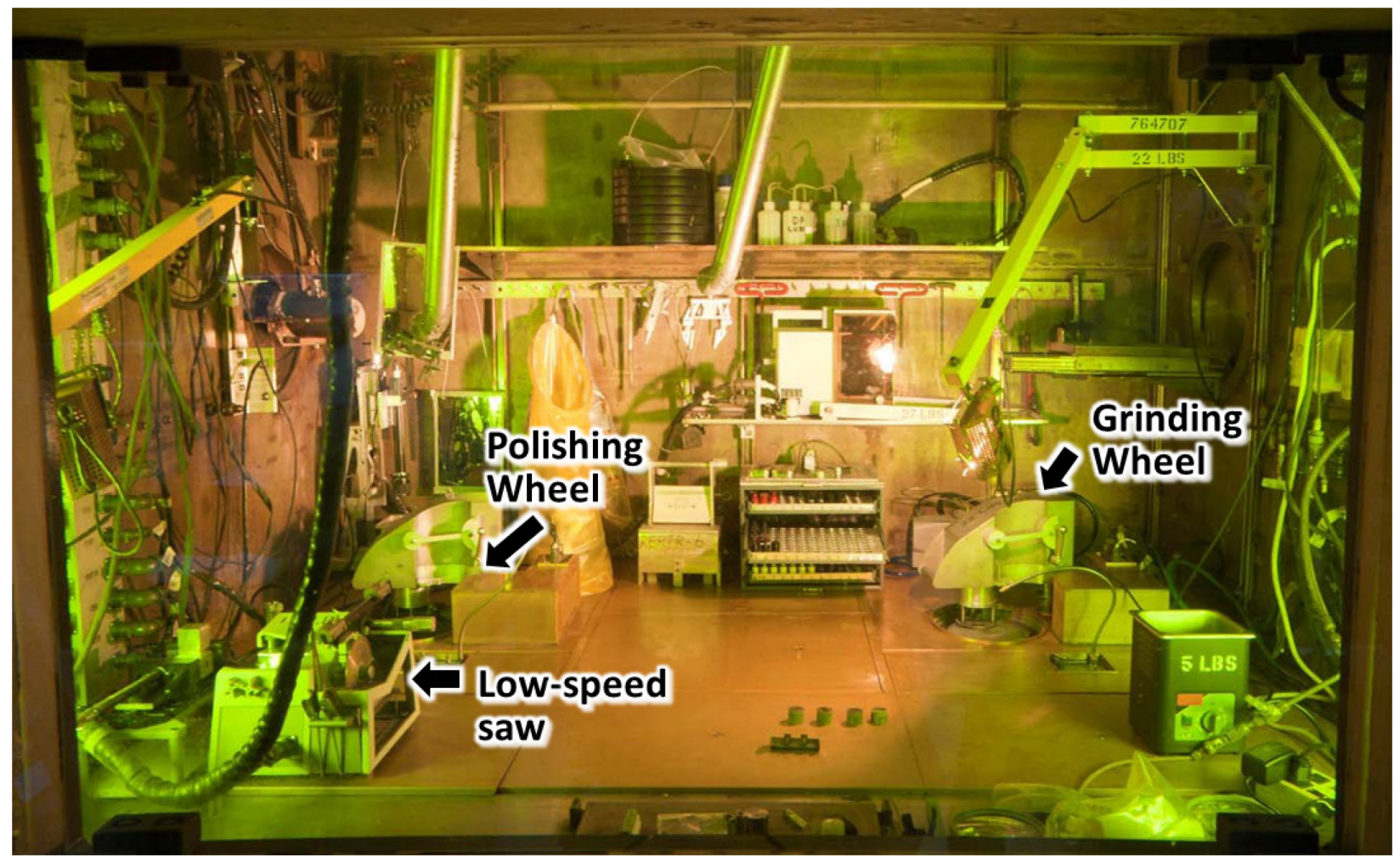

Figure 4. Sample preparation equipment at Window 2M (also known as the "Containment Box") at HFEF.

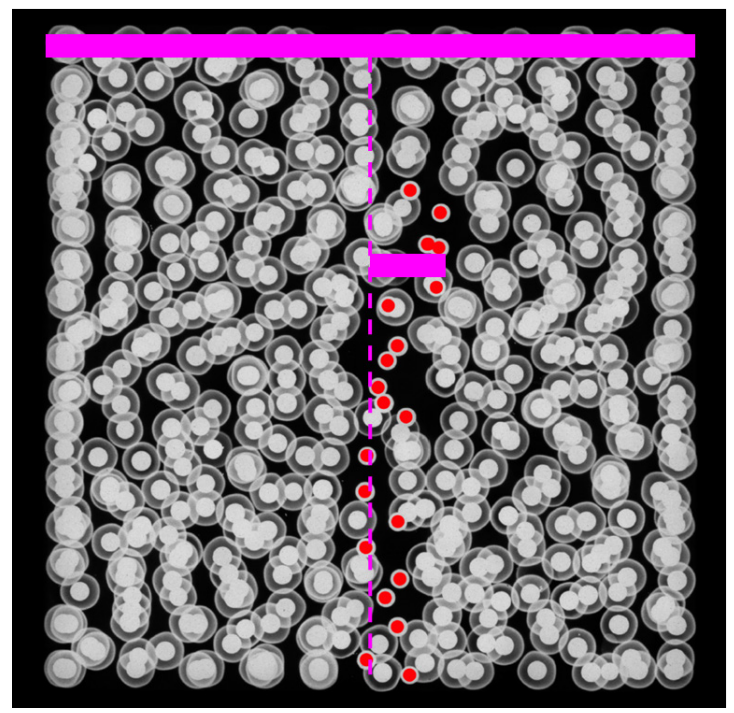

Figure 5. X-ray radiograph of as-fabricated compact from Figure 1-8 of (Hunn et al. 2011). Kernels farthest from compact centerline were estimated to be $1.4 \mathrm{~mm}$ from centerline. Red dots highlight DTF particles. Top purple bar denotes extent of compact diameter used to calibrate image. Lower purple bar shows maximum distance between DTF particles and compact center $(\sim 1.4 \mathrm{~mm})$. 


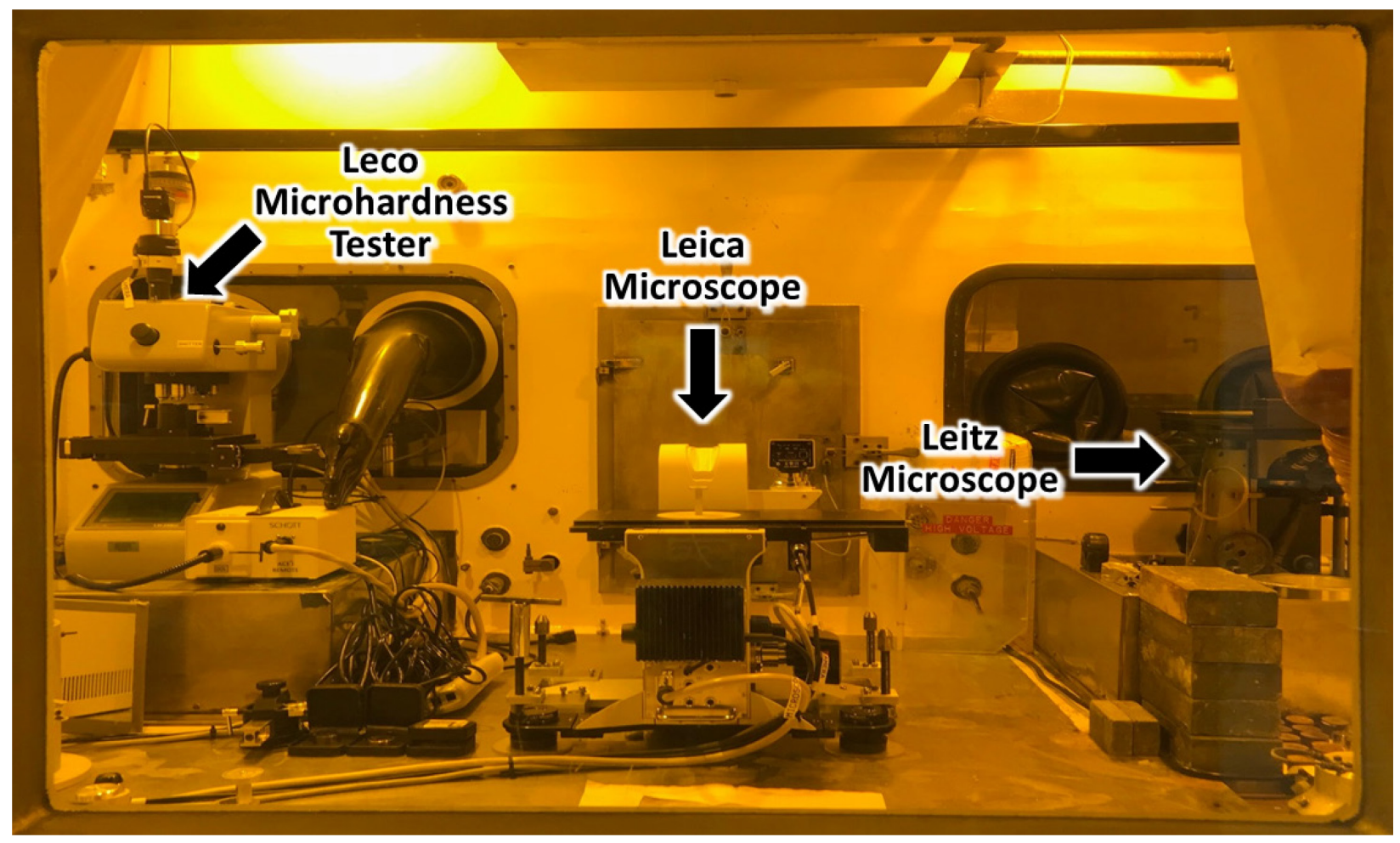

Figure 6. Instruments in the "Met Box" located in Room 133 at HFEF. The Leica microscope was used for this work.

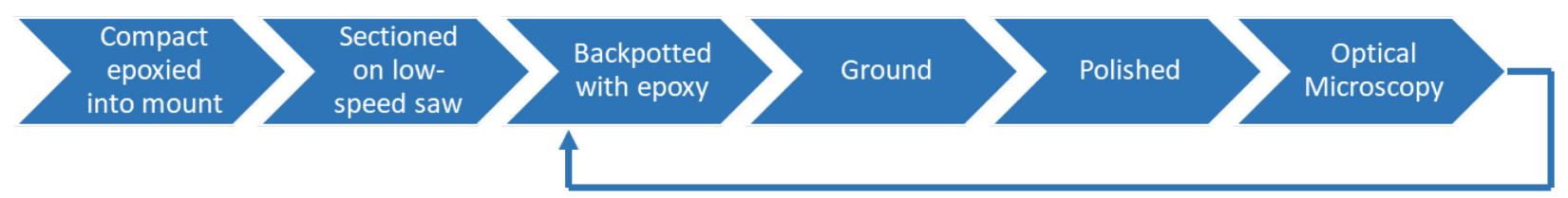

Figure 7. Compact ceramography process diagram.

\section{CERAMOGRAPHY RESULTS}

\subsection{Unirradiated Compact Cross-Sections}

Limited ceramography of unirradiated AGR-3/4 Compact Z138 (mount ID: MNT78A) was performed to allow comparison with the irradiated compacts to follow. Figure 8 shows a montage of multiple micrographs taken of the cross-section of the unirradiated compact. Five DTF particles were visible in the cross-section and were labeled 1 through 5 . The kernel diameters of four of these DTF particles and three TRISO-coated driver fuel particles were measured and compared to the as-fabricated kernel diameter (see Table 1) as an indication of the distance of the cross-section to the midplane of the kernel. For example, the measured kernel diameter for DTF Particle 1 is consistent with as-fabricated kernel diameters, meaning the cross-section is very near to this particle's midplane; however, the crosssection of DTF Particle 4 is well above its midplane.

Figure 9 shows two optical micrographs of unirradiated DTF particles. Major features of the particles are labeled. The image at left is a magnified view of the DTF particle labeled as 1 in Figure 8. The white blotches in the kernel are uranium carbide phases amid the gray uranium oxide phase. Compared to the 
micrograph at right in Figure 9, the particle at left had significant pullout of the uranium carbide phase from the kernel surface during grinding/polishing. Note also that the particle at left in Figure 9 has a faceted area at the 8 o'clock position and a soot inclusion in the $\mathrm{PyC}$ at the 4 o'clock position.

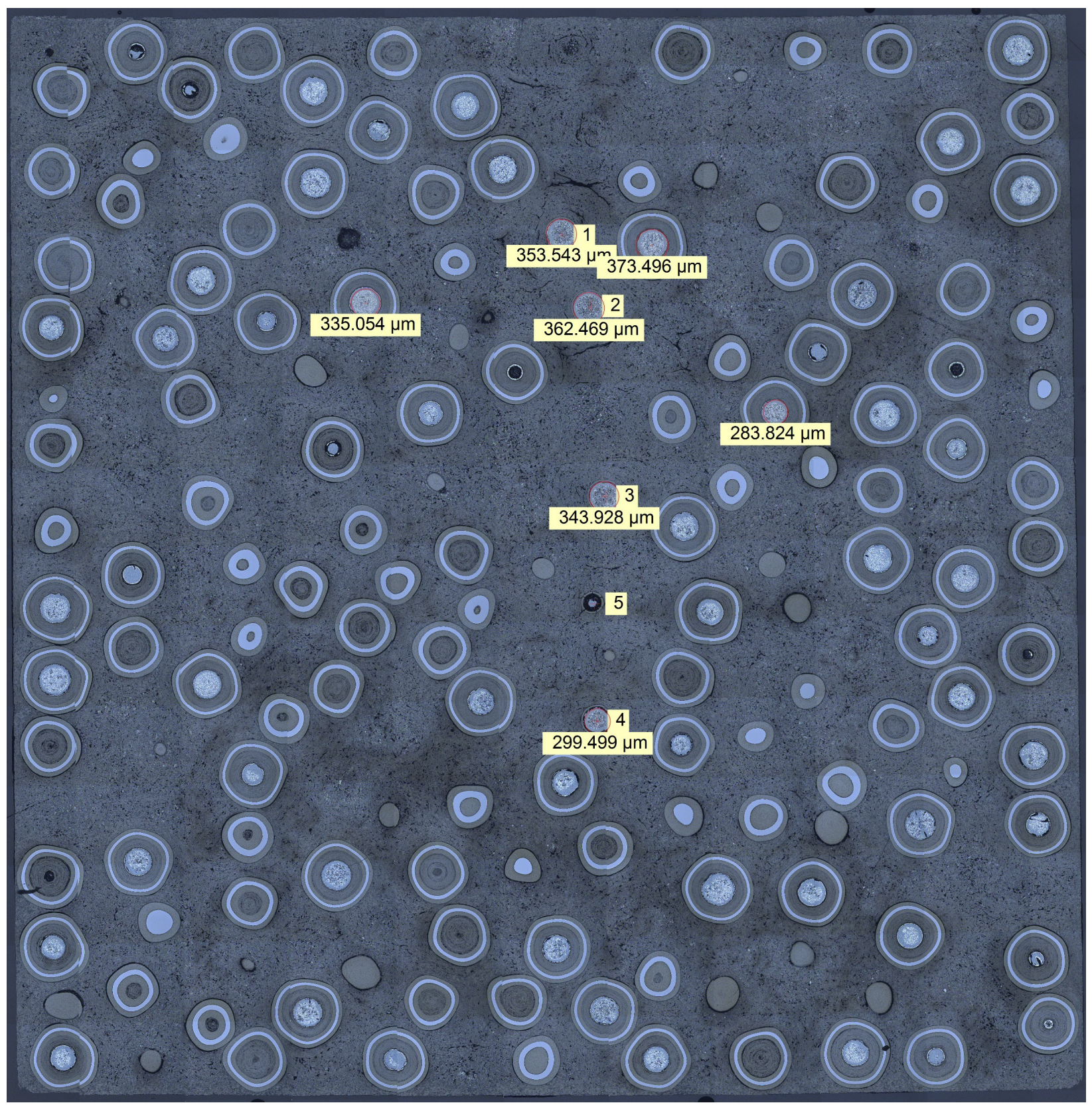

Figure 8. Montage of multiple micrographs of a unirradiated Compact Z138 (MNT78A) cross-section with five DTF particles visible. Kernel diameter measurements were also made on a three TRISO driver particles. 


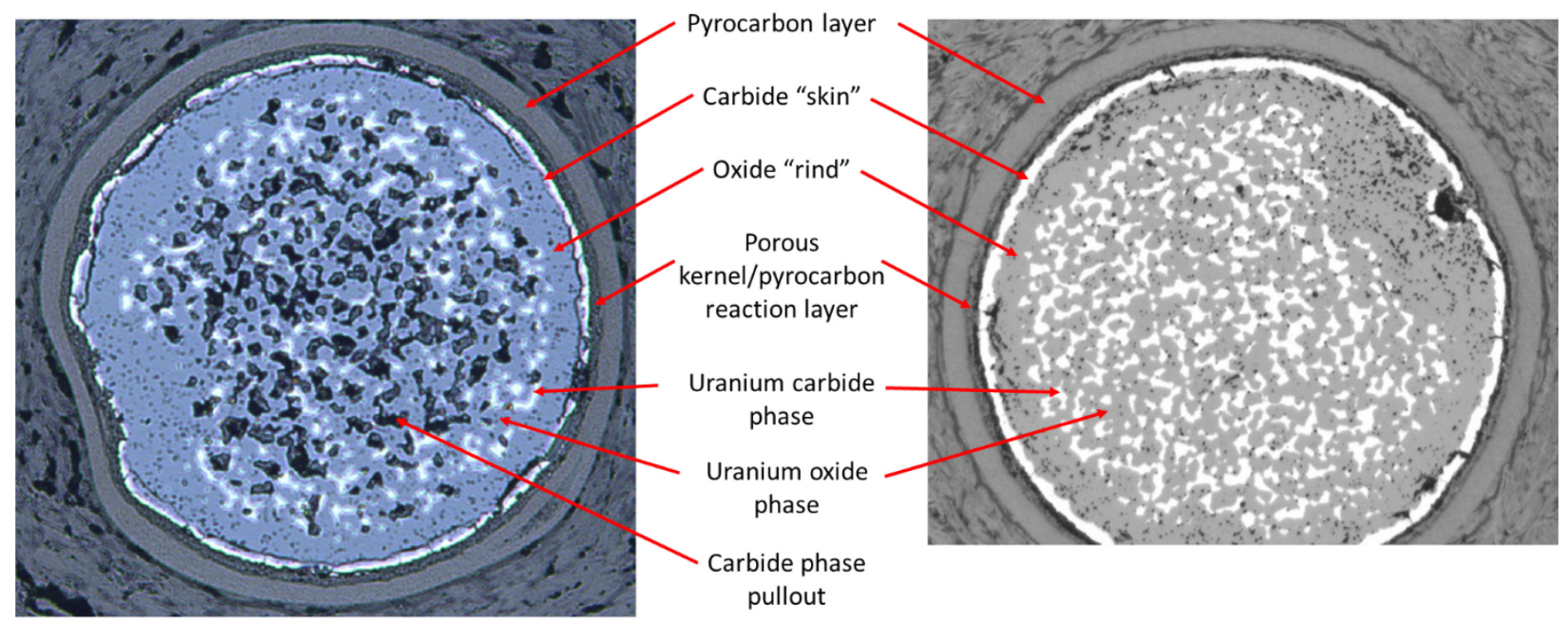

Figure 9. Cross-section of unirradiated DTF particle "1" from MNT78A (see Figure 8) in this work (left) and from work on a different, unirradiated compact in Hunn et al. 2011 Figure 1-13 (right).

\subsection{Compact 5-2 Cross Sections}

Figure 10 shows the evolution of the Compact 5-2 cross-sections in MNT79A through three rounds of grinding and polishing. After the first polish, seven DTF particle kernels were visible, and three other features of the cross-section were deemed likely be DTF particles still below the surface of the compact cross-section. After the second polish, an additional four DTF particle kernels were uncovered, and two DTF particles visible after the first polish were no longer visible because they had been ground all the way through. No additional DTF particle kernels were uncovered by the third polish. A total of 11 DTF particles were observed. Figure 11 shows the Compact 5-2 cross-section after the third polish and labels each of the 11 DTF particles. Micrographs of select individual DTF particles are shown in Figure 12 through Figure 17. Figure 12 and Figure 13 are labeled with major features common to all Compact 5-2 DTF micrographs. Figure 19 shows micrographs of five selected TRISO-coated driver fuel particles representative of the general driver particle morphologies in Compact 5-2. Full-size micrographs of each compact cross-section are given in Appendix A.1. Micrographs of any individual DTF particle not shown in the body of this report are shown in Appendix A.1. 


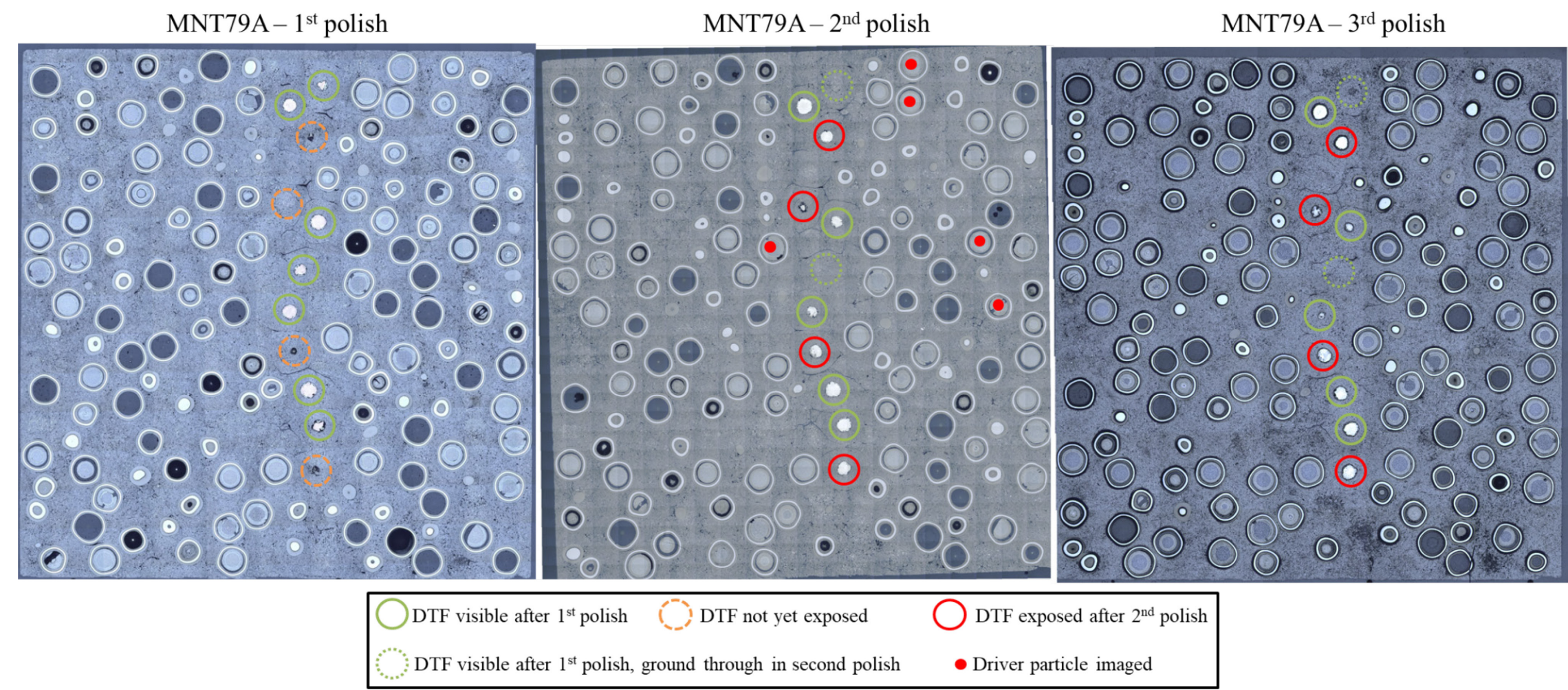

Figure 10. Montages of optical micrographs of the cross-sections of AGR-3/4 Compact 5-2 after each of the three rounds of polishing/grinding. 


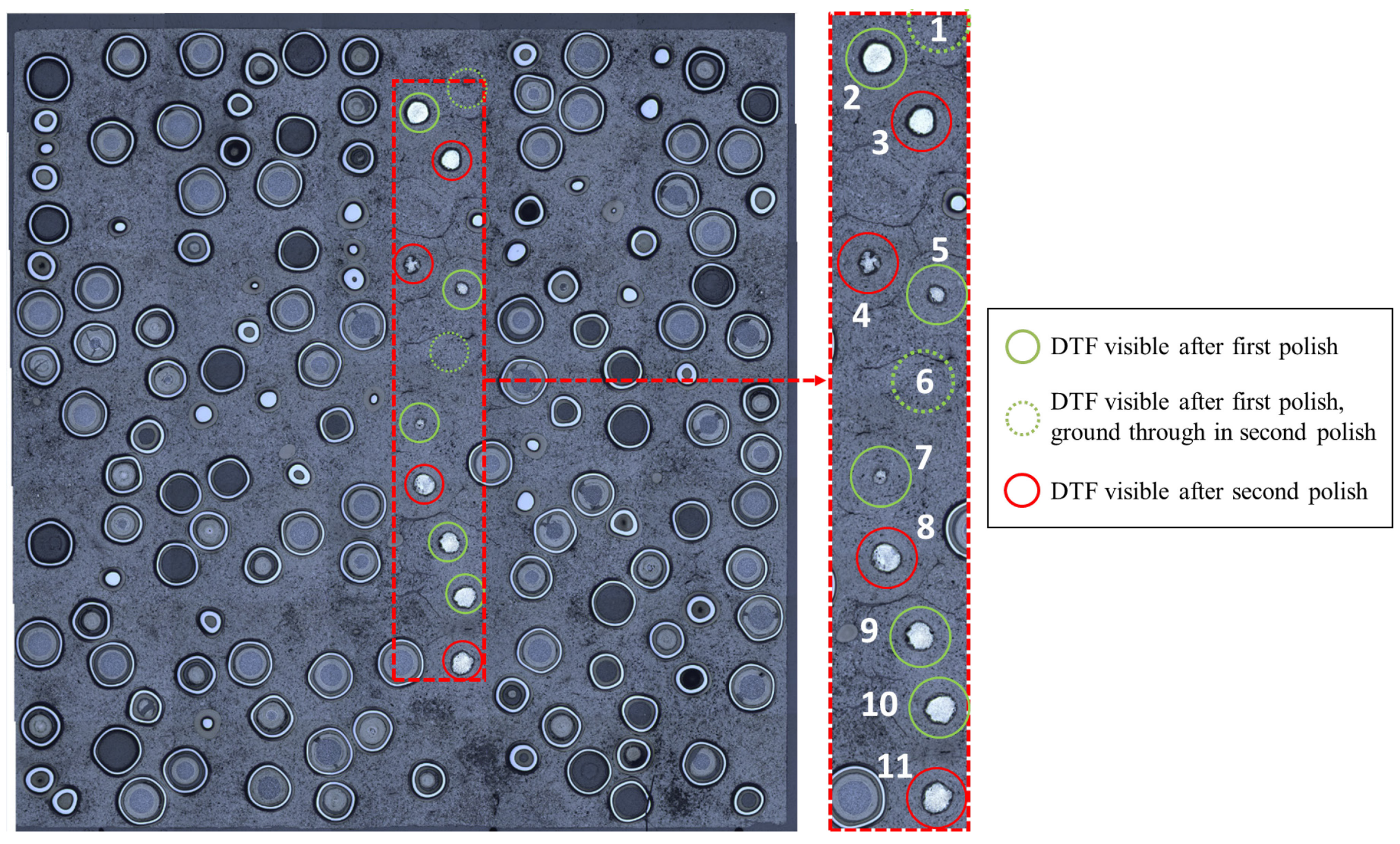

Figure 11. Compact 5-2 cross-section after third polish. DTF particles are highlighted and labeled 1 through 11. 


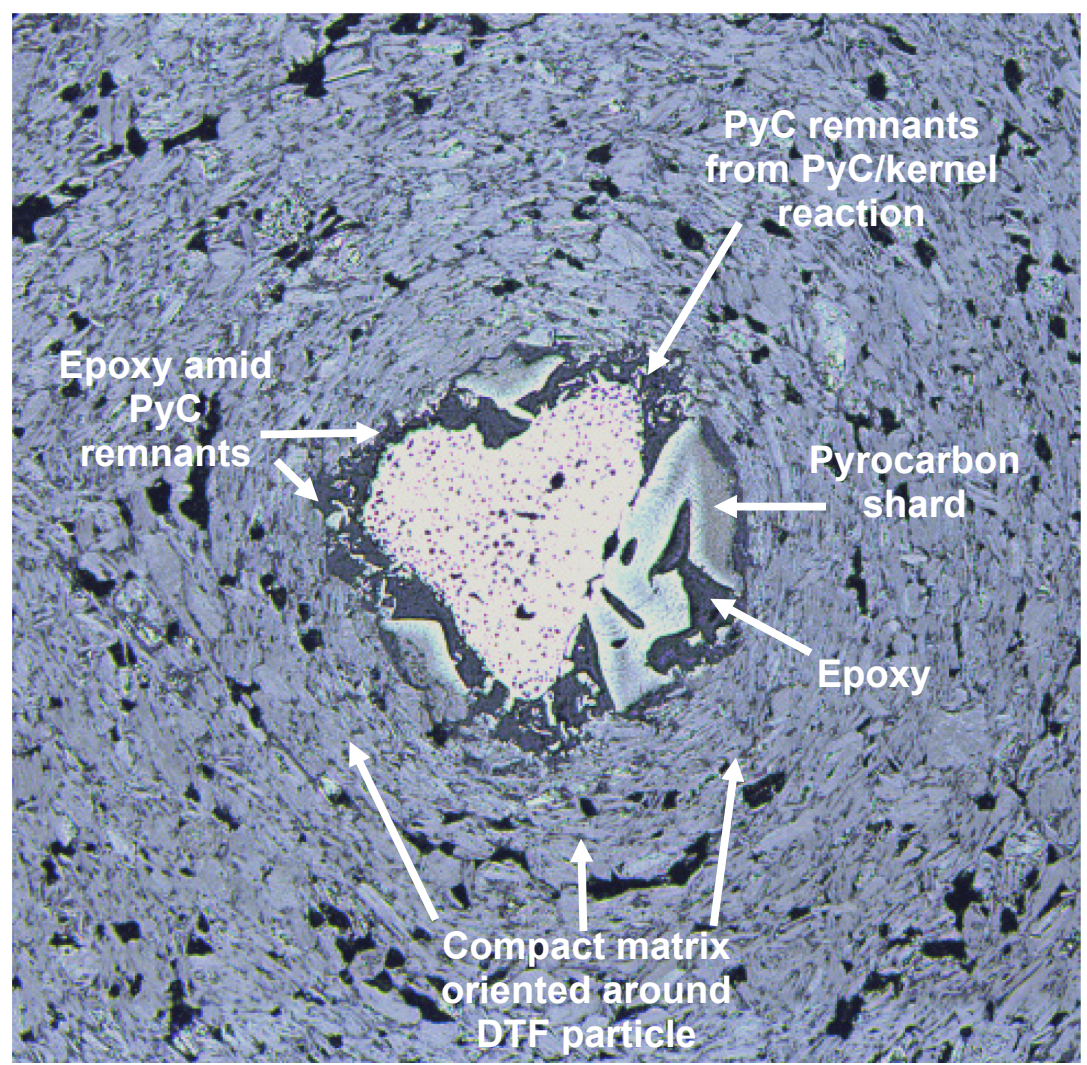

Figure 12. Optical micrograph of DTF 1 from the first polished cross-section of Compact 5-2.

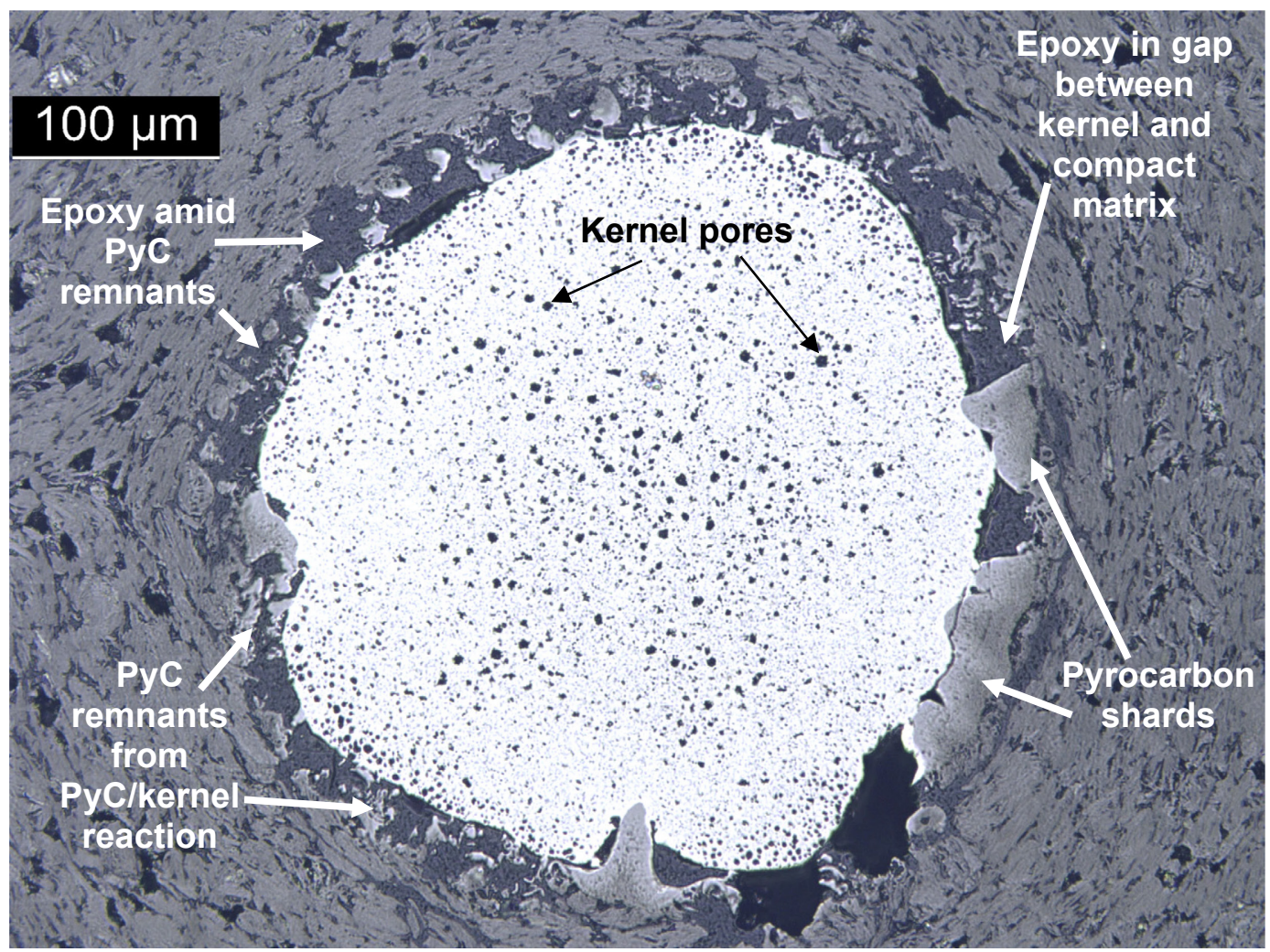

Figure 13. Optical micrograph of DTF 2 from the second polished cross-section of Compact 5-2. 

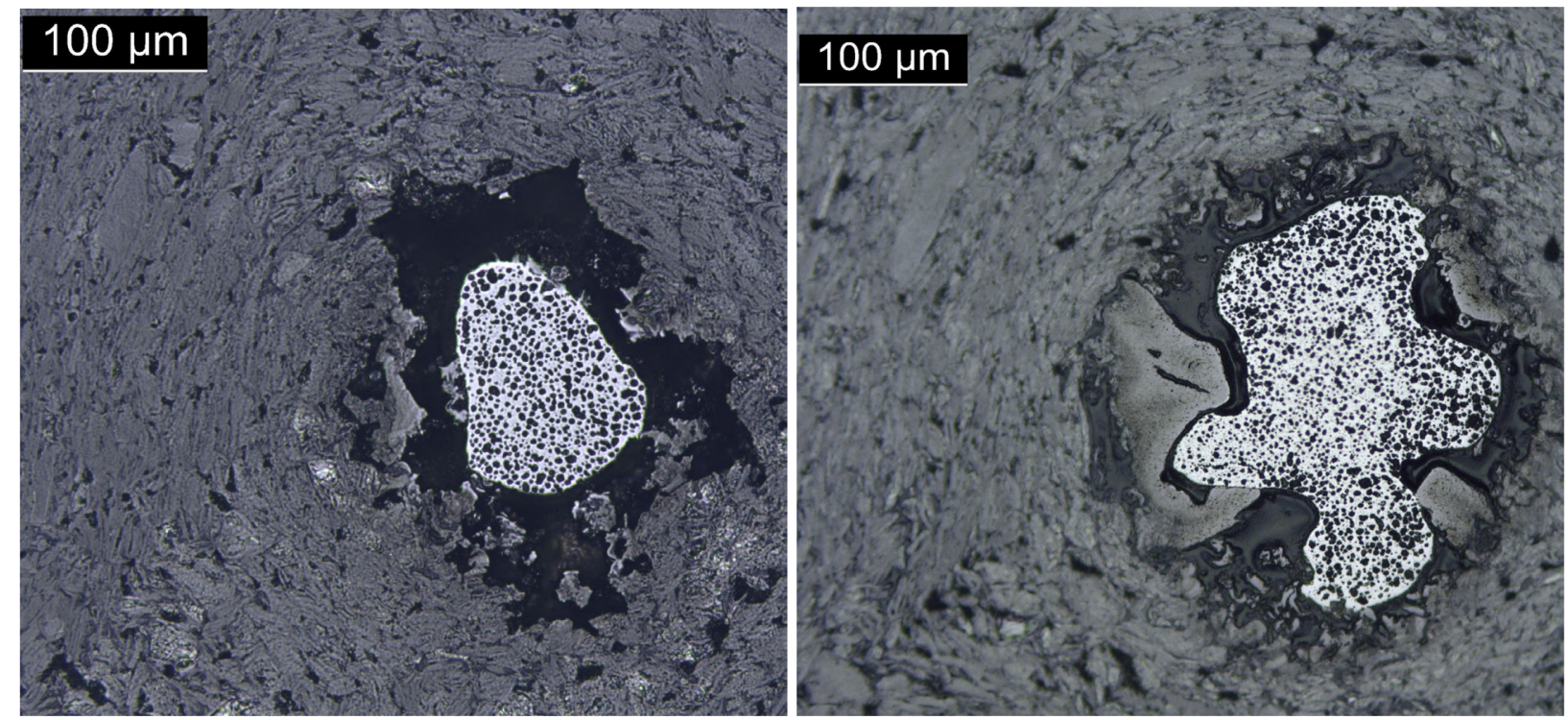

Figure 14. Optical micrograph of DTF 4 from the second polished cross-section of Compact 5-2 (left). Optical micrograph of the same particle from the third polished cross-section (right).

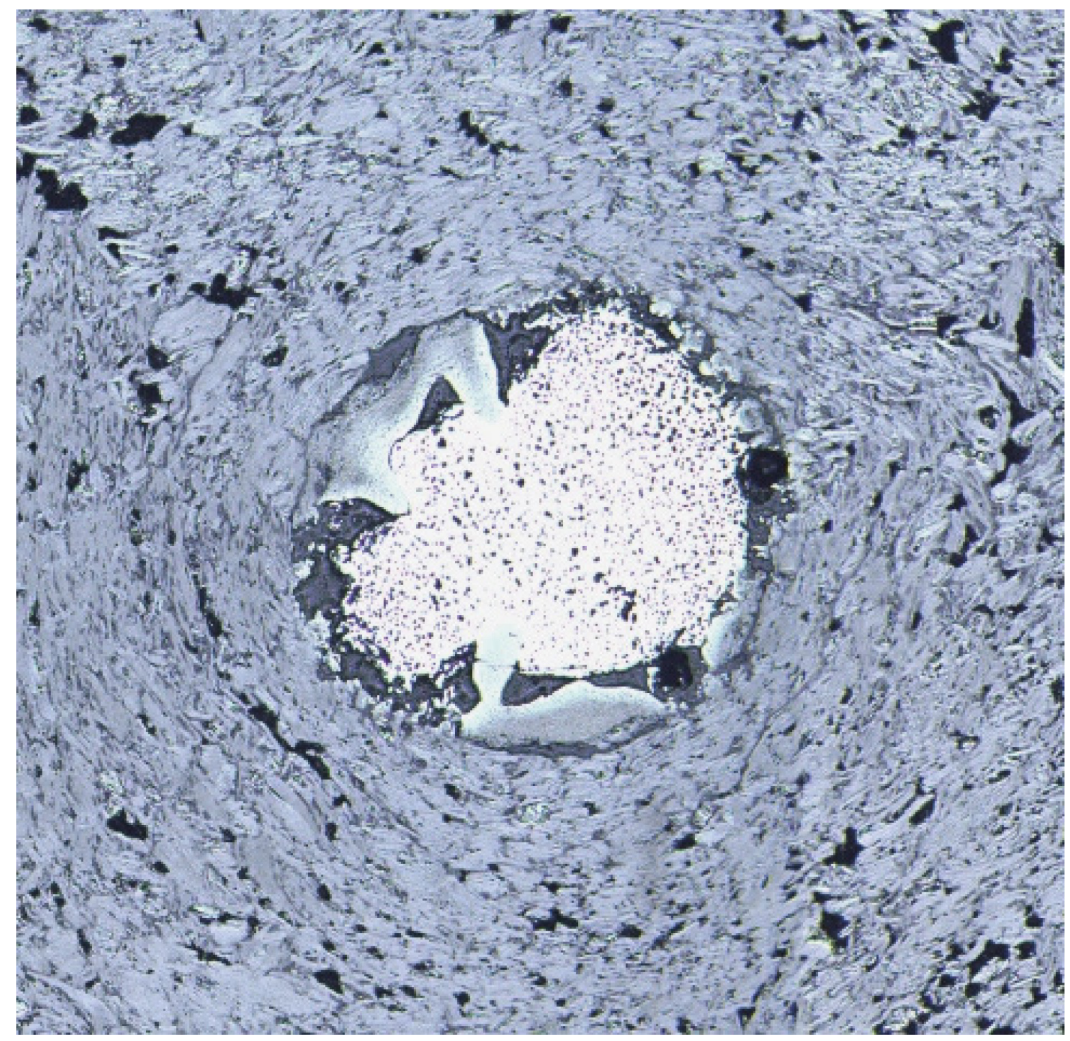

Figure 15. Optical micrograph of DTF 6 from the first polished cross-section of Compact 5-2. 


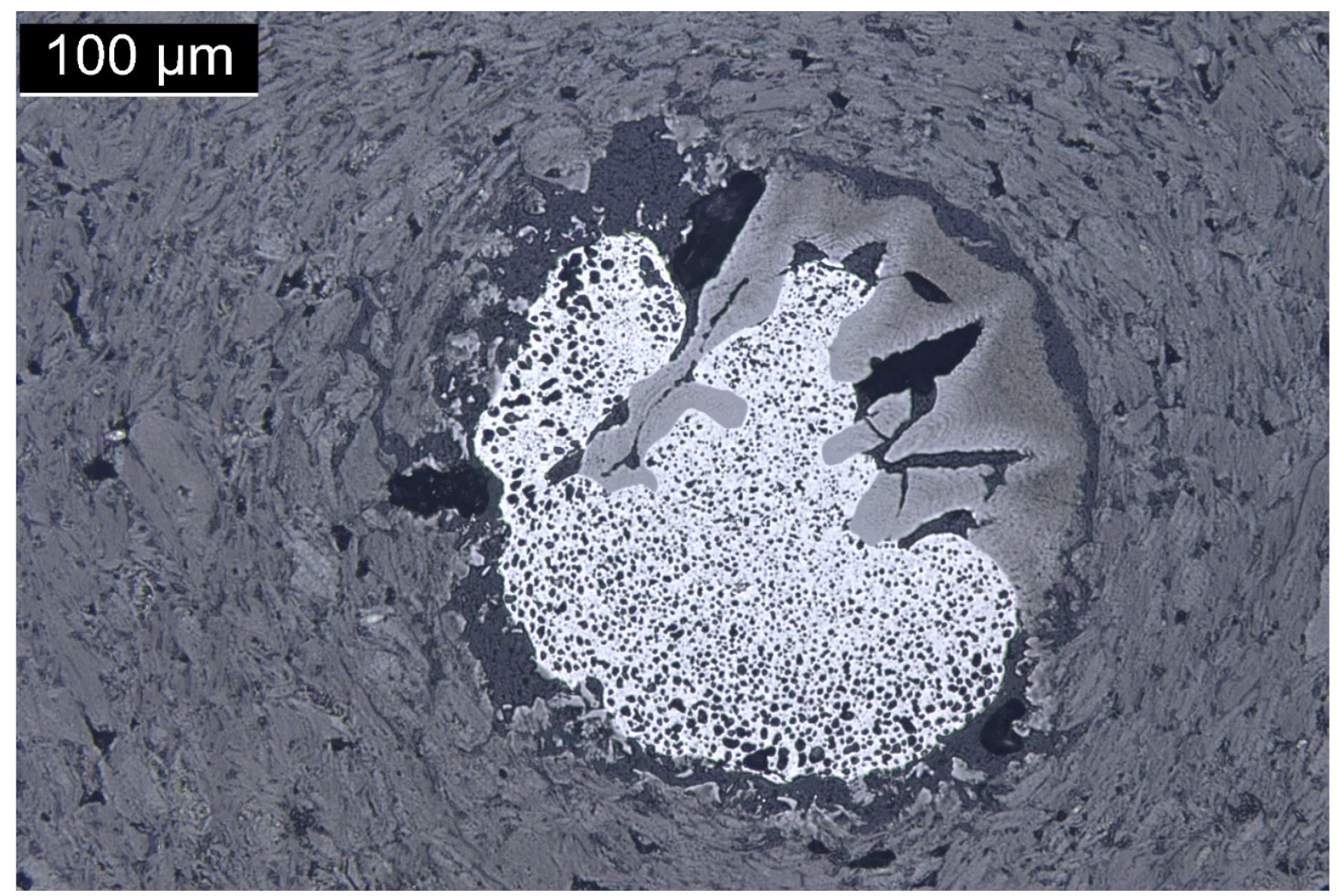

Figure 16. Optical micrograph of DTF 7 from the second cross-section of Compact 5-2.

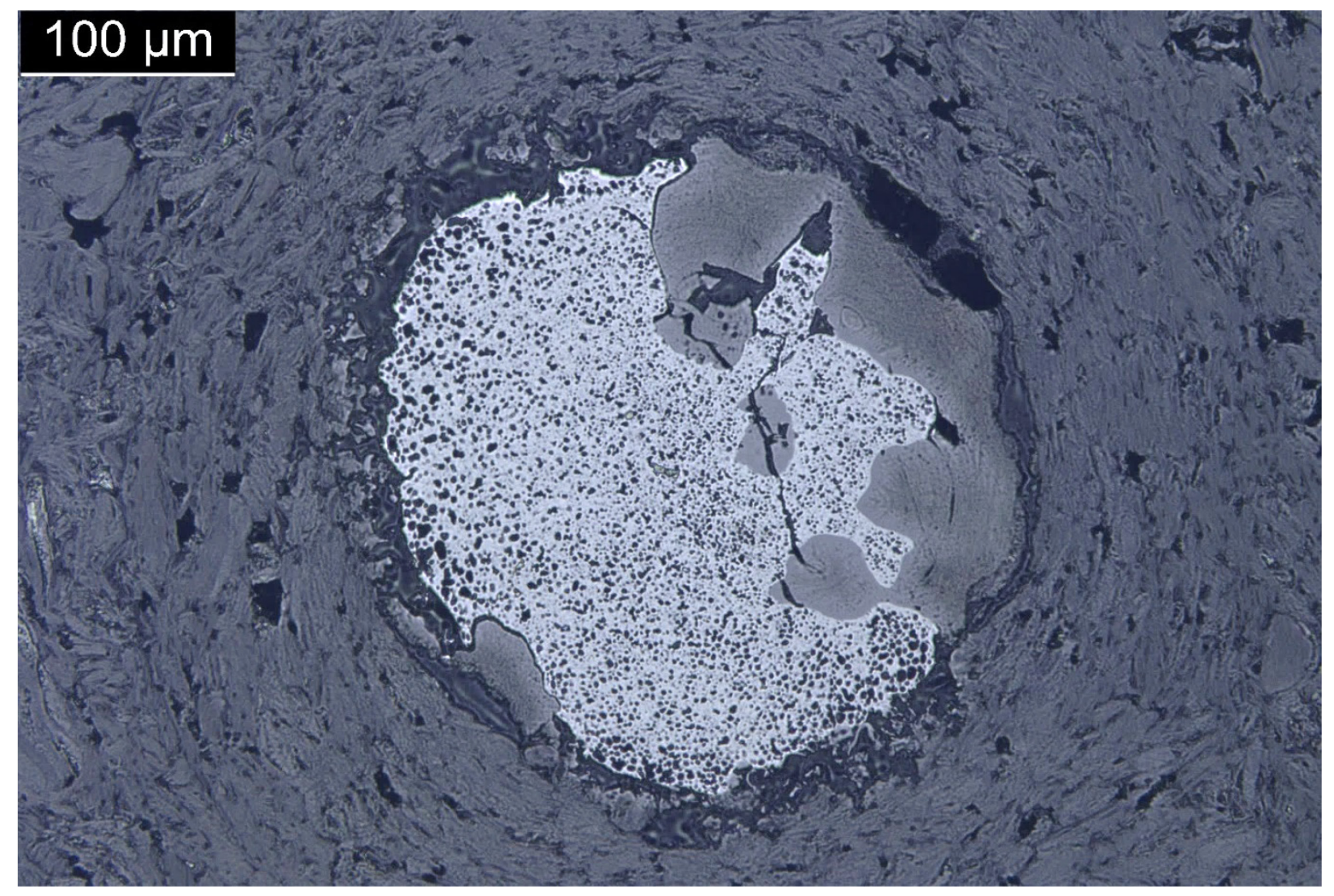

Figure 17. Optical micrograph of DTF 8 from the second cross-section of Compact 5-2. 

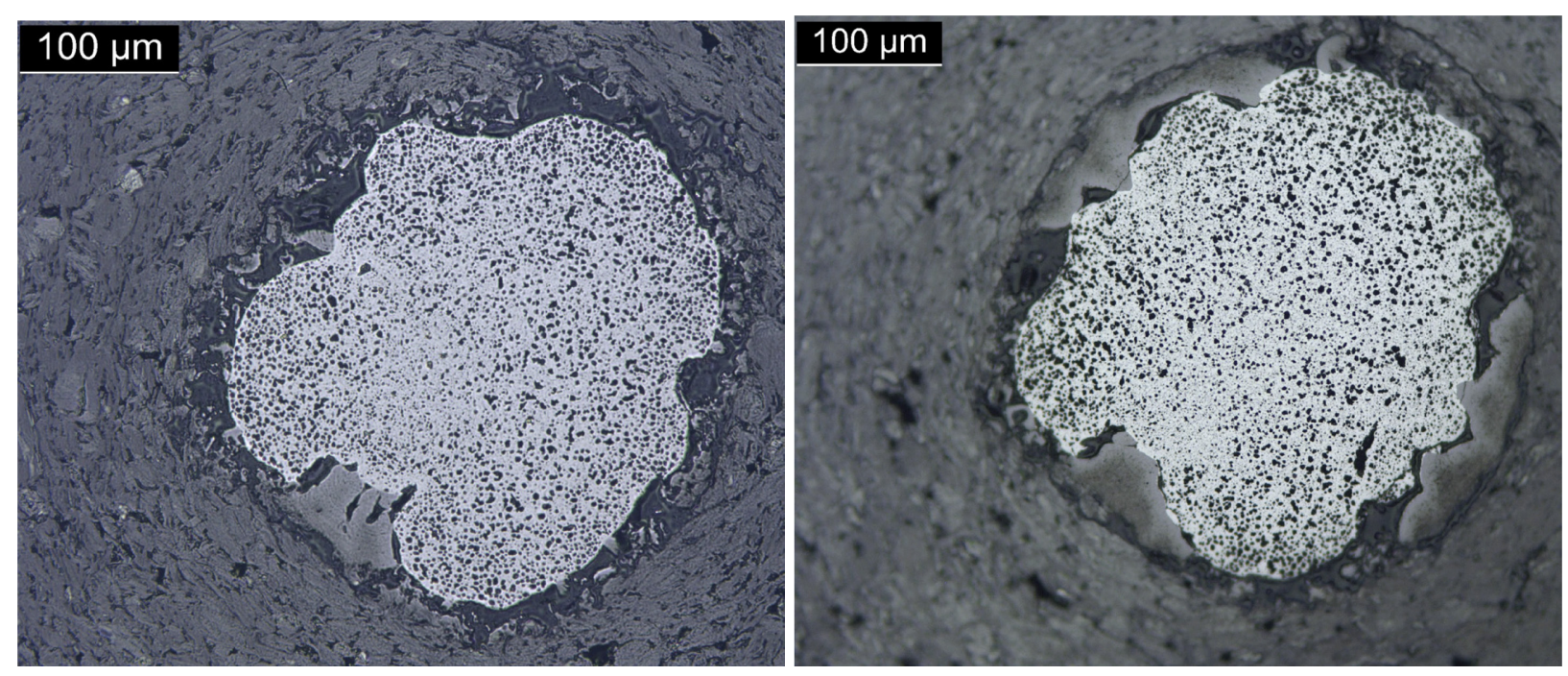

Figure 18. Optical micrograph of DTF 11 from the second cross-section of Compact 5-2 (left) and from the third cross-section (right). 

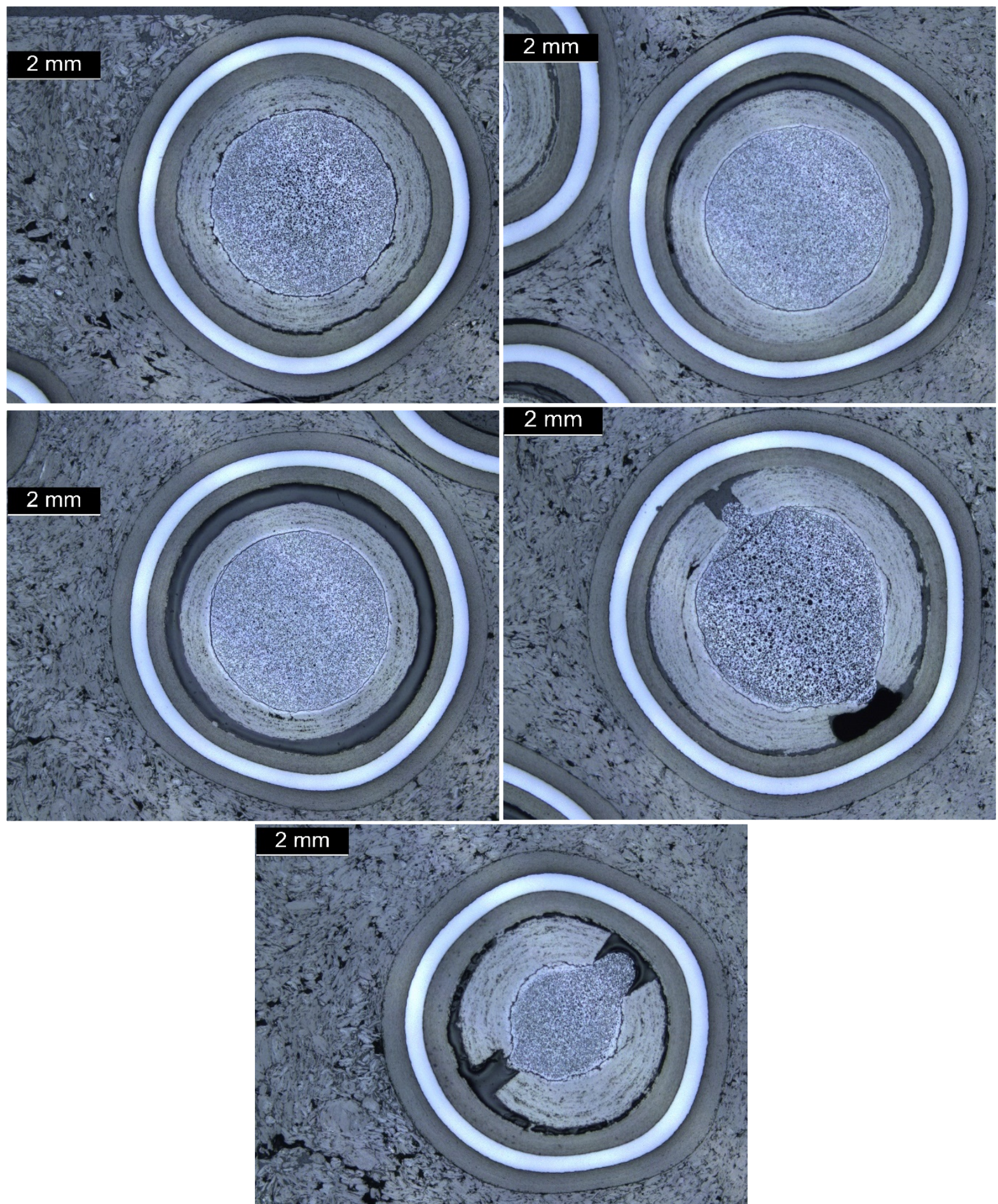

Figure 19. Optical micrographs of five different TRISO-coated driver fuel particles from the third polished cross-section of Compact 5-2. The locations of these driver particles within the mount were indicated by red dots in the middle image in Figure 10. 


\subsection{Compact 7-2 Cross-Sections}

Figure 20 shows the evolution of Compact 7-2 cross-sections in MNT80A through three rounds of grinding and polishing. After the first polish, six DTF particle kernels were visible. After the second polish, one additional DTF particle was revealed, but one of the six DTF particles visible after the first polish had been ground through. After the third polish, three additional DTF particle kernels were visible, and another one of the particles visible in the first cross-section had been completely removed by grinding/polishing. Figure 21 shows the third polished cross-section and highlights the location (or prior location) of identified DTF particles. Figure 22 through Figure 25 show micrographs of DTF Particles 1 through 6. Figure 26 shows micrographs of DTF 8 after each of the three rounds of grinding/polishing. Figure 27 shows the third polished cross-section of Compact 7-2 and highlights some of the driver particles. Full-size micrographs of each compact cross-section are given in Appendix A.2. Micrographs of any individual DTF particle not shown in the body of this report are shown in Appendix A.2. 
MNT80A $-1^{\text {st }}$ polish

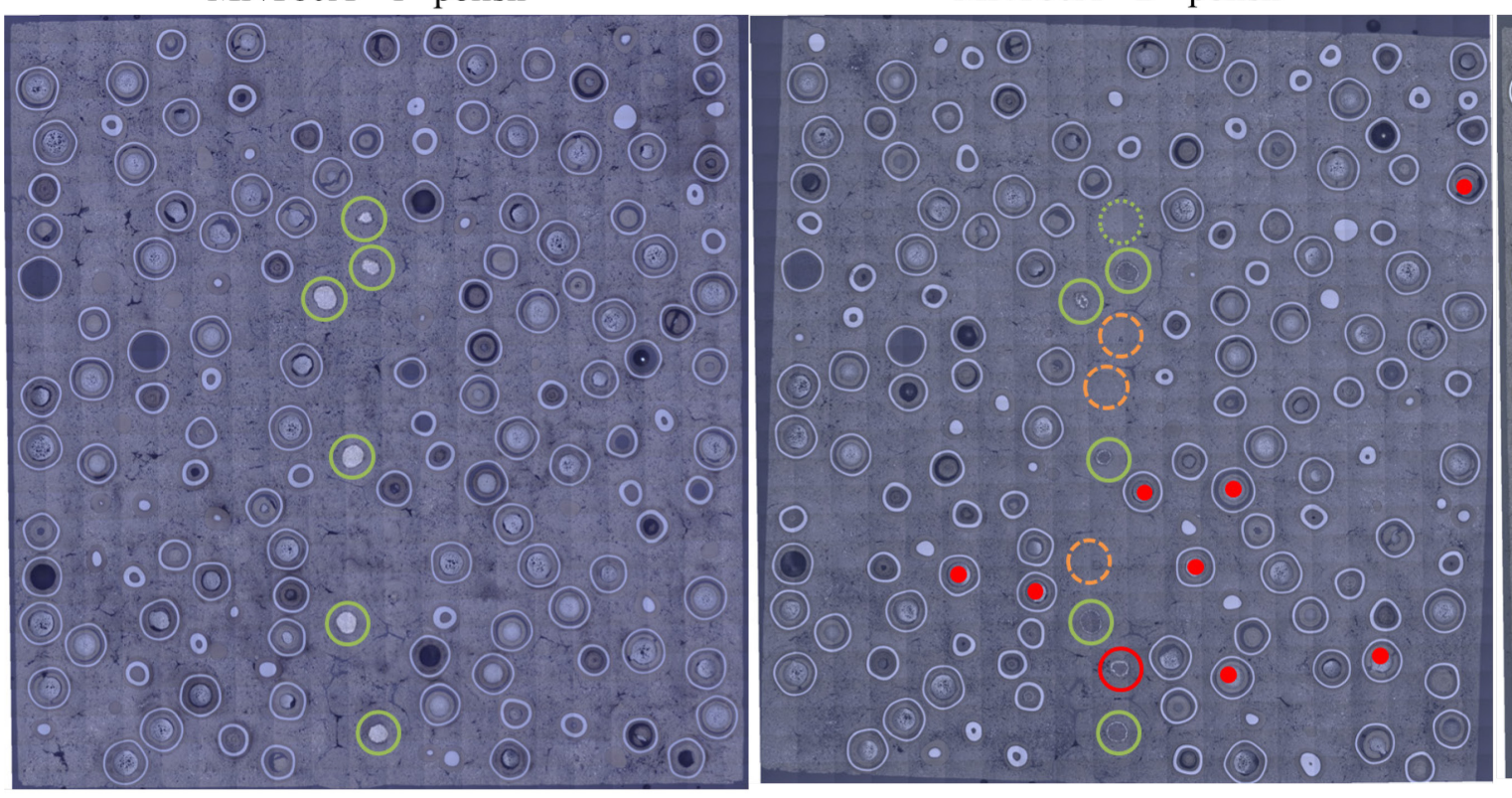

DTF visible after $1^{\text {st }}$ polish $\quad$ DTF not yet exposed $\quad$ DTF exposed after $2^{\text {nd }}$ polish

DTF visible after $1^{\text {st }}$ polish, ground through in second polish

Driver particle imaged
MNT80A $-3^{\text {rd }}$ polish

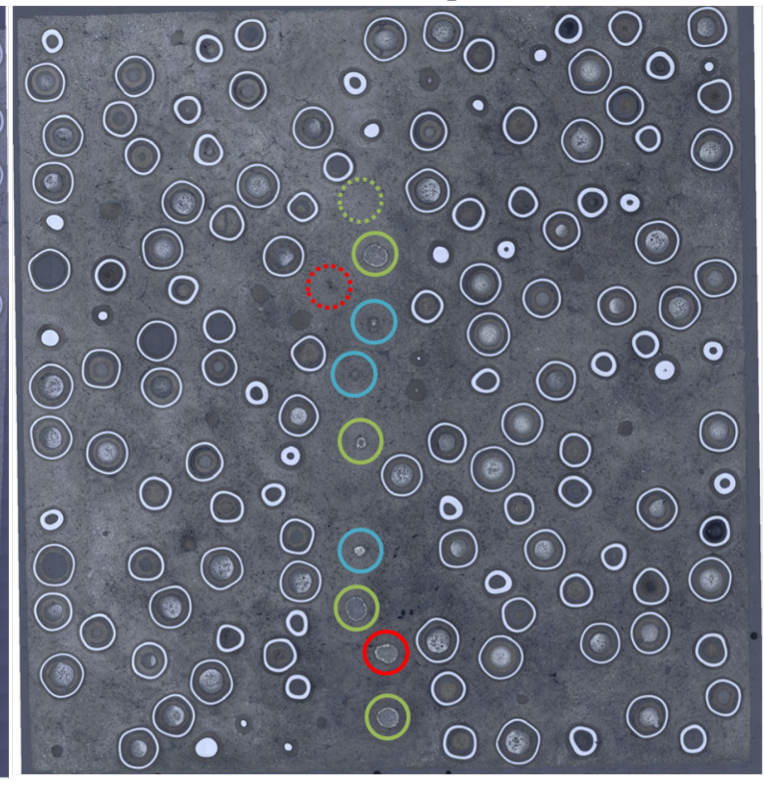

DTF ground through after $3^{\text {rd }}$ polish

DTF kernel exposed after $3^{\text {rd }}$ polish

Figure 20. Montages of optical micrographs of the cross-sections of AGR-3/4 Compact 7-2 after each of the three rounds of grinding/polishing. 


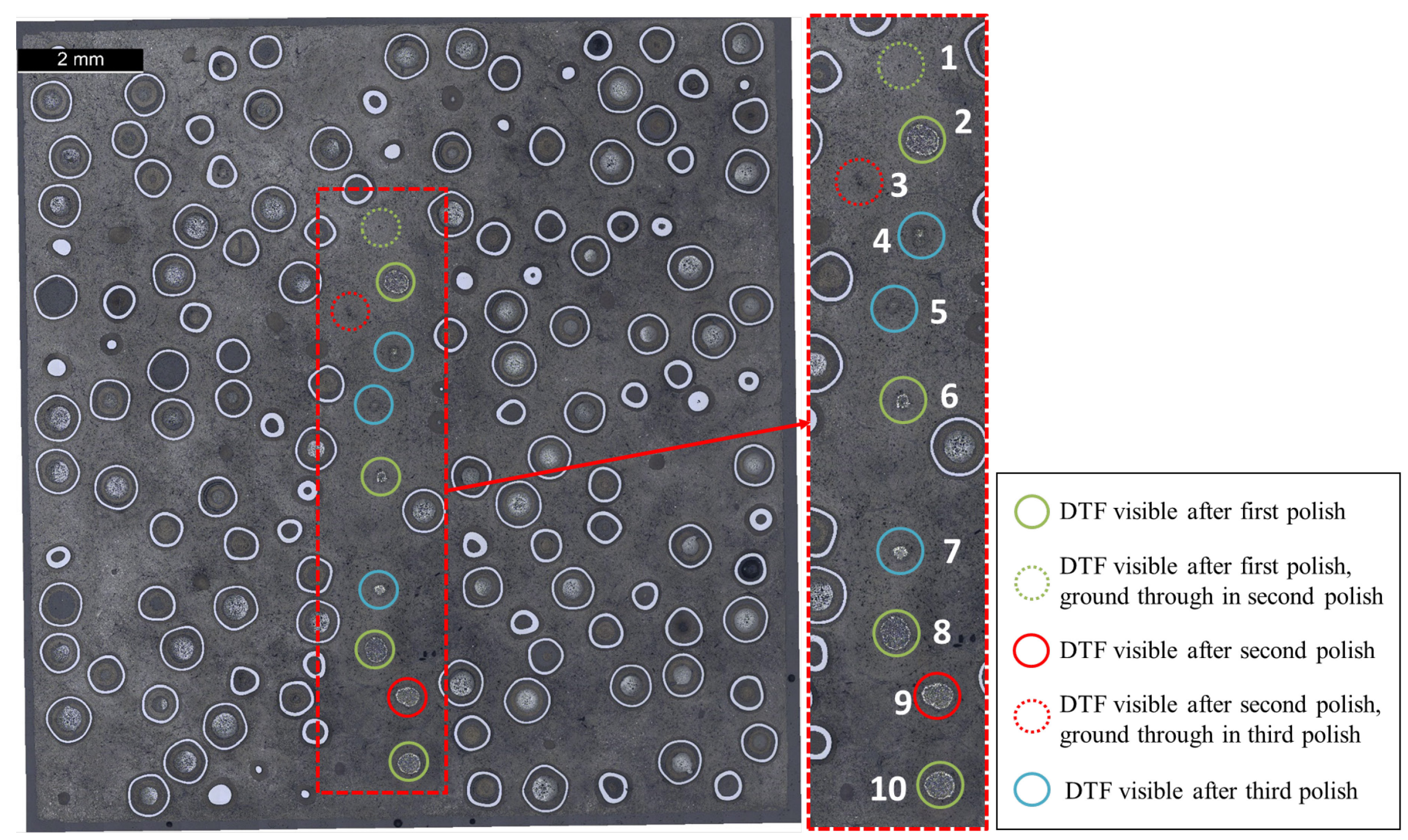

Figure 21. Montage of optical micrographs from the third polish of Compact 7-2. Each DTF particle imaged from any of the three cross-sections is labeled and numbered. 


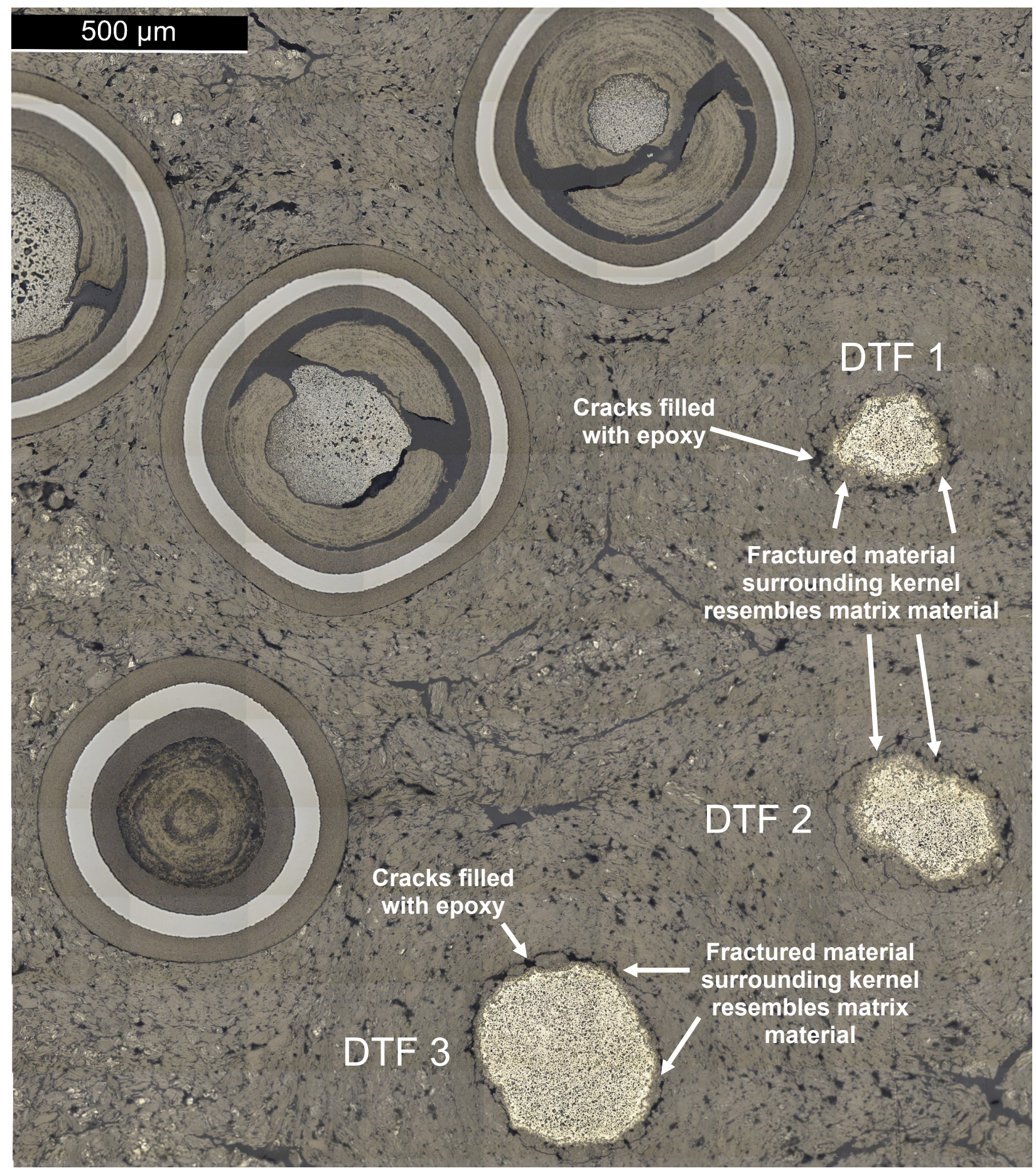

Figure 22. Montage of optical micrographs of DTF 1 through DTF 3 and several TRISO-coated driver fuel particles after the first polish of Compact 7-2. 


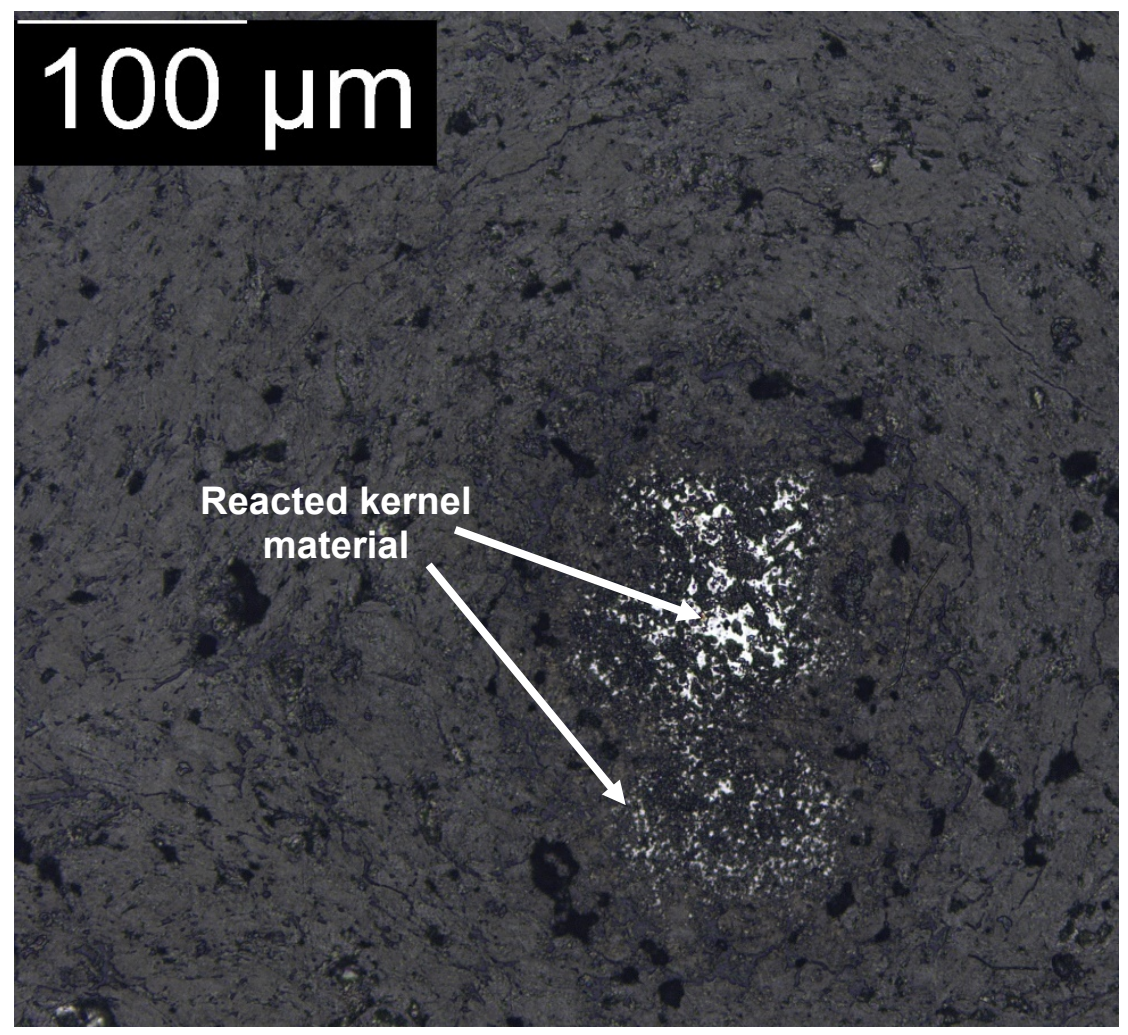

Figure 23. DTF 4 barely exposed from cross-section 3.

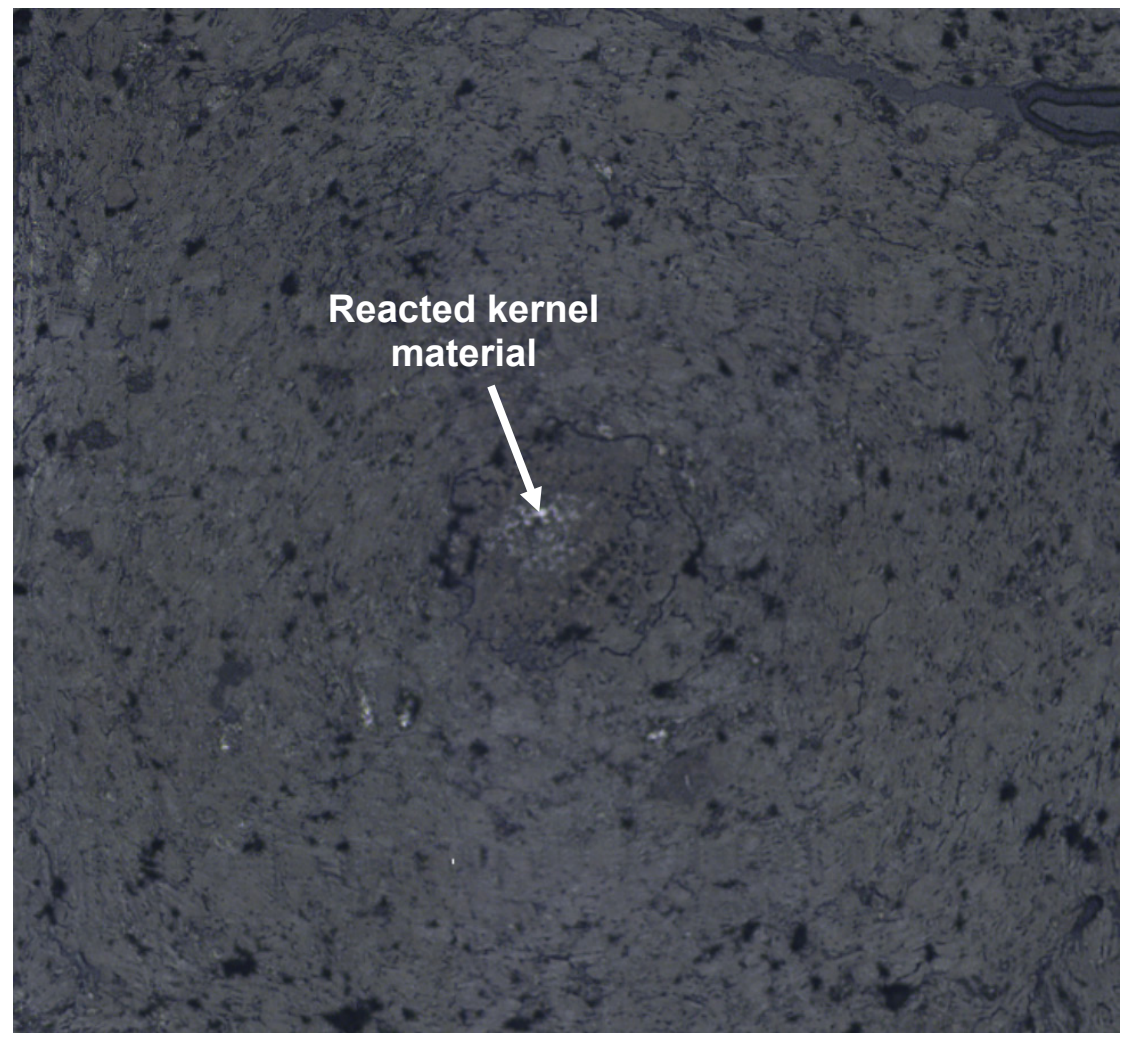

Figure 24. DTF 5 barely exposed from cross-section 3. 


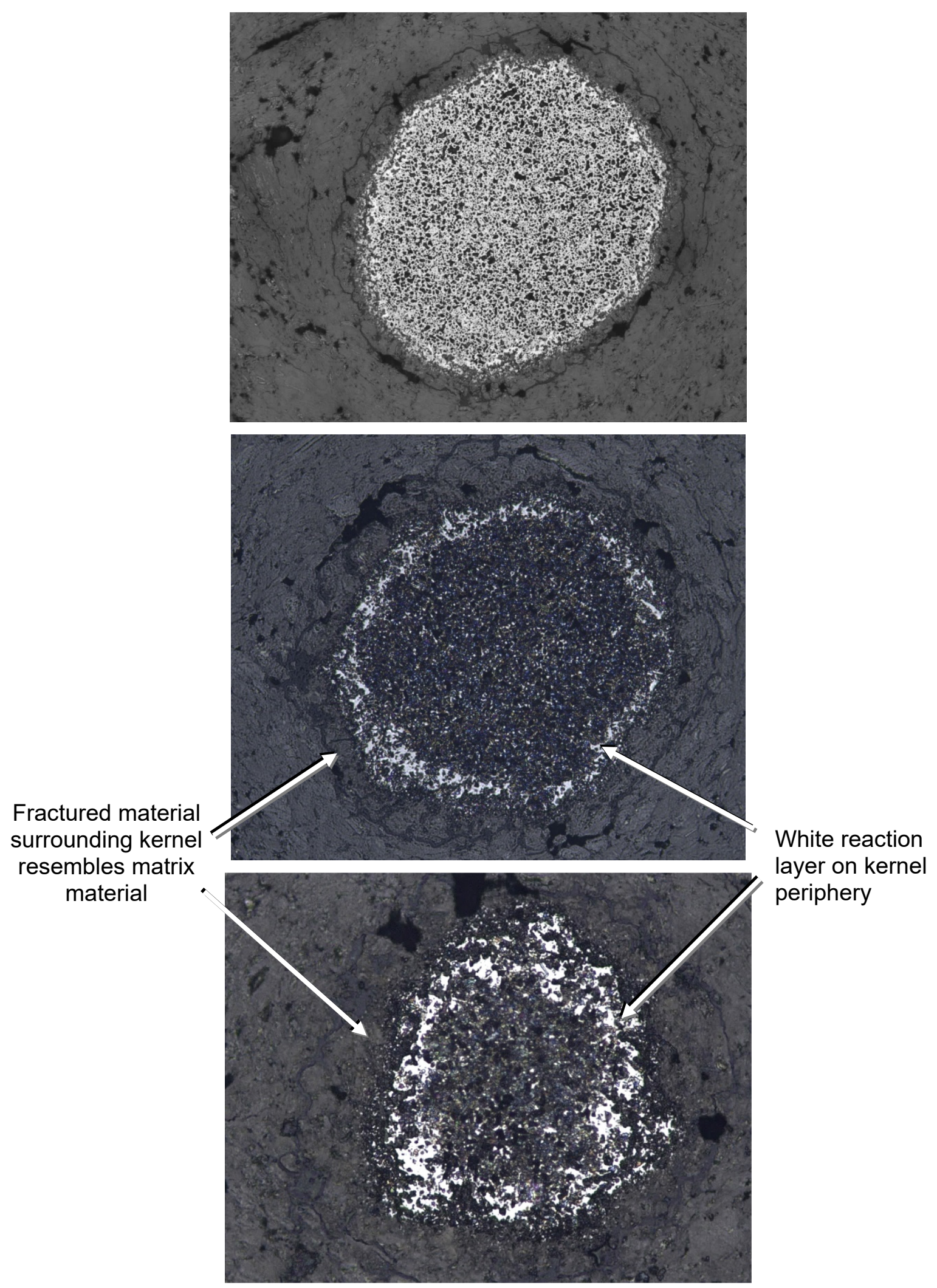

Figure 25. DTF 6 from first cross-section (top), second cross-section (middle), and third cross-section (bottom). 


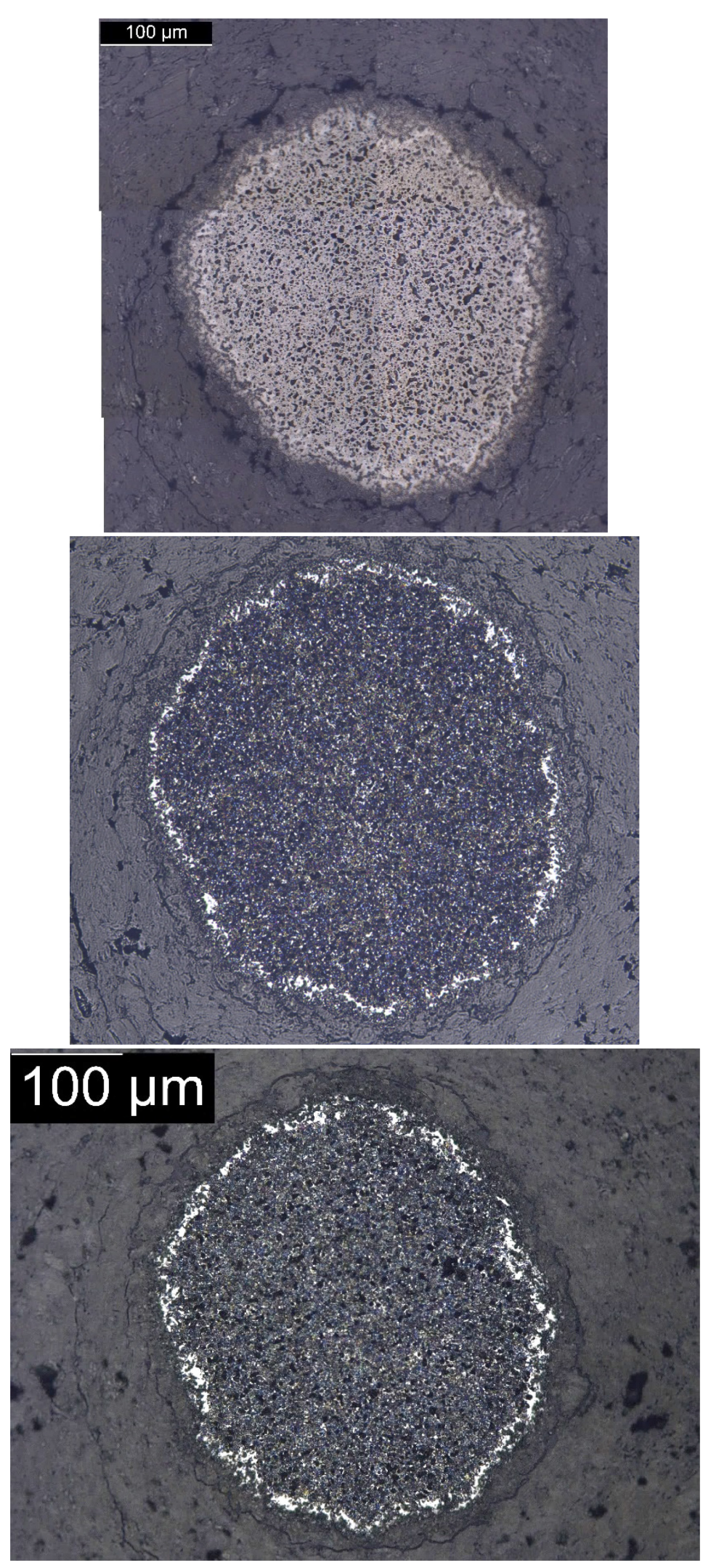

Figure 26. DTF 8 first cross-section (top), second cross-section (middle), third cross-section (bottom). 


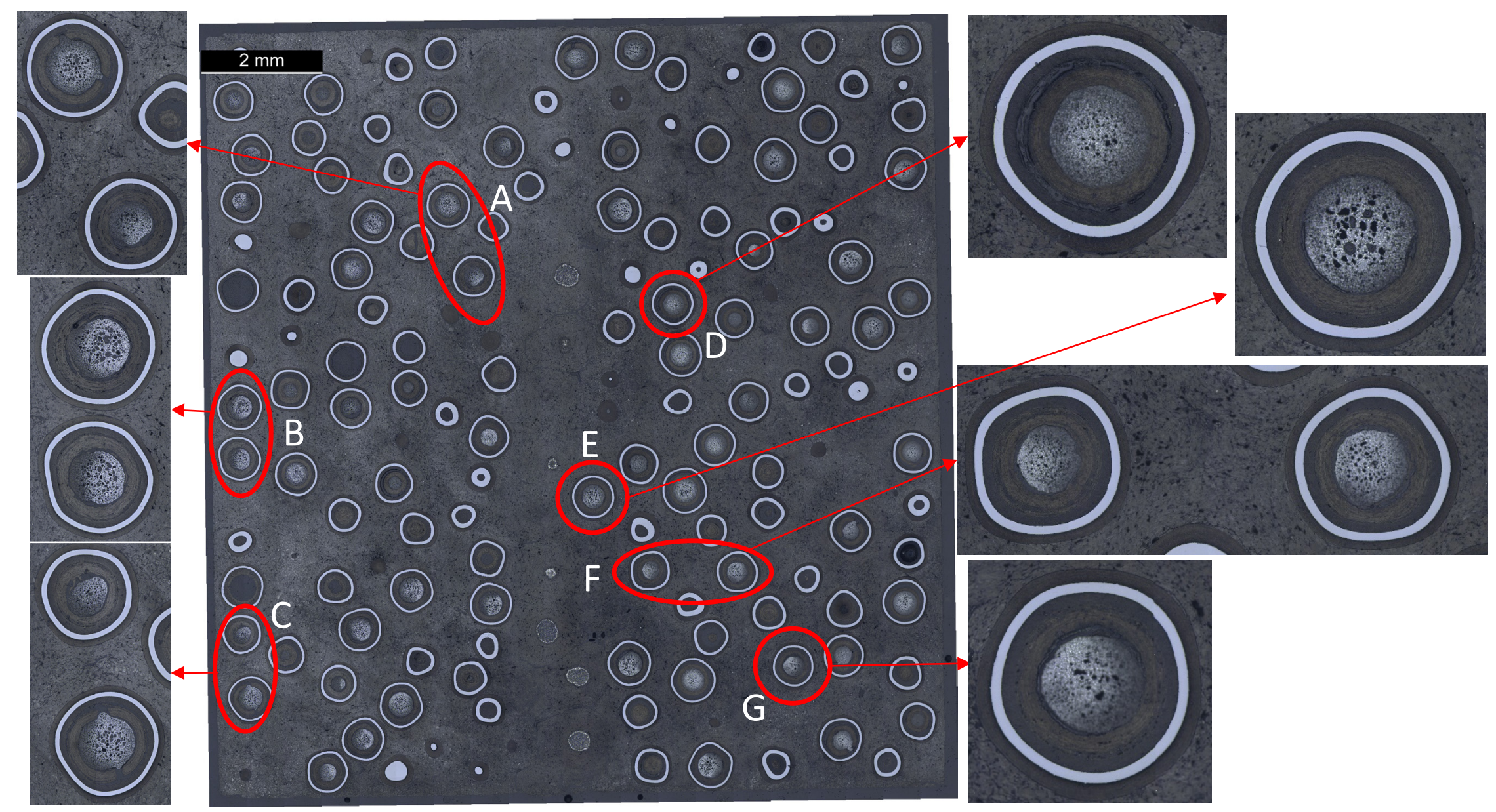

Figure 27. Montage of optical micrographs from the third cross-section of Compact 7-2. Driver particles and pairs of driver particles are highlighted and labeled A through G. These labels will be referenced in later sections of the report. 


\subsection{Compact 12-2 Cross Sections}

Figure 28 shows the evolution of Compact 12-2 cross-sections in MNT81A through three rounds of grinding and polishing. After the first polish, six DTF particles were visible. The second polish did not

reveal any additional DTF particles; however, two features appeared to be DTF particles that were about to be breached by additional grinding. The third round of grinding and polishing exposed two additional DTF particles for a total of eight DTF particles visible in the third cross-section. Figure 29 shows a montage of high-resolution optical micrographs of the third polished cross-section from Compact 12-2. Eight DTF particles are visible in this cross-section. Figure 30 through Figure 37 show optical micrographs of the cross-sections of each DTF particle. Figure 30 and Figure 31 micrographs are annotated to highlight major features common in Compact 12-2 DTF cross-sections. In addition to showing the images of DTF 4 and 5 after the third polish (when the kernels were first exposed at the mount surface), Figure 33 and Figure 34 also show images of these particles from the second polish, where grinding had almost exposed the kernels of these particles. Both Figure 33 and Figure 34 are annotated to highlight features unique to these particles within Compact 12-2. Figure 38 through Figure 41 show micrographs of driver particles characteristic of those in the Compact 12-2 cross-sections. Fullsize micrographs of each compact cross-section are given in Appendix A.3. 


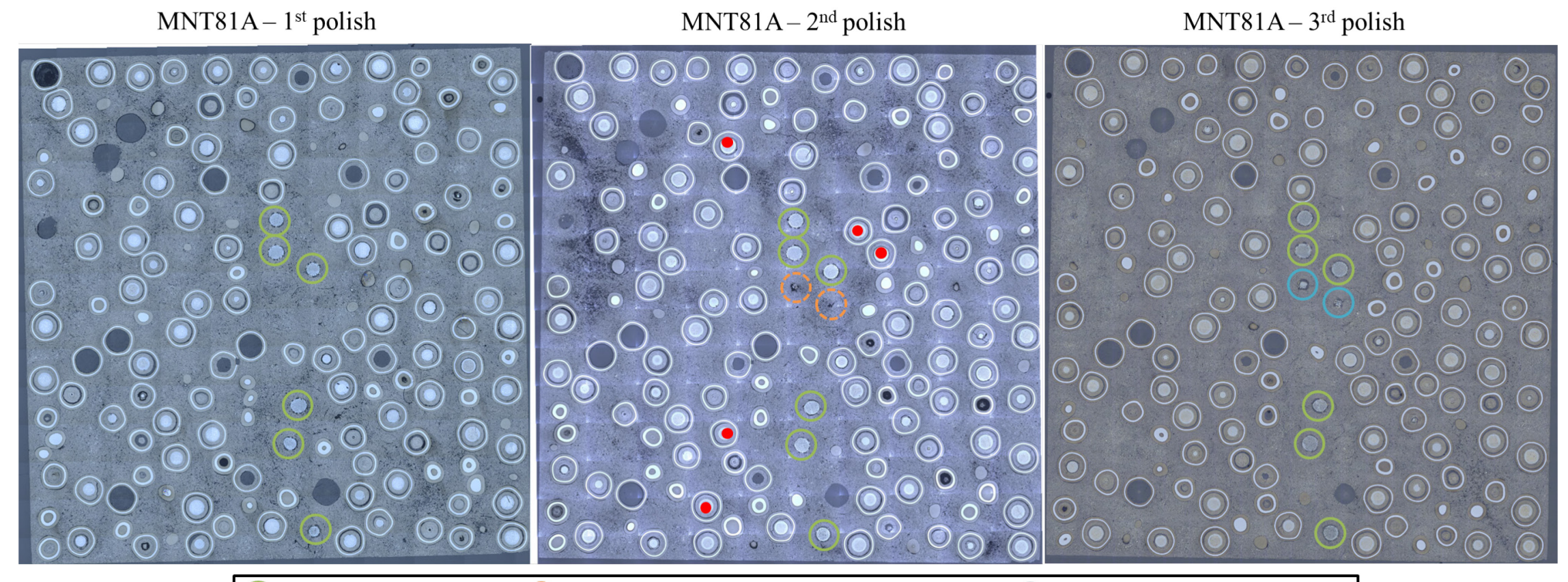

DTF visible after $1^{\text {st }}$ polish $\quad$ C DTF not yet exposed particle imaged $\bigcirc$ DTF kernel exposed after $3^{\text {rd }}$ polish

Figure 28. Montage of optical micrographs after each of three rounds of grinding and polishing of AGR-3/4 Compact 12-2. 


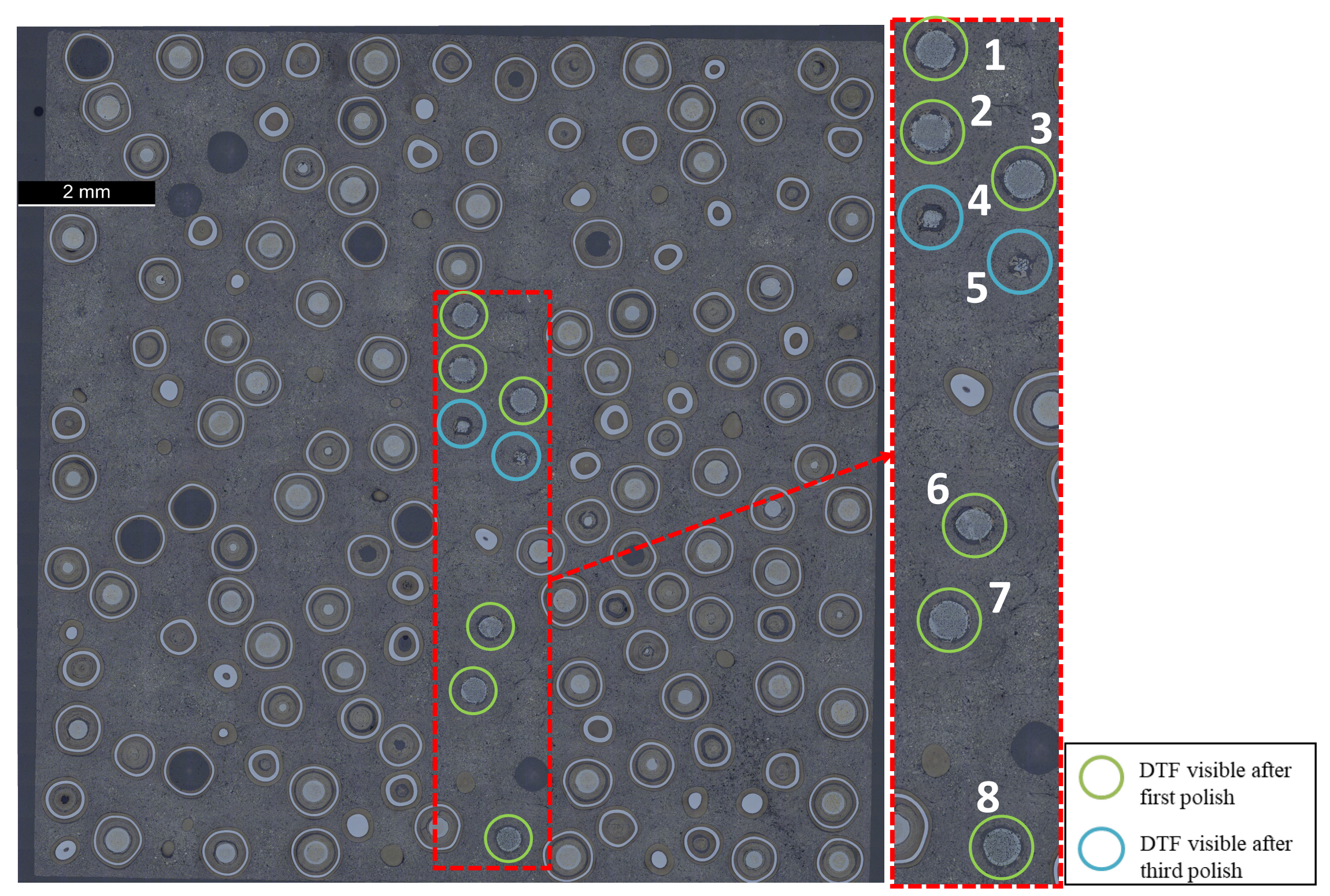

Figure 29. Montage of optical micrographs from the third polished cross-section of Compact 12-2. DTF particles are highlighted and numbered. 


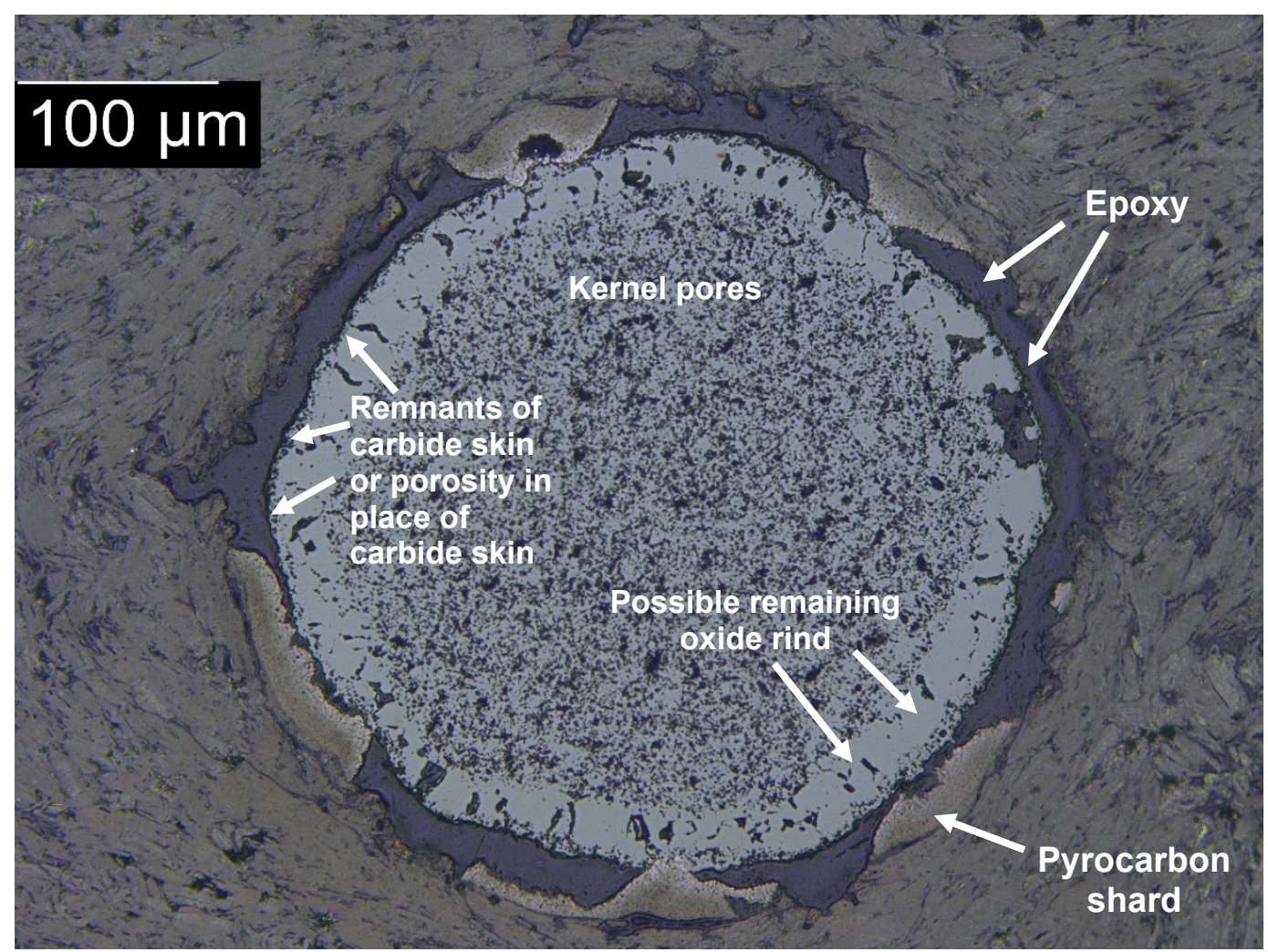

Figure 30. Optical micrograph of DTF 1 from the third polished cross-section of Compact 12-2.

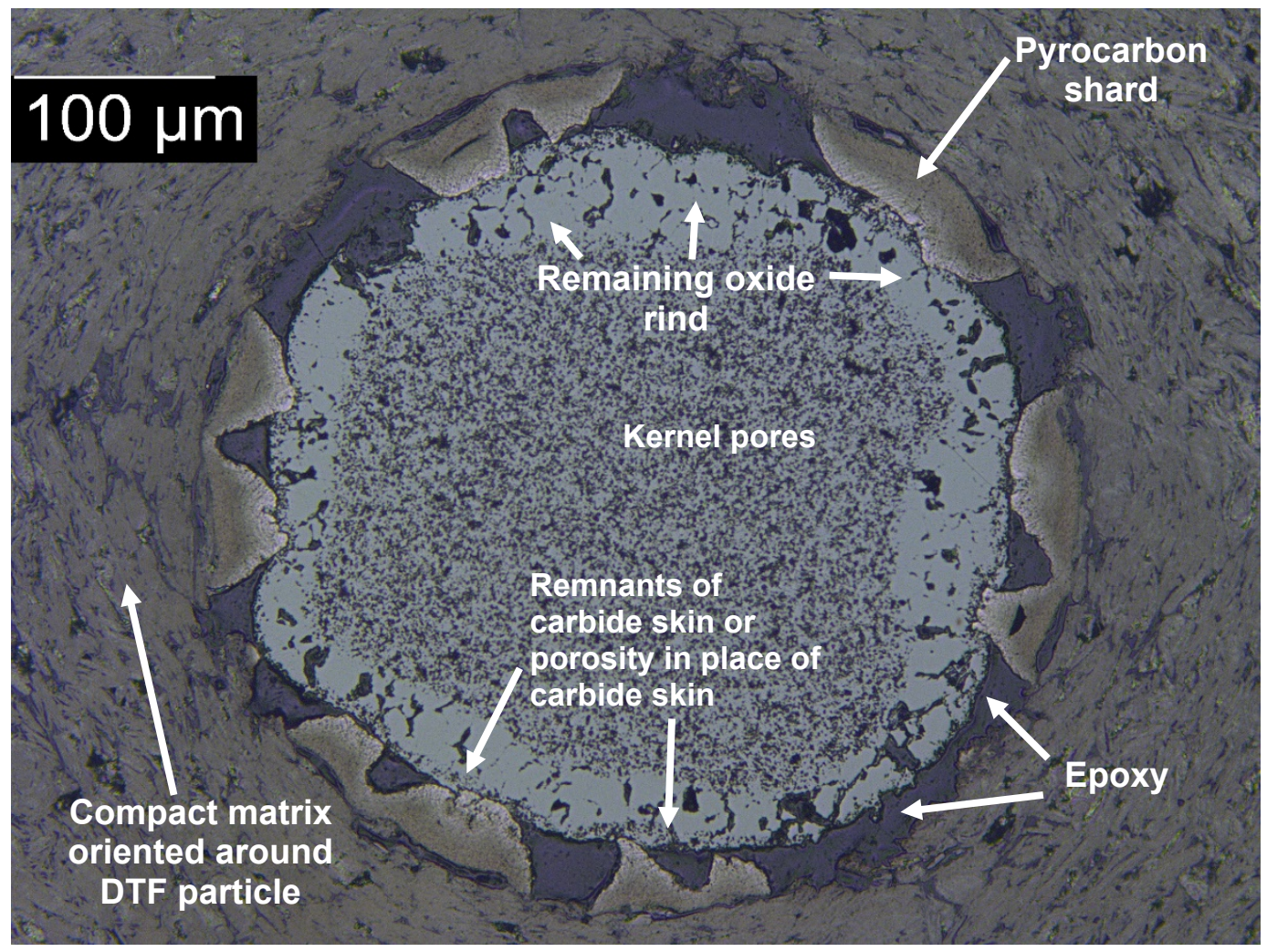

Figure 31. Optical micrograph of DTF 2 from the third polished cross-section of Compact 12-2. 


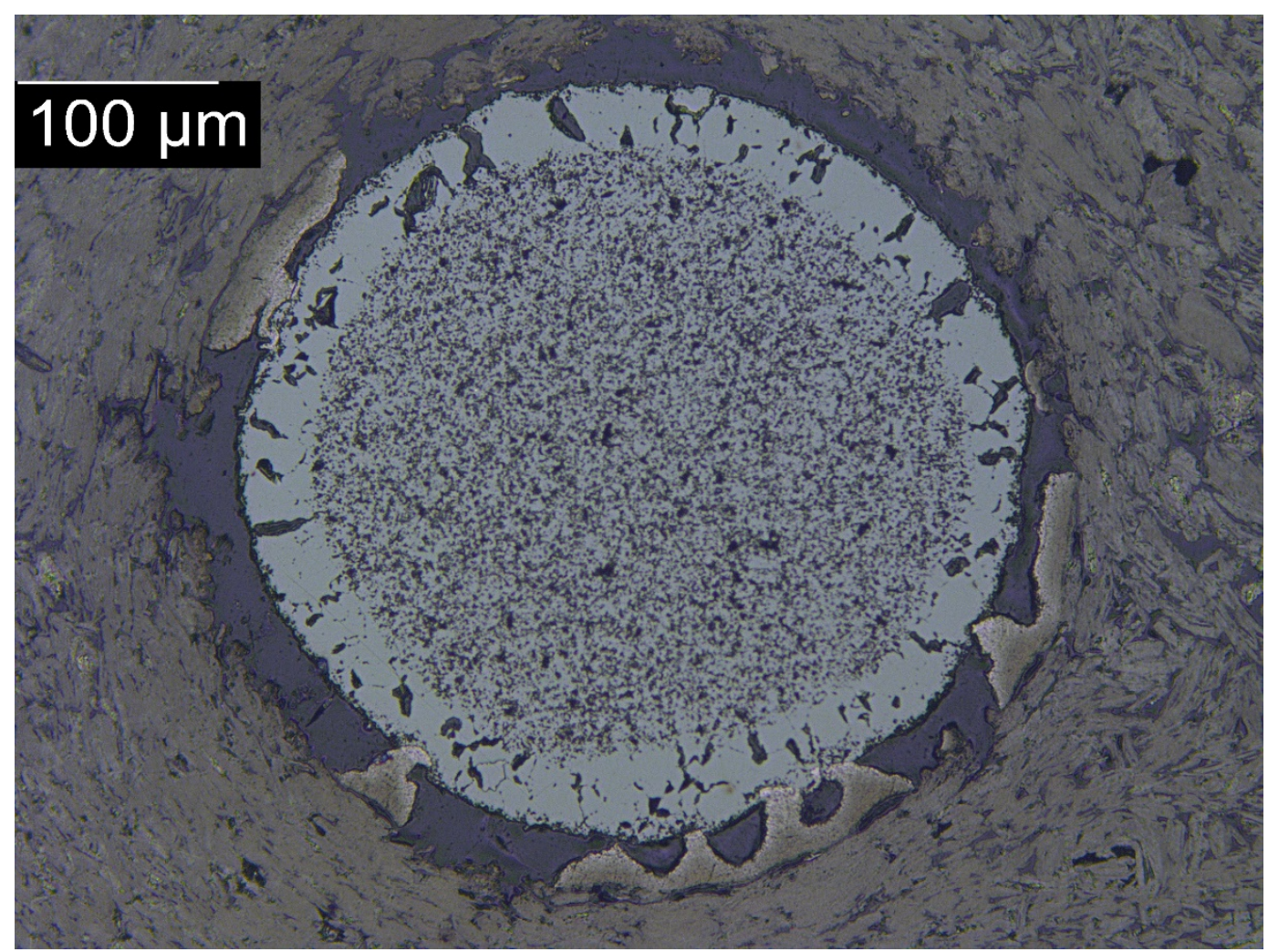

Figure 32. Optical micrograph of DTF 3 from the third polished cross-section of Compact 12-2.
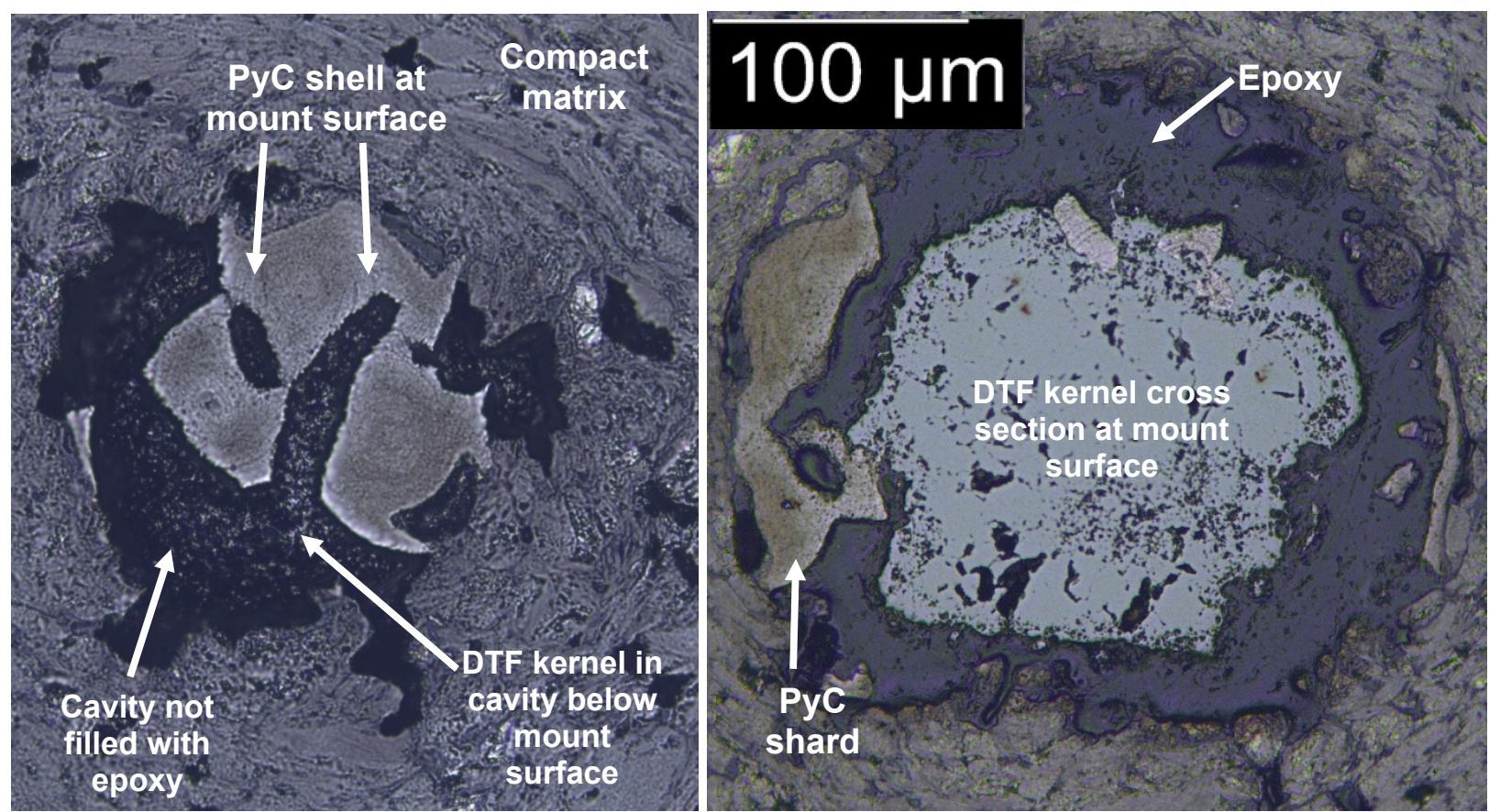

Figure 33. Optical micrographs of DTF 4 after the second polish (left) and third polish (right). Scale applies to right image only. 

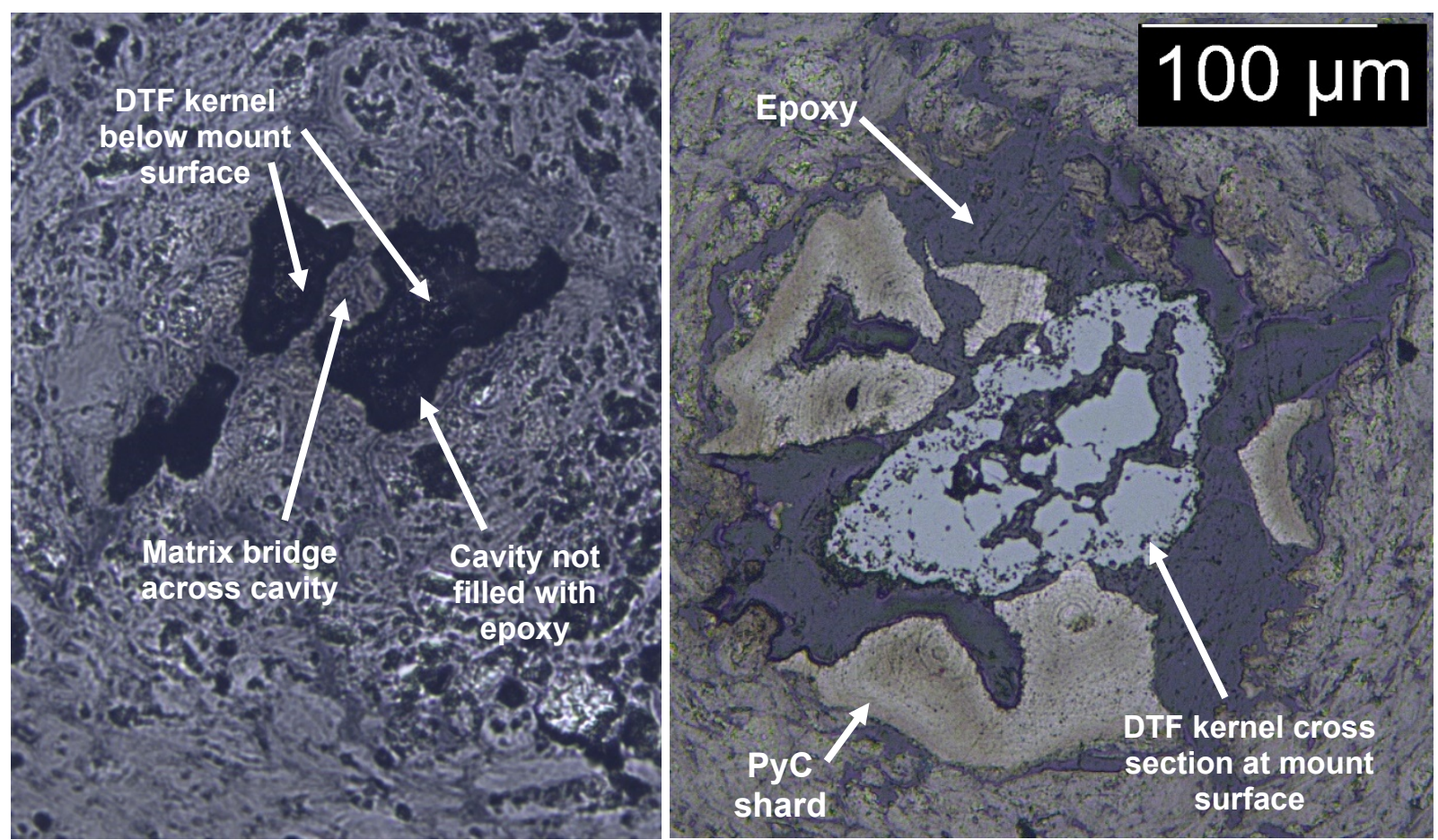

Figure 34. Optical micrographs of DTF 5 after the second polish (left) and the third polish (right). Scale applies to right image only.

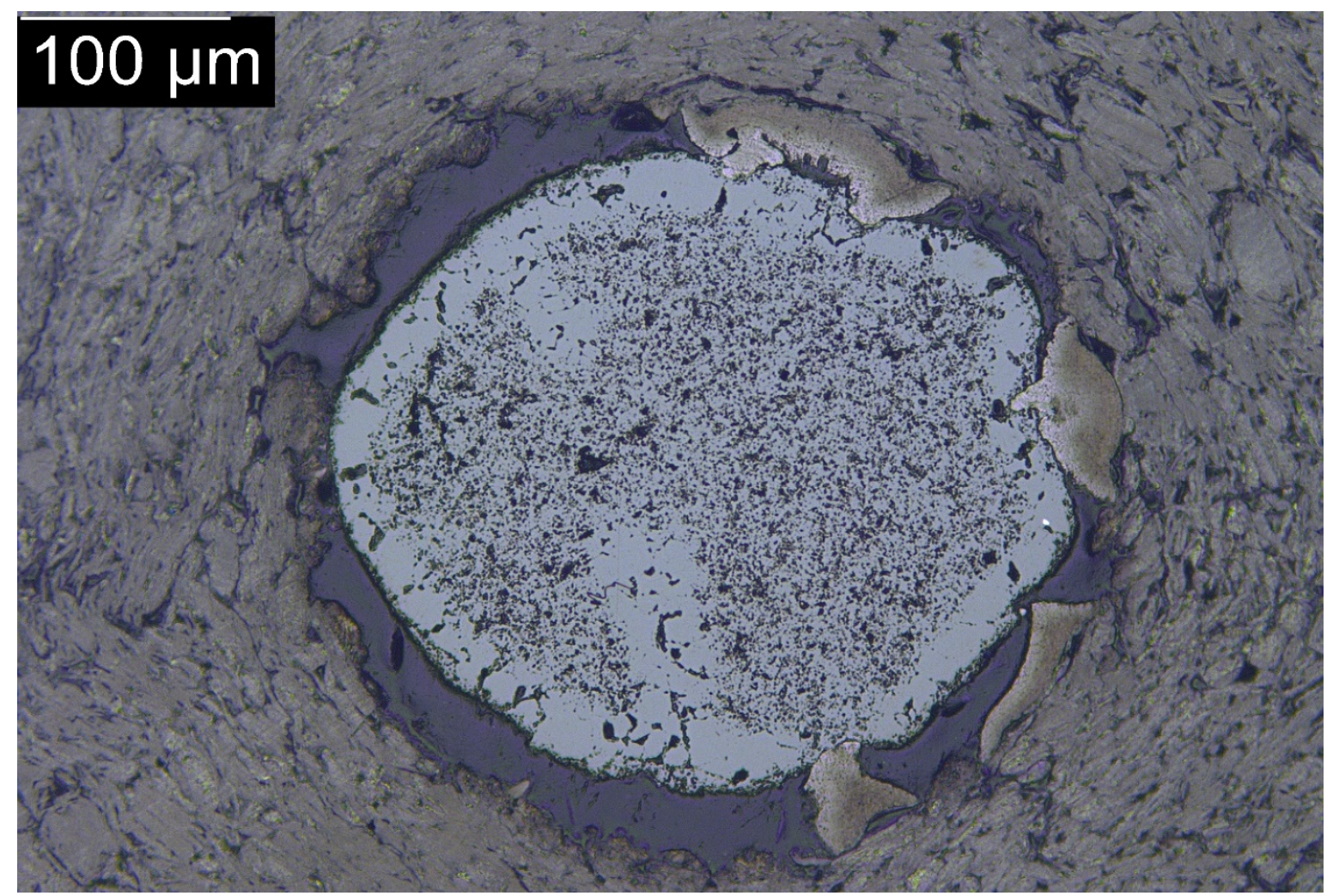

Figure 35. Optical micrograph of DTF 6 from the third polished cross-section of Compact 12-2. 


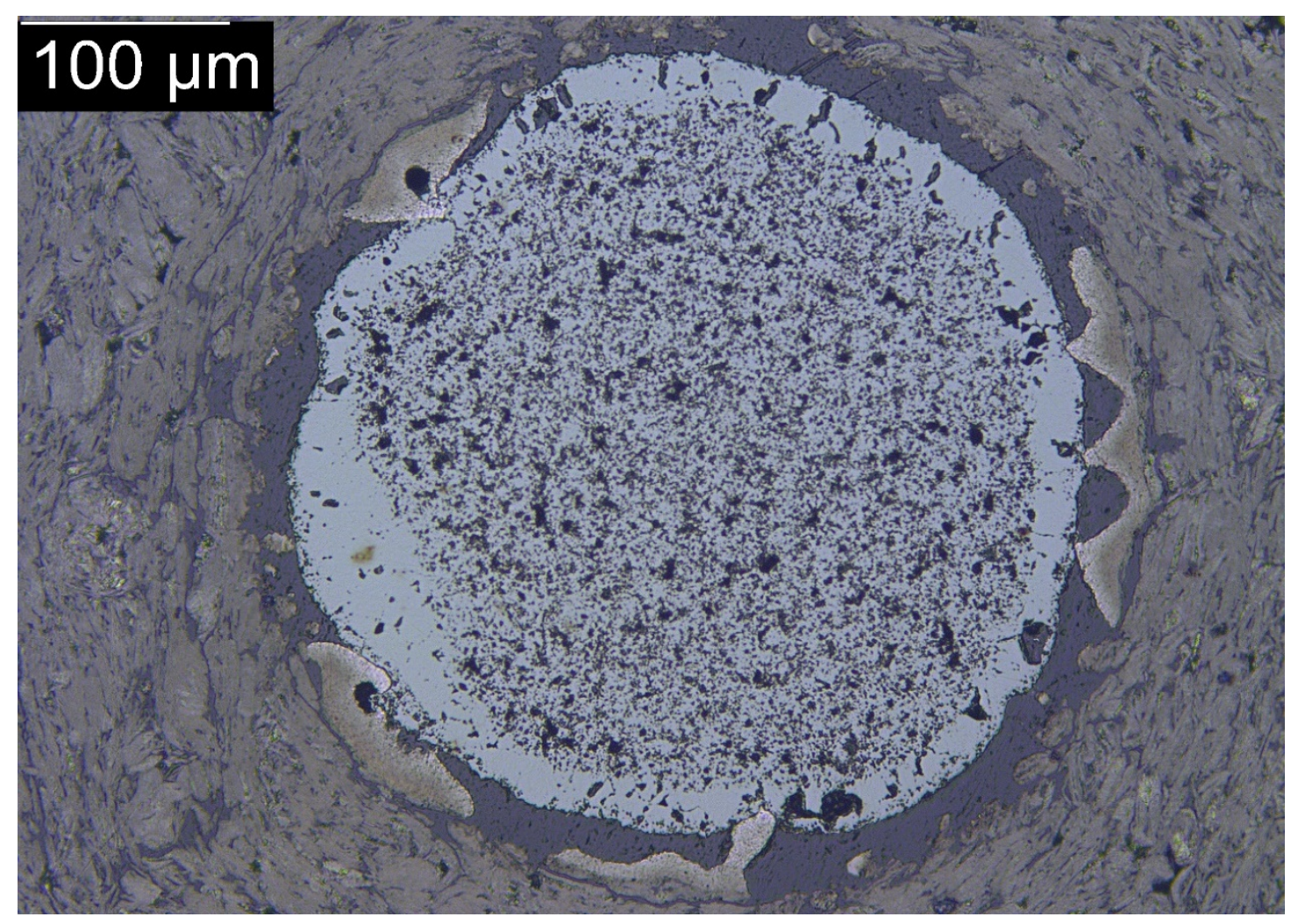

Figure 36. Optical micrograph of DTF 7 from the third polish of Compact 12-2.

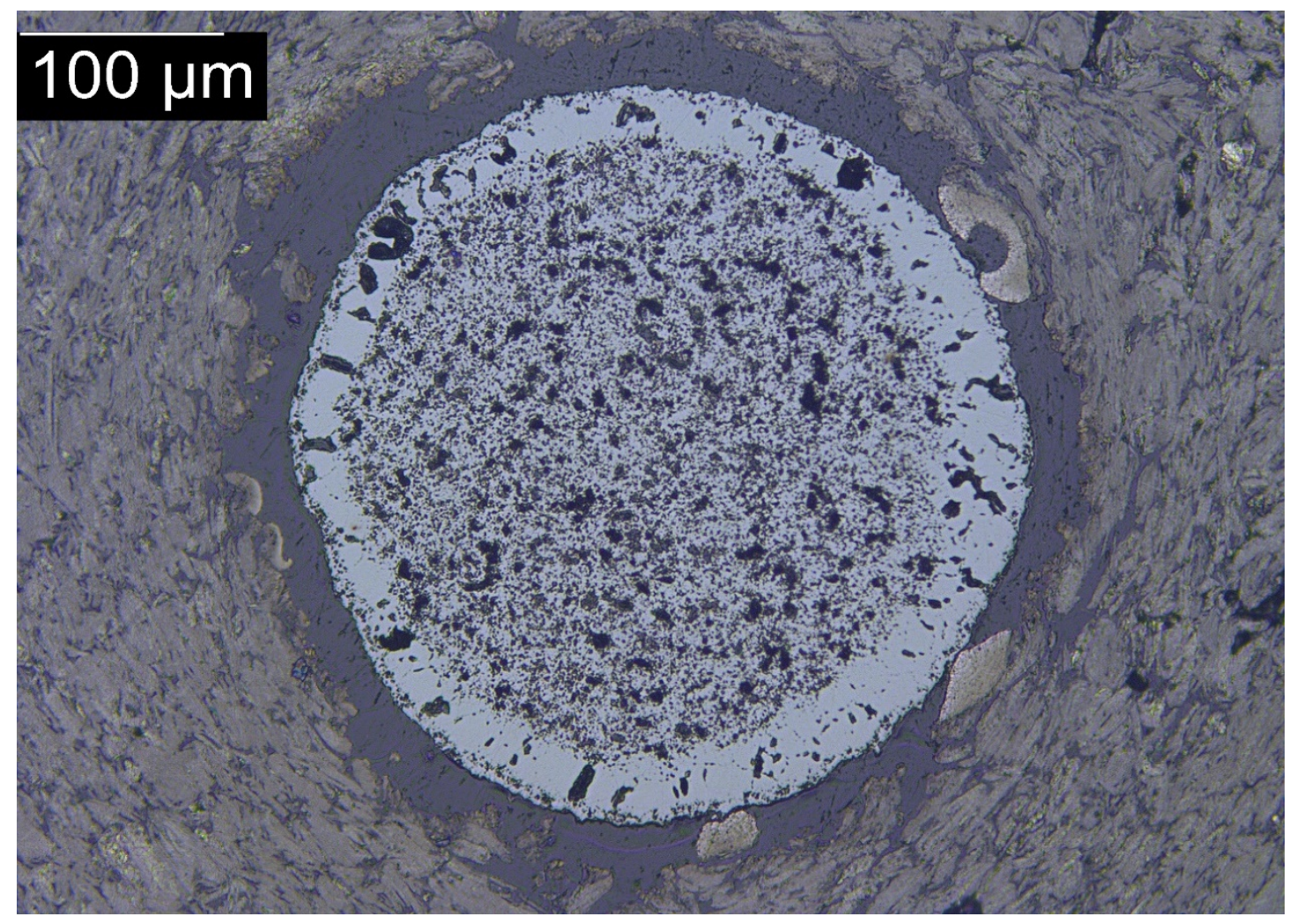

Figure 37. Optical micrograph of DTF 8 from the third polish of Compact 12-2. 


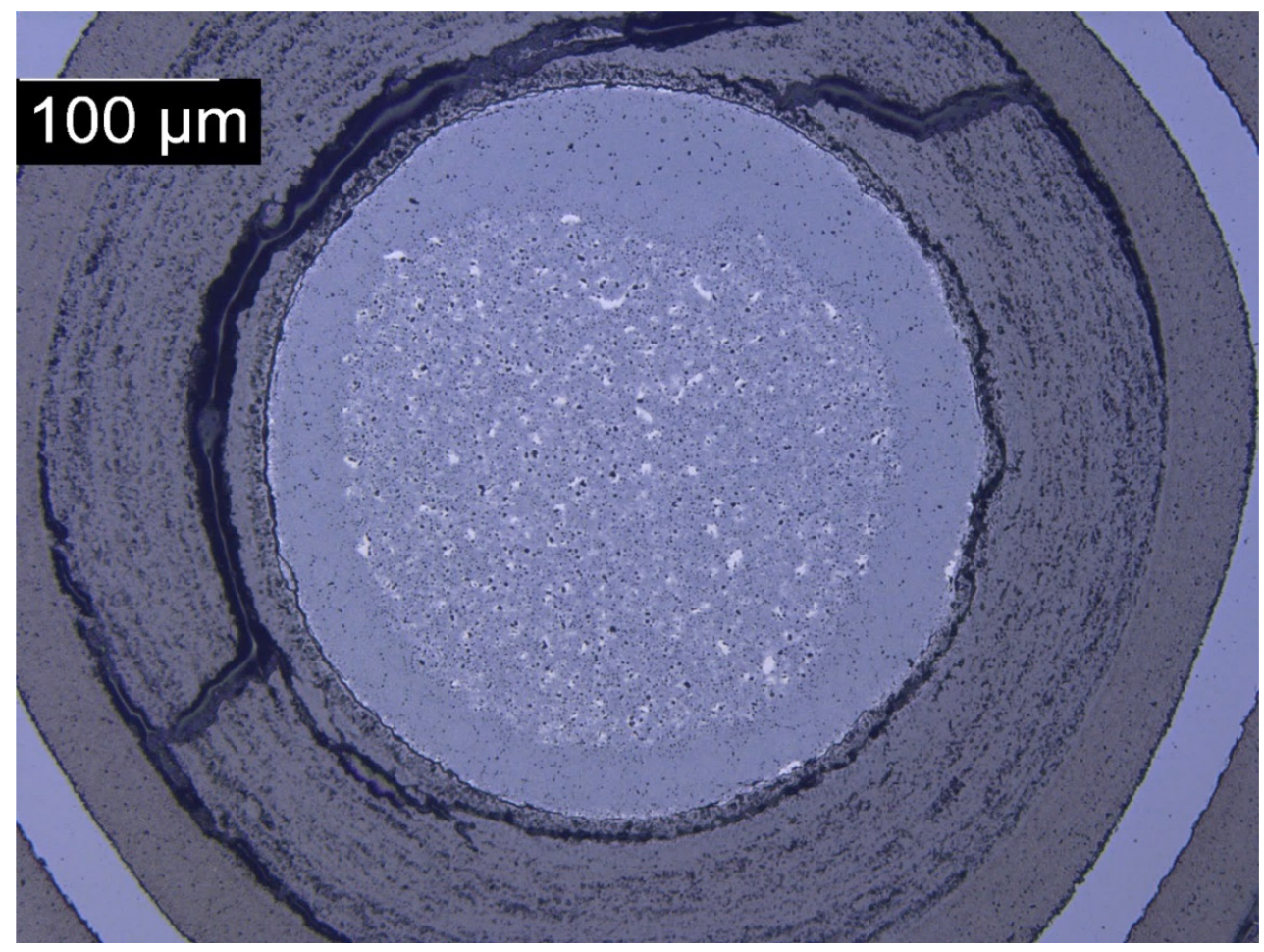

Figure 38. Optical micrograph of TRISO-coated driver fuel particle from Compact 12-2 after first polish. Particle was located immediately to the left of DTF 8 in Figure 29. This figure is enlarged and annotated in Figure 49 in Section 4.3.2.

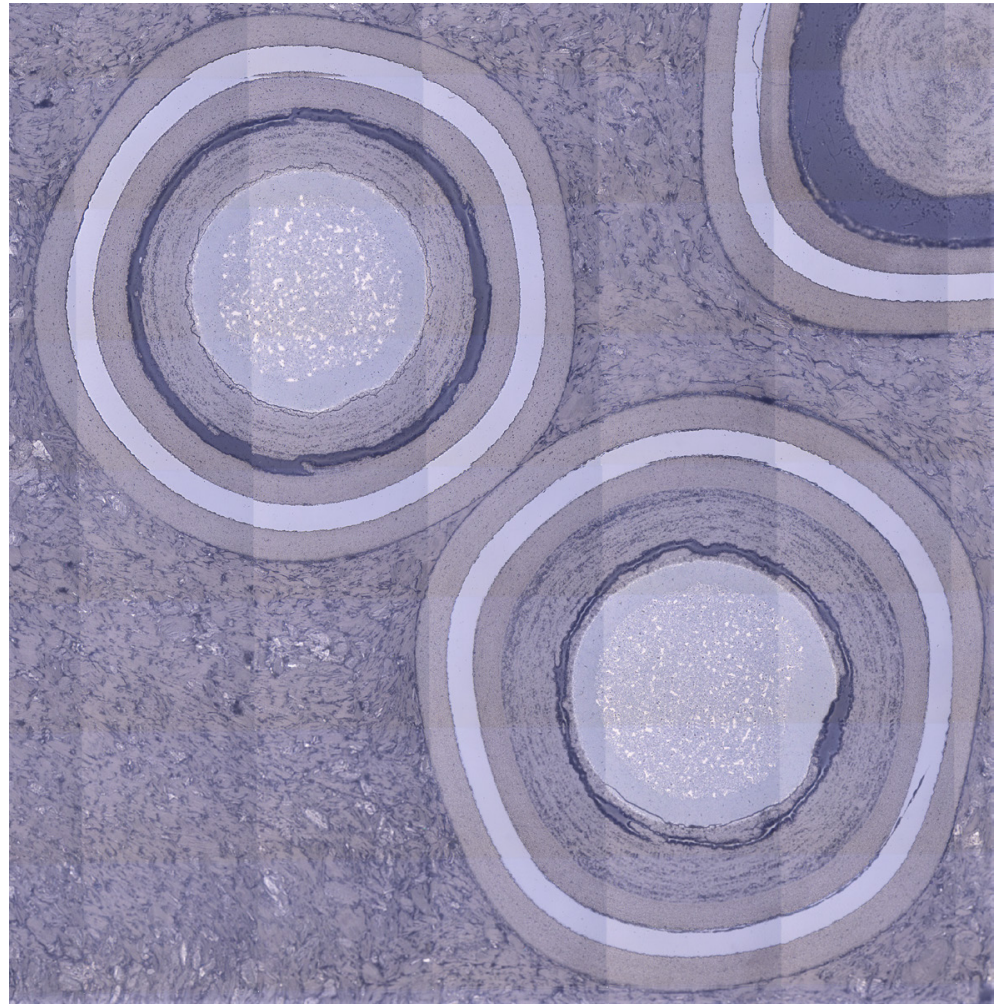

Figure 39. Montage of optical micrographs of driver particles from the first cross-section of Compact 122. These particles were located to the right of DTF 1, 2, and 3, in Figure 29. 


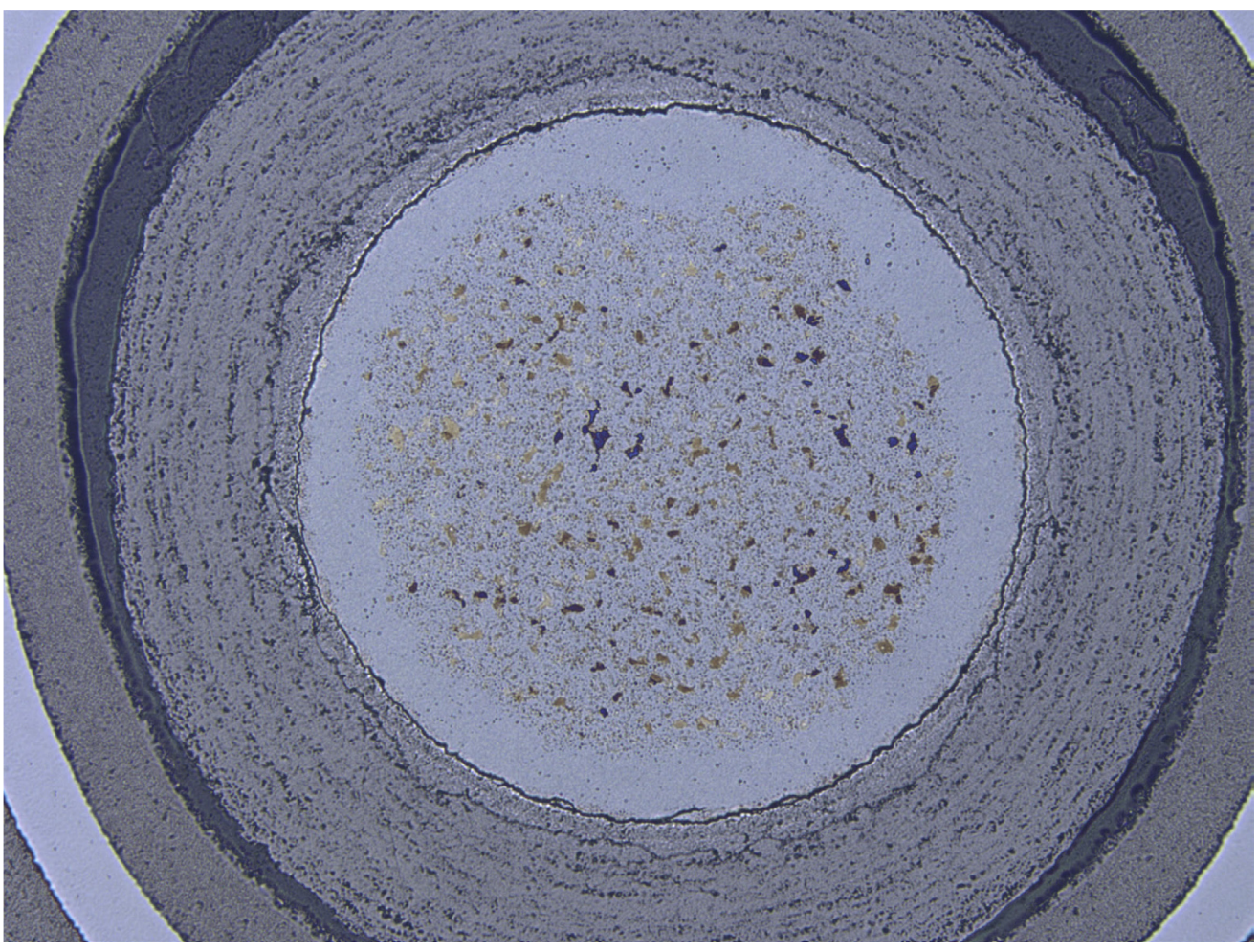

Figure 40. Optical micrograph of a driver particle from the second cross-section of Compact 12-2.

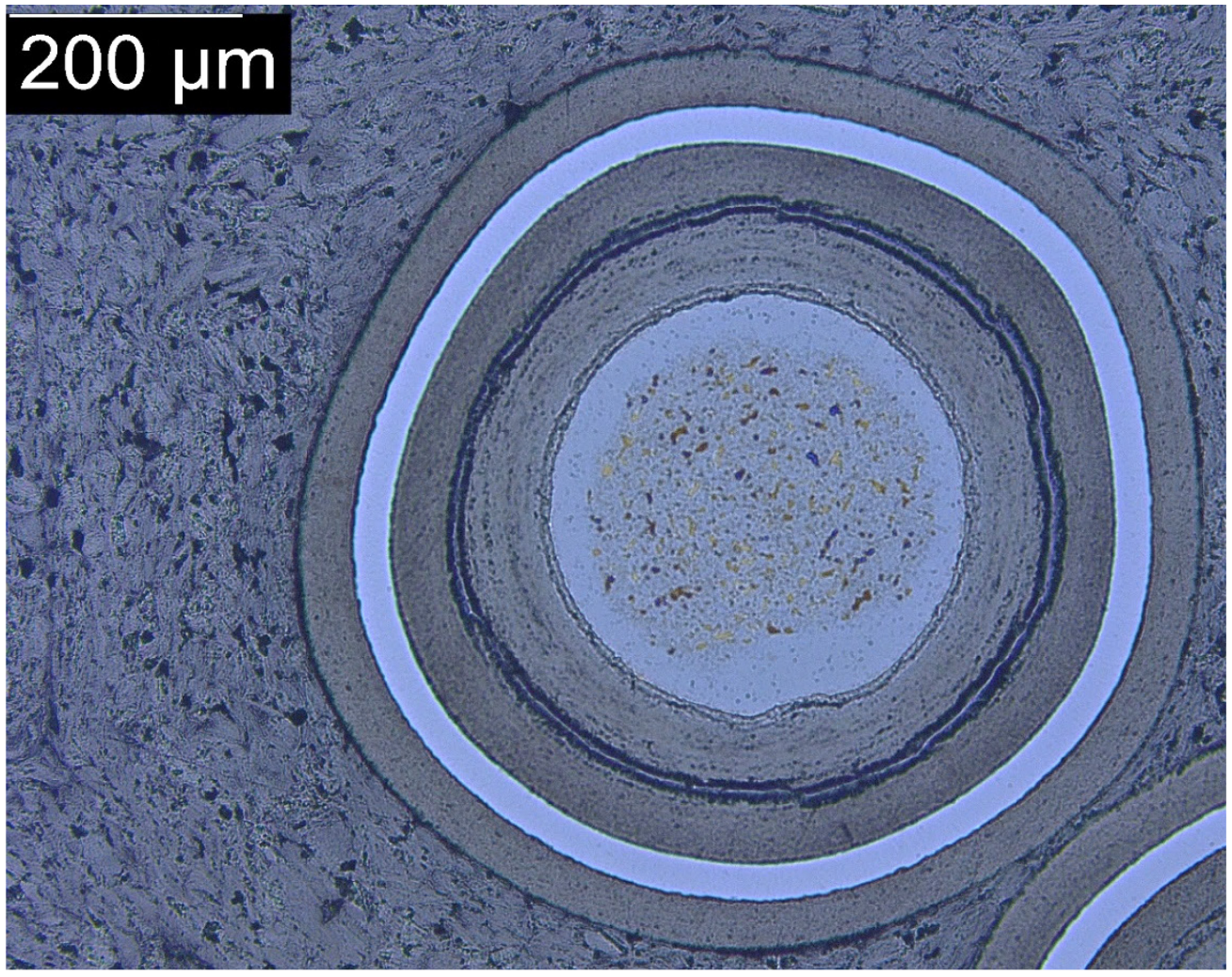

Figure 41. Optical micrograph of a driver particle from the third polish of Compact 12-2. 


\section{RESULTS DISCUSSION \\ 4.1 DTF Pyrocarbon Coating Integrity and Morphology}

A total of 29 DTF particles were observed across three compacts. The DTF particle PyC morphologies for Compact 5-2 (see Figure 11 through Figure 18) and Compact 12-2 (see Figure 29 through Figure 37) are very similar. In Compacts 5-2 and 12-2, the PyC layer appears to have buckled (folded in on itself and broken apart) during irradiation. This is believed to be due to non-uniform irradiation-induced volumetric shrinkage in these highly anisotropic DTF PyC layers. The fast neutron fluences for Compacts 5-2 and 12-2 were $5.2 \mathrm{E} 25 \mathrm{n} / \mathrm{m}^{2}$ and $1.6 \mathrm{E} 25 \mathrm{n} / \mathrm{m}^{2}$, respectively. A common PyC correlation gives volumetric shrinkage of approximately $7 \%$ at a fast fluence of $2 \mathrm{E} 25 \mathrm{n} / \mathrm{m}^{2}$ (Schappel et al. 2018). Beyond $2 \mathrm{E} 25 \mathrm{n} / \mathrm{m}^{2}$, the PyC volume change begins to turn around, but the net shrinkage is still several percent at fast fluences of $5 \mathrm{E} 25 \mathrm{n} / \mathrm{m}^{2}$ (Schappel et al. 2018). With irradiation-induced, nonuniform PyC shrinkage, the DTF PyC coatings pulled themselves apart.

The irradiation-induced buckling in Compacts 5-2 and 12-2 DTF PyC was such that only shards of the coatings remained. This buckling clearly occurred during irradiation because the DTF kernels deformed around the $\mathrm{PyC}$ shards. Kernel morphology and kernel accommodation of PyC shards are each discussed further in Section 4.2. DTF particle cross-sections from Compacts 5-2 and 12-2 appear to have similar numbers of large shards; however, in addition to the PyC shards, Compact 5-2 DTF cross-sections also have some areas with smaller, irregular pyrocarbon remnants with a more mottled appearance (e.g. Figure 12 and Figure 13). This suggests that either formation of finer cracks within portions of the pyrocarbon or some chemical reaction between the pyrocarbon and the kernel occurred in addition to buckling.

In Compacts 5-2 and 12-2, significant areas or gaps around portions of the DTF kernels, which would have consisted of pyrocarbon at the time of fabrication, now have little or no remaining pyrocarbon material and little evidence of significant chemical reaction of the pyrocarbon with other materials in the compact. These resultant gaps have been filled with epoxy through the backpotting process used between rounds of grinding and polishing. As the DTF particles were uncovered via grinding, it is possible that pieces of the pyrocarbon that had buckled during irradiation were lost during the PIE grinding process before the pyrocarbon could be stabilized by epoxy. For example, Figure 33 and Figure 34 show Compact 12-2 DTF particles when the particles were first breached by the second round of grinding/polishing and then after backpotting, followed by the third round of grinding/polishing. The micrographs indicate that the DTF pyrocarbon and/or compact matrix around the DTF particles in Compact 12-2 acted as somewhat of a shell, making a cavity that the DTF kernels sat in. When the shell was first breached, these figures show that the cavity with the kernel was not initially full of epoxy. Some pieces of the pyrocarbon that had buckled during irradiation could have been lost when the DTF particles were first breached. After initially breaching these Figure 33 and Figure 34 DTF particles, backpotting stabilized these kernels and other structures within the cavity for the third round of grinding/polishing. Similar phenomena could have occurred for other particles in Compacts 5-2 and 12-2.

The state of the DTF pyrocarbon coatings in Compact 7-2 was distinctly different from what was observed in Compacts 5-2 and 12-2. No remaining pyrocarbon coating was distinguishable in any of the micrographs of any of the Compact 7-2 DTF particles. While there was some evidence of minor chemical reaction between the DTF pyrocarbon and kernel in Compact 5-2 (e.g. Figure 12 and Figure 13), the Compact 7-2 pyrocarbon appears to have reacted completely with the kernel (see Figure 22 through Figure 26). The only materials clearly present in micrographs of Compact 7-2 DTF particles were the kernel and compact matrix material. The second and third polished cross-sections in Figure 21, Figure 25, and Figure 26 clearly show a whiteish $\mathrm{PyC} / \mathrm{kernel} /$ matrix reaction layer encircling the kernel. This feature is difficult to see in the native images from Compact 7-2 cross-section 1 (see Figure 22 and the top micrographs in Figure 25 and Figure 26); however, darkening the image and reducing the contrast improves the visibility of this feature, as was done in Figure 42, below. 
The complete chemical reaction of the Compact 7-2 PyC with the kernel is attributed to the hotter irradiation temperatures in Compact 7-2 (TA peak $1417^{\circ} \mathrm{C}$ ) compared to Compacts $5-2\left(\mathrm{TA}\right.$ peak $1101^{\circ} \mathrm{C}$ ) and $12-2$ (TA peak $888^{\circ} \mathrm{C}$ ). The TA peak temperatures are referenced here because the DTF particles were located along the center of the compacts where the fuel temperatures were highest. The higher temperatures in Compact 7-2 would have promoted chemical reaction between the kernel material adjacent to the $\mathrm{PyC}$ and any fission products that diffused to the $\mathrm{PyC}$ (a thermally-driven process) or were recoiled into the PyC from fission. It is possible that the pyrocarbon cracked before or during chemical reaction with the kernel; or it is possible that the chemical reaction occurred before the onset of any pyrocarbon cracking. The mounts do not allow a determination of when or if any pyrocarbon cracking occurred in Compact 7-2 prior to kernel/PyC chemical reaction during the irradiation.

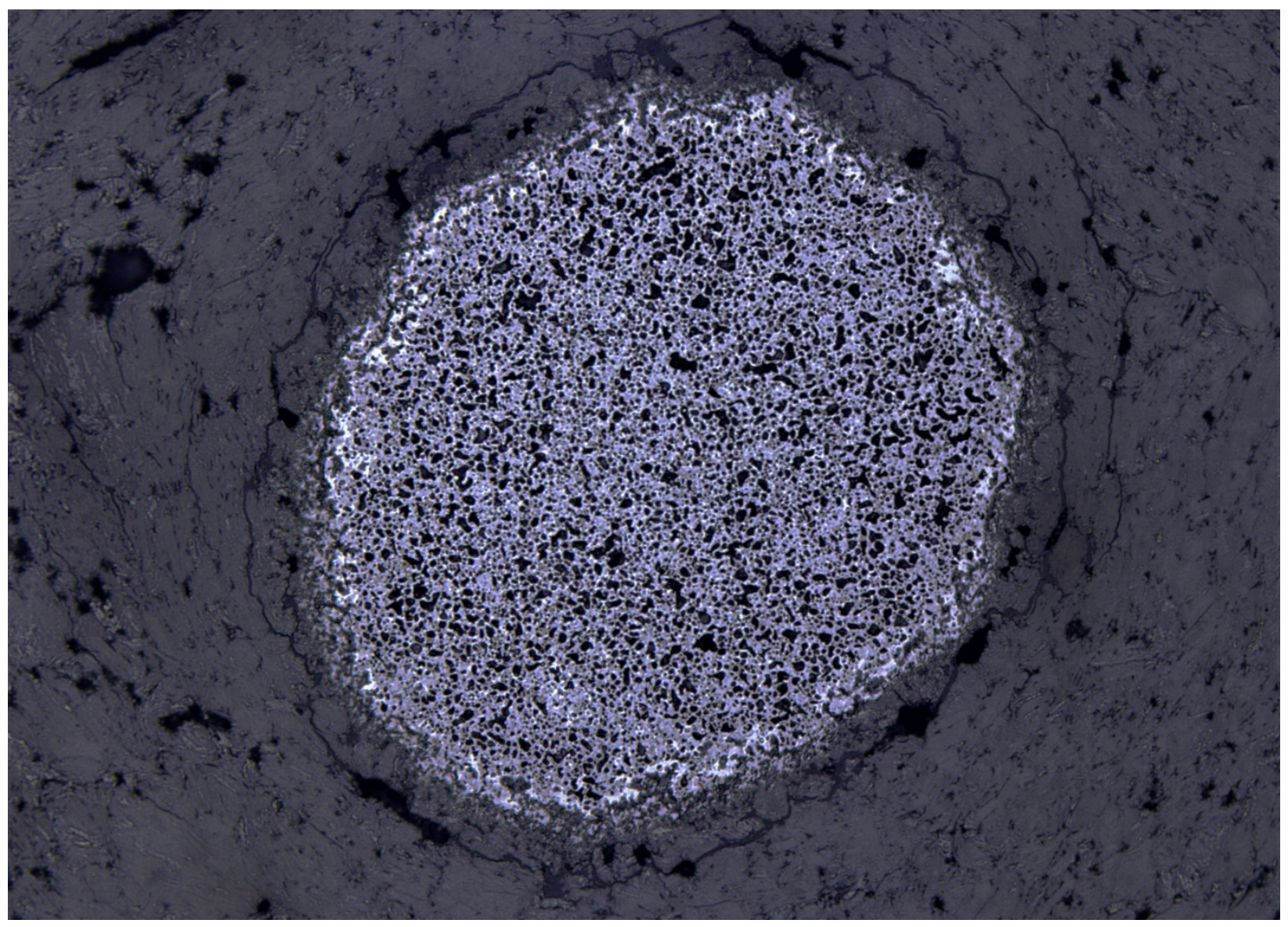

Figure 42. Optical micrograph of DTF 6 from the first cross-section of Compact 7-2 after reducing brightness and contrast. Compare with top micrograph in Figure 25.

The High Flux Reactor (HFR)-B1 experiment (irradiated in HFR Petten in the Netherlands from April 1987 to July 1989) featured DTF particles similar in concept to those use in AGR-3/4 (a UCO kernel approximately $350 \mu \mathrm{m}$ in diameter with a pyrocarbon coating approximately $20 \mu \mathrm{m}$ thick) (Hanson 2006). HFR-B1 Capsule 1 featured 12 fuel compacts, each with 1,396 TRISO-coated driver particles and 87 DTF particles (Hanson 2006). The average Capsule 1 burnup, fast fluence, and irradiation temperature were $21.5 \%$ FIMA, $4.9 \mathrm{E} 25 \mathrm{n} / \mathrm{m}^{2}$ (similar to AGR-3/4 Capsules 5 and 7), and $931 \pm 42{ }^{\circ} \mathrm{C}$, respectively (Hanson 2006). Some post-irradiation ceramography was performed on these compacts in (Derz and Flossdorf 1994), and (Hanson 2006) excerpted the two DTF particle micrographs shown below in Figure 43. Here, as with the AGR-3/4 Compacts 5-2 and 12-2 pyrocarbon coatings, only discontinuous shards of pyrocarbon remain, suggesting a similar mechanism of in-pile pyrocarbon fracture via irradiation-induced buckling from PyC shrinkage. The kernel then deformed around the PyC shards. 


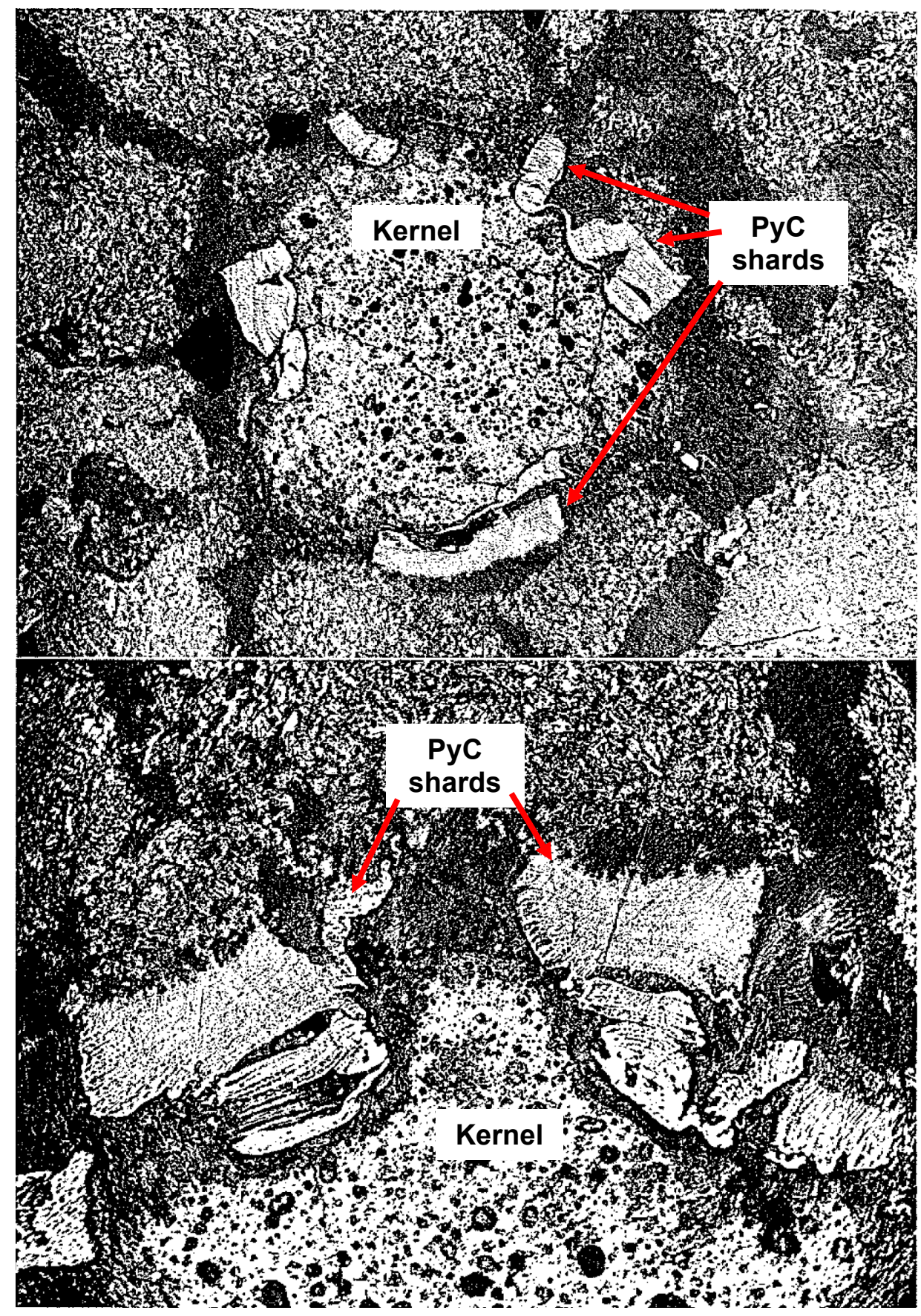

Figure 43. Optical micrographs from two DTF particles in HFR-B1 Capsule 1 Compact DC 012100 (Hanson 2006). Annotations added.

Eleven DTF particles were observed via ceramographic cross-sectioning of Compact 5-2, 10 DTF particles were observed in Compact 7-2, and eight DTF particles were observed in Compact 12-2. In each compact, all observed DTF particles had completely failed pyrocarbon coatings. Table 4 summarizes the number of DTF particles observed via ceramography, the number of observed DTF particle failures, and the probability based on the observed failures that (at 95\% confidence from binomial statistics) all 20 DTF particles within a compact had failed. Even though only eight to 11 of the 20 DTF particles were 
observed in the compacts, the probability that all the DTF particles in the compacts were failed ranged from 99.4 to $99.6 \%$.

Table 4. Observed DTF failures and probability that all 20 DTF particles in a compact had failed.

\begin{tabular}{|c|c|c|c|}
\hline Compact & $\begin{array}{c}\text { Number of DTF } \\
\text { Particles Observed }\end{array}$ & $\begin{array}{c}\text { Failed DTF Particles } \\
\text { Observed }\end{array}$ & $\begin{array}{c}\text { Probability All 20 DTF } \\
\text { Failed (95\% } \\
\text { Confidence) }\end{array}$ \\
\hline $5-2$ & 11 & 11 & 0.996 \\
\hline $7-2$ & 10 & 10 & 0.995 \\
\hline $12-2$ & 8 & 8 & 0.994 \\
\hline
\end{tabular}

\subsection{DTF Kernel Morphology}

Compact 5-2 DTF kernels have primarily small, spherical pores that are relatively evenly distributed. The carbide and oxide phases of the kernel are no longer distinguishable from one another as they were in the as-fabricated kernels. In comparison, the Compact 12-2 DTF particles appear to have a greater number of small, non-spherical, interconnected pores. Unlike the evenly distributed pores of Compact 52, the Compact 12-2 DTF kernel pores are located primarily in the central region of the kernel that would have contained the UCO mixture at fabrication. The Compact 12-2 DTF kernels appear to still have the oxide rind around the periphery of the kernel with long, radial pores, and there are places where there is either increased porosity or remnants of the carbide skin around the outer perimeter of the oxide rind. The Compact 12-2 driver particles (see Section 4.3.2) also exhibit features reminiscent of the oxide rind and carbide skin (for example see Figure 38 through Figure 40). In fact, the Compact 12-2 driver particles still have distinct uranium oxide and uranium carbide phases in the central part of the kernel. It is reasonable to conclude that the significantly lower irradiation temperature (TA peak $888^{\circ} \mathrm{C}$ ) and lower burnup $(5.5 \%$ FIMA) of Compact 12-2 is a major factor in the differences between the Compact 12-2 and 5-2 (burnup $14.9 \%$ FIMA, TA peak $1101^{\circ} \mathrm{C}$ ) kernel morphology observed in PIE. This would explain why the Compact 12-1 DTF kernels appear to retain features of as-fabricated kernels (e.g. oxide rind and carbide skin) that are typically not found in fuel irradiated at higher temperatures and burnups.

Compact 12-2 DTF kernels appear to have retained sphericity more than Compact 5-2 DTF kernels; however, in both compacts, the kernels appear to have accommodated the pyrocarbon shards by deforming around the shards. Kernel deformation around the PyC shards is evidence that the pyrocarbon layers failed by buckling and folding in on themselves during irradiation in such a way that the kernel had enough time to accommodate this pyrocarbon deformation. This is particularly obvious for Compact 5-2 (see for example Figure 14 and Figure 16 through Figure 18). The higher irradiation temperatures in Compact 5-2 seem to have allowed the DTF kernels to deform around and accommodate the PyC shards to a greater extent than in the cooler Compact 12-2 (e.g., Figure 31, Figure 35, and Figure 36).

The kernel and pyrocarbon appear to have completely reacted chemically in Compact 7-2 (TA peak $1417^{\circ} \mathrm{C}$ ) such that no pyrocarbon remains. Unlike Compact $12-2$, no evidence of an oxide rind or carbon skin remains on the DTF kernels, and the $\mathrm{UC}_{2}$ and $\mathrm{UO}_{2}$ phases present in the center of the kernel at fabrication cannot be distinguished. Like Compact 5-2, the Compact 7-2 DTF kernel cross-sections are ellipsoidal rather than circular. The porosity in the Compact 7-2 DTF kernels (particularly in the first cross-section) appears to be similar to the type of porosity observed in Compact 5-2 (i.e., spherical, evenly distributed, etc.).

Figure 25 and Figure 26 show micrographs from all three Compact 7-2 cross-sections of particles DTF 6 and DTF 8, respectively. In the first cross-sections, the DTF kernels have similar color and features to the driver particles. In the second and third cross-sections, however, the DTF kernels have a much darker appearance, and there is a white-colored ring around the periphery of the kernels. There was no reason to expect the DTF kernel's appearance to change dramatically from one cross-section to the 
next. The driver particle kernels appear similar in all three cross-sections. The difference in DTF appearance from the first cross-section to the second and third cross-sections is believed to be due to the grinding process and the specific Compact 7-2 DTF kernel structure itself. The first Compact 7-2 crosssection has very little relief between the $\mathrm{SiC}$ and $\mathrm{PyC}$ layers in the driver particles, indicating very even grinding/polishing. In the second and third cross-sections, there are significant shadows at the driver particle SiC-PyC interfaces where it is clear that the softer PyC material was ground in preference to the harder $\mathrm{SiC}$ material. It is hypothesized that the high irradiation temperature of Compact 7-2 resulted in changes to the DTF kernels that made their centers softer and/or more friable than the edges of the DTF kernels and the driver particle kernels. The preferential grinding of this softer/friable material in the second and third cross-sections led to the different appearance of the second and third DTF cross-sections.

\subsection{Driver Particle Buffer/Kernel and Matrix Morphologies}

The primary goal of AGR-3/4 ceramography was to observe the DTF particles and their kernels and pyrocarbon coatings (if any remained). A secondary goal was to observe cross-sections of the TRISO driver fuel in high-temperature Compact 7-2 and low-temperature/low-burnup Compact 12-2. To find DTF particles quickly and fulfill the primary goal, larger grinding steps were taken between each crosssection. This approach allows more expeditious observation of DTF particles, but it may have been less than ideal for the driver fuel because the larger steps between backpotting might have reduced the amount of epoxy supporting the TRISO coatings at each grinding/polishing step. Even with the larger steps, however, the quality of the TRISO cross-sections appears to be similar to ceramography dedicated specifically to TRISO-coated fuel particles in AGR-1 (Ploger et al. 2012, Ploger et al. 2014) and AGR-2 (Rice et al. 2016, Rice et al. 2018).

The AGR-3/4 driver fuel TRISO coatings are similar to the AGR-1 "baseline" TRISO coating, and AGR-1 compact ceramography already examined three fuel compacts with baseline TRISO coatings (Ploger et al. 2012, Ploger et al. 2014). However, compared to AGR-1, the AGR-3/4 experiment had irradiation temperatures both considerably higher and considerably lower than AGR-1. To further expand the PIE database to more irradiation conditions, observations of AGR-3/4 buffer layers and kernels are given in the following sections, along with comparisons to AGR-1 and AGR-2.

\subsubsection{Buffer Layer}

Buffer fracture has been implicated in the degradation and/or cracking of the IPyC. The IPyC cracking exposes the $\mathrm{SiC}$ layer to metallic fission product attack, particularly from fission product palladium (Hunn et al. 2016, Morris et al. 2018). On occasion, chemical reaction between palladium and $\mathrm{SiC}$ may fail the $\mathrm{SiC}$ layer. Some examples of driver particles with fractured-buffer layers are available in Figure 19, Figure 22, Figure 38, and Figure 44. The micrograph in Figure 44 shows two radial cracks all the way through the buffer and kernel extrusion into the buffer cracks. Kernel extrusion into the crack is a clear indication that buffer fracture occurred in-pile and not during grinding or polishing. A buffer/IPyC gap exists around most of the buffer layer. Small strips of the buffer appear to have separated from the bulk of the buffer and remain attached to the IPyC. This indicates that the buffer/IPyC bond in this particle, at this particular cross-section, is stronger than the buffer itself.

Each of the three AGR-3/4 compacts analyzed here went through three rounds of grinding and polishing. It is possible that certain features and particles visible in one cross-section were not visible in another cross-section. For example, a particle with no visible buffer fracture in cross-section 1 might have a visible buffer fracture in cross-section 3. Furthermore, a particle visible in cross-section 1 might have been completely removed (ground through) by the time the second or third cross-sections were prepared. To simplify the analysis, only the third cross-sections, which had the highest number of driver particles with intact/visible kernels, were used to estimate the frequency of buffer fracture in these AGR-3/4 compacts. This process is consistent with the one used to collect buffer fracture statistics from AGR-1 and 
AGR-2 Compact ceramography and AGR-2 loose particle ceramography where only a single compact or particle cross-section was analyzed. In the future, the other two cross-sections from the AGR-3/4 compacts could be analyzed for driver fuel buffer fracture. In the present work, driver particles with visible fuel kernels were counted, and the number of particles with through-buffer fractures were determined. Table 5 summarizes the buffer fracture frequencies for the AGR-3/4 compacts.

AGR-3/4 TRISO particles had coatings similar to AGR-1 particles, and the AGR-3/4 SiC layer, in particular, was fabricated to AGR-1 baseline fuel specifications. The morphology of the buffer layer in irradiated AGR-1 TRISO particles was noted previously via cross-sectioning and ceramography of compacts (Ploger et al. 2012, Ploger et al. 2014). Figure 45 is a surface plot of the buffer fracture frequency as a function of the irradiation temperature and the fast neutron fluence for the AGR-1 compacts examined in the studies by Ploger et al. (The data used to make Figure 45 are tabulated in Appendix A.4 in Table A.1.) A "natural neighbor" interpolation scheme was used to fill in the surface between the Figure 45 data points. The buffer fracture frequency is highest at 0.35 at a TAVA temperature of $1106^{\circ} \mathrm{C}$ and a fast neutron fluence of $2.7 \mathrm{E} 25 \mathrm{n} / \mathrm{m}^{2}$ from AGR-1 Compact 6-3-3. The fracture frequency decreases for lower irradiation temperatures combined with both lower and higher fluences.

The buffer layer morphology in irradiated AGR-2 TRISO particles has been noted previously via cross-sectioning and ceramography of compacts at INL (Rice et al. 2016, Rice et al. 2018). In that study, the three AGR-2 UCO compacts had narrow burnup and fluence ranges from 11 to $11.5 \%$ FIMA and $2.88 \mathrm{E} 25$ to $3.08 \mathrm{E} 25 \mathrm{n} / \mathrm{m}^{2}$, respectively. The buffer fracture frequency was plotted versus TAVA temperature and appeared to decrease for temperatures above $1080^{\circ} \mathrm{C}$ (Rice et al. 2016, Rice et al. 2018). Ten additional data points on buffer fracture frequency in AGR-2 UCO fuel have been obtained via PIE at ORNL (Hunn et al. 2018a, Hunn et al. 2018b, Hunn et al. 2018c, Hunn 2019c). Combing the INL and ORNL data sets on AGR-2 UCO buffer fracture, the data were plotted as a surface in Figure 46. (The data used in Figure 46 are tabulated in Table A.2.) Here the buffer fracture frequencies are highest at TAVA temperatures of about $1100^{\circ} \mathrm{C}$ and fast fluences of about $3 \mathrm{E} 25 \mathrm{n} / \mathrm{m}^{2}$ (burnups of about $10 \%$ FIMA). In Figure 46, going to lower burnups and/or higher temperatures significantly reduces the buffer fracture frequencies. Lower buffer fracture frequencies are also observed at lower temperatures as long as the fluence is also significantly reduced. This is believed to be due to lower fast fluence resulting in less irradiation-induced dimensional change (shrinkage) of the buffer, and higher temperature promoting enhanced creep relaxation of stresses within the buffer, leading to less buffer fracture.

The AGR-3/4 buffer fracture frequency is plotted in Figure 47 versus TAVA irradiation temperature and fast neutron fluence. From the three available AGR-3/4 data points, the highest buffer fracture frequency is $23 \%$ at $1047^{\circ} \mathrm{C}$ and $5.18 \mathrm{E} 25 \mathrm{n} / \mathrm{m}^{2}$. At similar fluence $\left(5.29 \mathrm{E} 25 \mathrm{n} / \mathrm{m}^{2}\right)$ and significantly higher temperature $\left(1375^{\circ} \mathrm{C}\right)$, the buffer fracture frequency was reduced $14.3 \%$. Again, this is believed to be due to increased stress relaxation in the buffer at higher irradiation temperatures. At much lower temperature $\left(872^{\circ} \mathrm{C}\right)$ and fluence $\left(1.60 \mathrm{E} 25 \mathrm{n} / \mathrm{m}^{2}\right)$ the buffer fracture frequency is lower still. This is believed to be attributable to lower irradiation-induced buffer shrinkage at roughly $70 \%$ lower fluence.

The temperature and fluence dependencies of AGR-3/4 buffer fracture frequencies are similar to some of the AGR-2 behavior described earlier. However, the AGR-1 trend of lower observed buffer fracture frequencies at lower irradiation temperatures with higher fluences is the exact opposite of the AGR-2 and AGR-3/4 trends. It is not clear why this would be, but it is noteworthy that the AGR-1 data points cover a much narrower TAVA temperature range, from 988 to $1106^{\circ} \mathrm{C}$ compared to 894 to $1287^{\circ} \mathrm{C}$ for AGR-2 and 872 to $1375^{\circ} \mathrm{C}$ for AGR-3/4. The AGR-1 and AGR-3/4 kernel diameters were $350 \mu \mathrm{m}$, and the AGR-2 kernels were $425 \mu \mathrm{m}$. However, the difference in kernel size does not explain this because the differently-sized AGR-2 and AGR-3/4 buffers still had similar fracture frequency behavior for similar variations in temperature and/or irradiation temperature. 
Table 5. Summary of irradiation temperature, fluence, and buffer fracture frequency for AGR-3/4.

\begin{tabular}{|c|c|c|c|c|c|c|}
\hline Compact & $\begin{array}{c}\text { TAVA } \\
\text { Temp } \\
\left({ }^{\circ} \mathbf{C}\right)\end{array}$ & $\begin{array}{c}\text { Fast Fluence } \times \mathbf{1 0}^{\mathbf{2 5}} \\
\left(\mathbf{n} / \mathbf{m}^{\mathbf{2}} \mathbf{, ~ E}>\mathbf{0 . 1 8} \mathbf{~ M e V}\right)\end{array}$ & $\begin{array}{c}\text { Burnup } \\
\mathbf{( \%} \\
\text { FIMA) }\end{array}$ & $\begin{array}{c}\text { Particles with } \\
\text { suitable cross- } \\
\text { sections }\end{array}$ & $\begin{array}{c}\text { Particles with } \\
\text { through-buffer } \\
\text { fractures }\end{array}$ & $\begin{array}{c}\text { Buffer } \\
\text { fracture } \\
\text { frequency } \\
\mathbf{( \% )}\end{array}$ \\
\hline $5-2$ & 1047 & 5.18 & 14.86 & 53 & 12 & 22.6 \\
\hline $7-2$ & 1375 & 5.29 & 15.02 & 63 & 9 & 14.3 \\
\hline $12-2$ & 872 & 1.60 & 5.52 & 68 & 5 & 7.35 \\
\hline
\end{tabular}

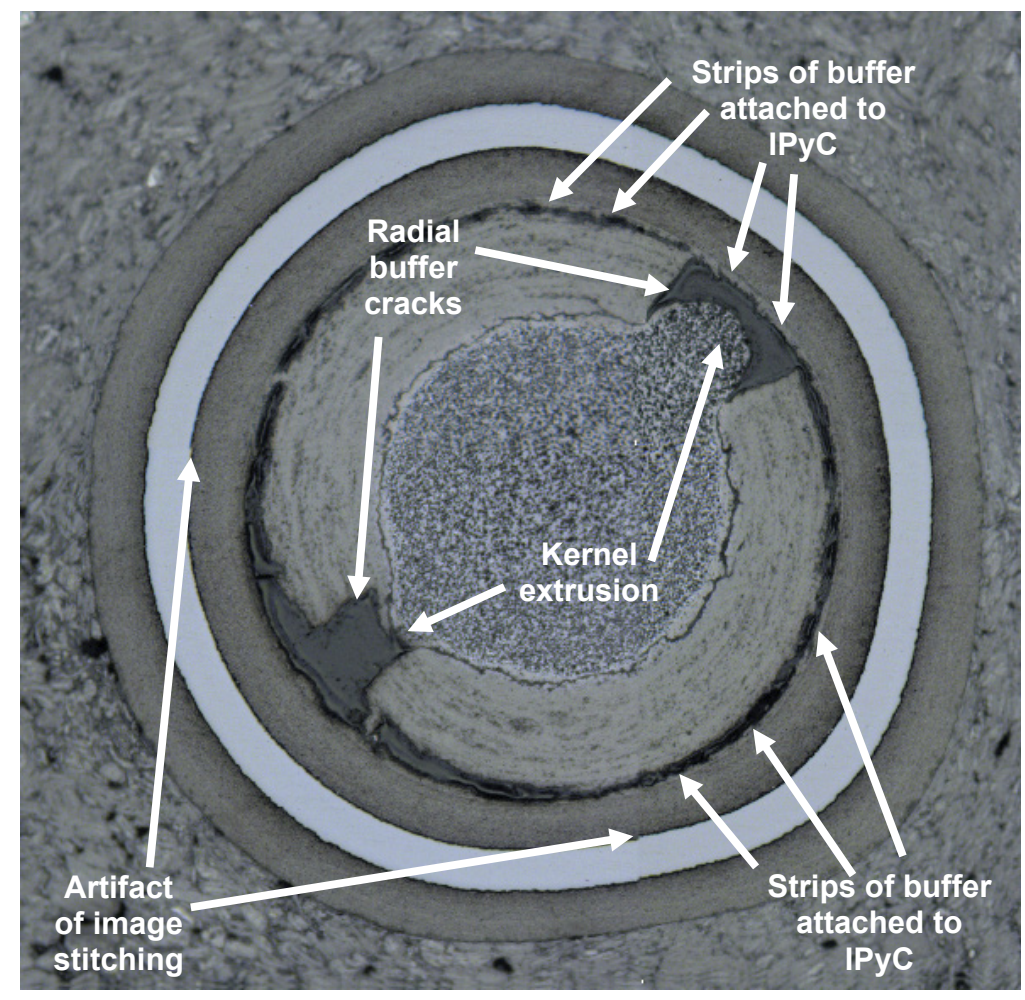

Figure 44. Montage of optical micrographs of a driver particle with fracture buffer layer and kernel extrusion. Particle from AGR-3/4 Compact 5-2. 


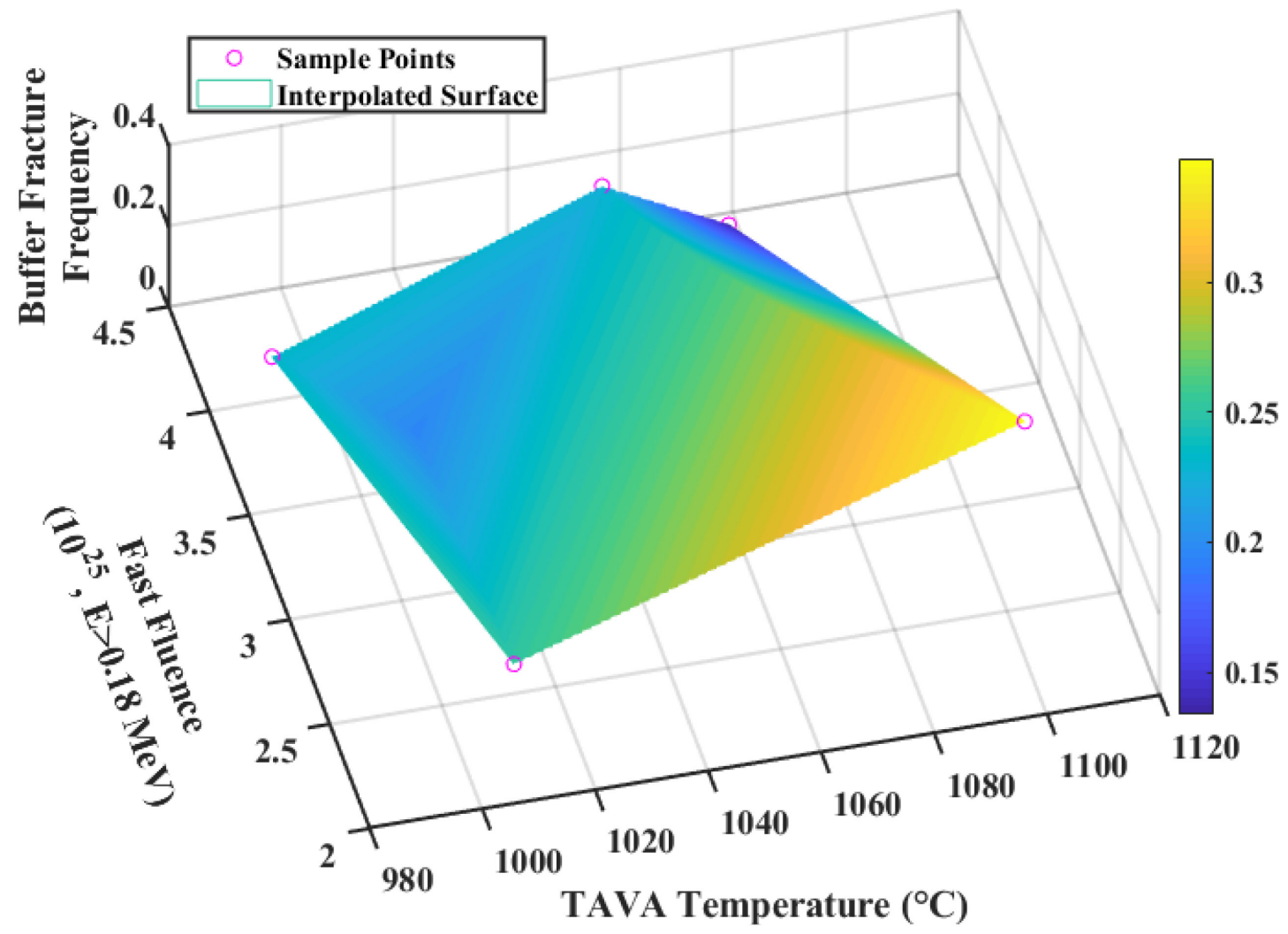

Figure 45. Buffer fracture frequency for AGR-1 TRISO particles.

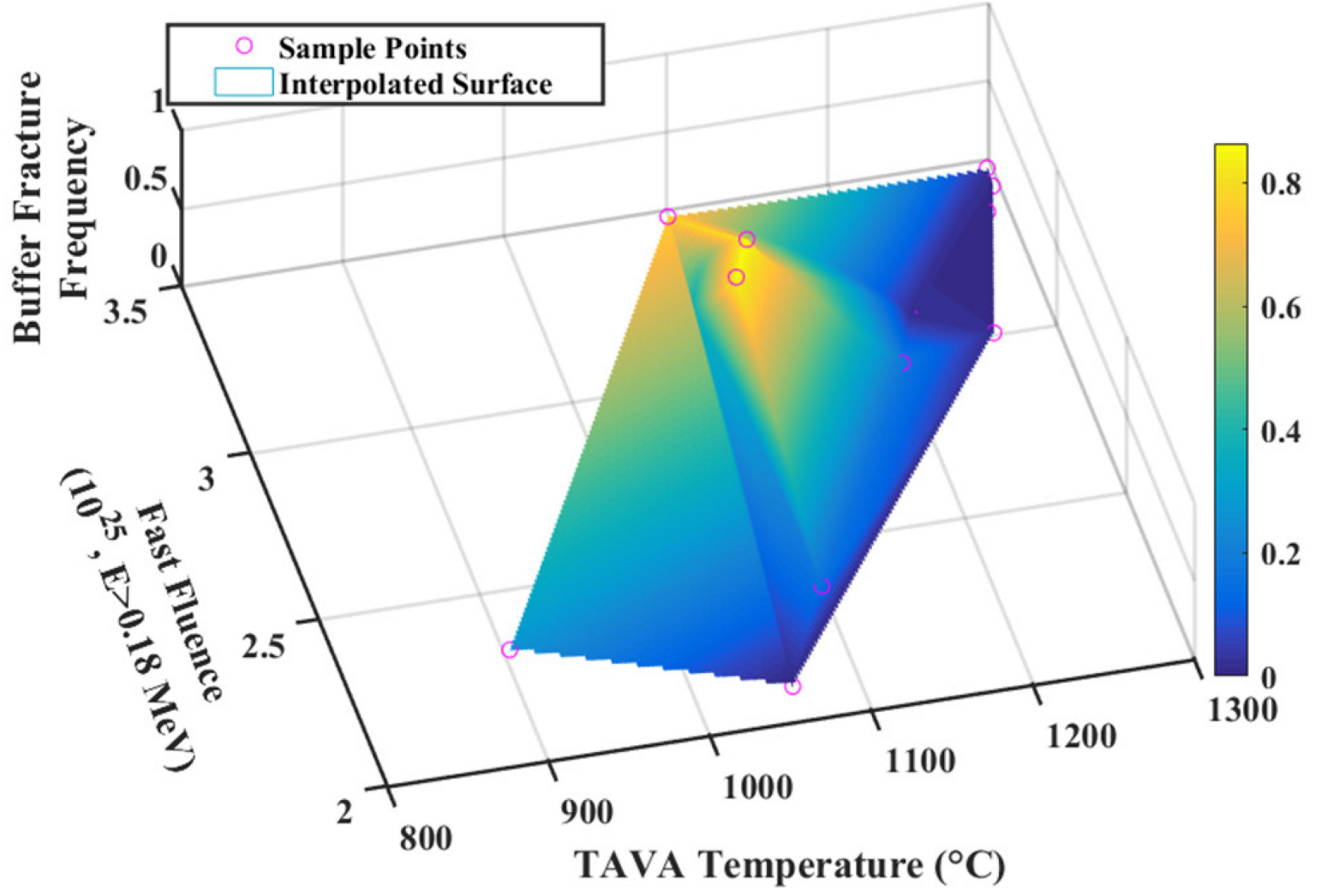

Figure 46. Buffer fracture frequency for AGR-2 (UCO fuel only). 


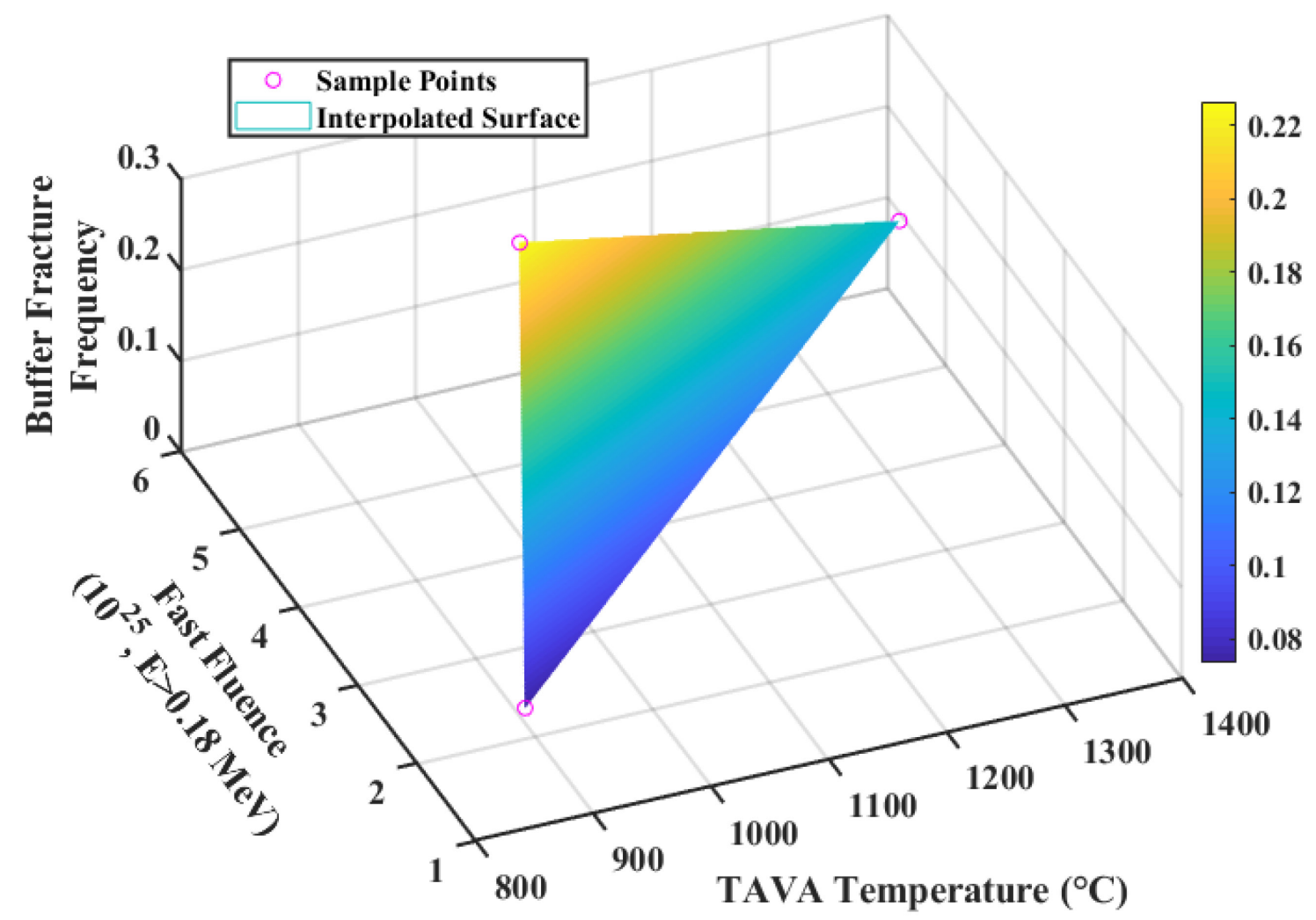

Figure 47. Buffer fracture frequency for AGR-3/4 TRISO particles.

\subsubsection{Kernels}

Three distinct driver particle kernel morphologies were observed among the three AGR-3/4 compacts, and these different morphologies are believed to be primarily due to the different irradiation temperatures. Compact 12-2 had a TAVA irradiation temperature of $872^{\circ} \mathrm{C}$, Compact 5-2 had a TAVA temperature of $1047^{\circ} \mathrm{C}$, and Compact $7-2$ had a TAVA temperature of $1375^{\circ} \mathrm{C}$. Figure 48 shows an optical micrograph from a typical driver particle from Compact 5-2. ${ }^{\mathrm{b}}$ This particle was also shown in Figure 19; however, it has been enlarged for Figure 48. Figure 49 shows a micrograph of a common driver particle from Compact 12-2. Figure 50 shows a driver particle from the second cross-section of Compact 7-2, and Figure 51 shows a montage of multiple micrographs of two driver particles from Compact 7-2. These two particles were also shown in region "B" of Figure 27.

The five Compact 5-2 driver particle kernels in Figure 19 and the particle shown in Figure 48 have small, round/spherical pores that are relatively evenly distributed. The carbide and oxide phases of the kernel are no longer distinguishable from one another as they were in the as-fabricated kernels (see Figure 9). These morphologies are very similar to those observed for TRISO particles from AGR-1 (Ploger et al. 2012, Ploger et al. 2014) and AGR-2 (Rice et al. 2016, Rice et al. 2018, Stempien et al. 2019). The AGR-1 compacts from the work of Ploger et al. had similar TAVA irradiation temperatures (988 to 1106 $\left.{ }^{\circ} \mathrm{C}\right)$ compared to AGR-3/4 Compact 5-2 $\left(1047^{\circ} \mathrm{C}\right)$, and the AGR-1 Compact burnups were approximately +/- 4\% FIMA of AGR-3/4 Compact 5-2 (14.9\% FIMA). Similar to AGR-1 particles, AGR-3/4 Compact 5-2 TRISO particles have some larger pores toward the center of the kernel. Both AGR-3/4 Compact 5-2 and AGR-1 particles with buffer fracture and kernel protrusion into the buffer cracks had even larger pores (see the two fractured-buffer particles in Figure 19).

\footnotetext{
${ }^{\mathrm{b}}$ Another observation from Figure 48 is the sizeable OPyC/matrix gap at the 12 o'clock position. OPyC/matrix gaps are also visible on the adjacent particles in the lower left of the micrograph. These are discussed further in Section 4.3.3.
} 
AGR-3/4 Compact 12-2 is unique among AGR samples because it is the lowest irradiation temperature $\left(872^{\circ} \mathrm{C}\right)$, lowest-burnup compact $(5.5 \%$ FIMA) to undergo ceramography. Fittingly, its kernels have morphologies not observed previously in irradiated AGR particles. Figure 49 shows a cropped and enlarged version of the micrograph first shown in Figure 38 that highlights major features of the kernel. (Other Compact 12-2 driver particles were shown earlier in Figure 39 through Figure 41.) Figure 9 showed micrographs of unirradiated DTF particles, and the TRISO-coated kernels in Compact 12-2 bear resemblance to those unirradiated kernels. In Compact 12-2, features present at fabrication are still visible after irradiation, including the separate uranium oxide and carbide phases in the kernel, the oxide rind, and the carbide skin. It is noteworthy that the distinct uranium oxide and carbide phases remaining in the TRISO-coated driver particle kernels are absent from the Compact 12-2 DTF particles (see Figure 30 through Figure 37). The reason why is unclear; however, one hypothesis is that the chemical equilibrium in the DTF particles would be different because a failed DTF particle (i.e., one that has a breached pyrocarbon coating) is no longer a sealed system. The greater number of pores in the DTF particles could also have promoted mixing or breaking up of the larger $\mathrm{UC}_{2}$ phases. Electron microscopy analysis of the Compact 12-2 cross-section might be useful for elucidating the kernel chemistries in these particles.

AGR-3/4 Compact 7-2 is also unique among AGR samples because it is the hottest compact to undergo ceramography (TAVA $1375^{\circ} \mathrm{C}$, TA Peak $1417^{\circ} \mathrm{C}$ ). Figure 50 shows a single driver particle with examples of major features highlighted. Figure 51 shows another two driver particles from this compact. These two particles were first shown in Figure 27 where they were labeled "B". Driver particle kernels in this compact have smaller pores located toward the outside of the kernel and large pores located toward the center of the kernels, similar to the large pores in the center of the hottest AGR-1 (Ploger et al. 2012, Ploger et al. 2014) and AGR-2 (Rice et al. 2016, Rice et al. 2018) fuel compacts. However, the large AGR-3/4 Compact 7-2 pores are less circular in the cross-sections than the large AGR-1 or AGR-2 pores.

Figure 27, Figure 50, and Figure 51 show that many of the driver particles in Compact 7-2 have an apparent gradient in the kernel such that the cool side of the kernel (away from the center of the compact) has a much darker appearance (like that of the buffer and pyrocarbon). There is some gray material that resembles the $\mathrm{UO}_{2}$ phase interspersed with the dark material and pores on this cool side. On the hotter side of the particle, there is gray material that resembles the $\mathrm{UO}_{2}$ phase, large pores, and some sizable, irregularly-shaped white/reflective spots.

It is hypothesized that the irradiation temperature of Compact 7-2 was high enough to activate a process that led to a sharp gradient in kernel morphology. This presently unidentified thermochemical process requires primarily a high irradiation temperature and secondarily a spatial temperature gradient. Prior to ceramography of AGR-3/4 Compact 7-2, AGR-2 Compacts 2-1-3 (TAVA $1194^{\circ} \mathrm{C}$, TA Peak $1305^{\circ} \mathrm{C}$ ), and $2-4-3$ (TAVA $1216^{\circ} \mathrm{C}$, TA Peak $1342^{\circ} \mathrm{C}$ ) were the hottest compacts to undergo ceramography, and no spatial gradient in the kernel morphology was observed in these (Rice et al. 2016, Rice et al. 2018). Based on the absence of kernel morphology gradients in AGR-2 Compact 2-4-3 and the presence of these gradients in AGR-3/4 Compact 7-2, the TAVA activation temperature for this phenomenon lies somewhere between $1216^{\circ} \mathrm{C}$ and $1375^{\circ} \mathrm{C}$.

A temperature gradient within the fuel is also required; however, a large temperature gradient is not required. The largest temperature variation in Compact $7-2$ was $109^{\circ} \mathrm{C}$ from the hottest part of the compact to the coldest part of the compact at the beginning of the AGR-3/4 irradiation (20 days into ATR cycle $151 \mathrm{~A}){ }^{\mathrm{c}}$ This equates to an average gradient of $8.3^{\circ} \mathrm{C} / \mathrm{mm}$ between the hottest and coldest points, which were about $13.2 \mathrm{~mm}$ apart. Local temperature gradients may be hotter. Two adjacent finite elements used in calculating temperatures at the top of Compact 7-2 had centers separated in the radial direction by $0.68 \mathrm{~mm}$. The largest gradient between these two elements was $28.1^{\circ} \mathrm{C} / \mathrm{mm}$ and occurred 20

\footnotetext{
${ }^{\mathrm{c}}$ The variation from highest to lowest temperature was reduced to $85^{\circ} \mathrm{C}$ and $72^{\circ} \mathrm{C}$ at 52 days into cycles $154 \mathrm{~A}$ and $155 \mathrm{~B}$, respectively.
} 
days into ATR cycle 151A. In AGR-2 Compact 2-1-3, the difference between the hottest and the coldest point was about $207^{\circ} \mathrm{C}$ (at the beginning of irradiation in ATR). This difference was $348^{\circ} \mathrm{C}$ (roughly halfway through irradiation in ATR) and equated to a spatial temperature gradient of $13.5^{\circ} \mathrm{C} / \mathrm{mm}$. The largest radial temperature gradient between adjacent finite elements in AGR-2 Compact 2-1-3 was $37.2^{\circ} \mathrm{C} / \mathrm{mm}$. AGR-2 Compact 2-4-3 had roughly the same temperature variations as 2-1-3. Therefore, AGR-2 compacts had larger spatial temperature variations than AGR-3/4 Compact 7-2, but the AGR-2 irradiation temperatures were not high enough to activate the mechanism that altered the kernel morphology in AGR-3/4 Compact 7-2.

The compositions of the hot and cold regions of the Compact 7-2 kernels are not known. However, similar, but smaller, white/reflective spots have also been observed in AGR-1 kernels where those spots are believed to be metallic fission product clusters (Demkowicz et al. 2016a, Demkowicz et al. 2016b, Hunn et al. 2013). Similar small spots were observed in AGR-3/4 Compact 5-2 kernels (although they are very difficult to see in the micrographs). High irradiation temperature may promote the formation of larger metallic fission product inclusions. These spots have a distinctly different size (smaller), shape (more circular), and distribution (more uniform throughout the kernel) than the uranium carbide phases observed in the as-fabricated particles and the fading remnants of the uranium carbide phases in AGR-3/4 Compact 12-2 particles. Electron microscopic techniques could be employed to identify the chemical compositions of the different structures in these kernels.

Kernel morphology similar to that in AGR-3/4 Compact 7-2 has been found in particles that were subjected to 300 -hour, $1800^{\circ} \mathrm{C}$ post-irradiation heating tests (Hunn et al. 2019a, Hunn et al. 2019b). For comparison to AGR-3/4 Compact 7-2, Figure 52 shows two different AGR-2 particles from two different $1800^{\circ} \mathrm{C}$-safety tests. The kernels in these particles show similar pore structures, relatively large white spots in the kernel (believed to be metallic fission product inclusions), and (especially in the particle at left) the formation of dark material on the kernel periphery. The safety-tested kernel morphologies in Figure 52 are distinctly different than in non-safety-tested AGR-2 Capsule 2 and Capsule 6 kernels, indicating that there is a temperature/time threshold above which this kernel morphology begins to occur. One difference between the safety-tested AGR-2 particles and the AGR-3/4 Compact 7-2 particles is that there is a clear spatial gradient in kernel color and porosity across the AGR-3/4 Compact 7-2 kernels related to both the high irradiation temperature and the temperature gradient within the particle during irradiation. The safety-tested AGR-2 particles do not have this same spatial gradient; however, they do have a ring of dark material evenly distributed around the kernel periphery. It is possible that this dark ring was caused by a thermochemical process similar to the one that caused the gradient in AGR-3/4 Compact 7-2 kernels. Because the AGR-2 particles would have had uniform temperatures during the postirradiation $1800^{\circ} \mathrm{C}$ heating tests, the dark ring is uniform at the kernel periphery. 


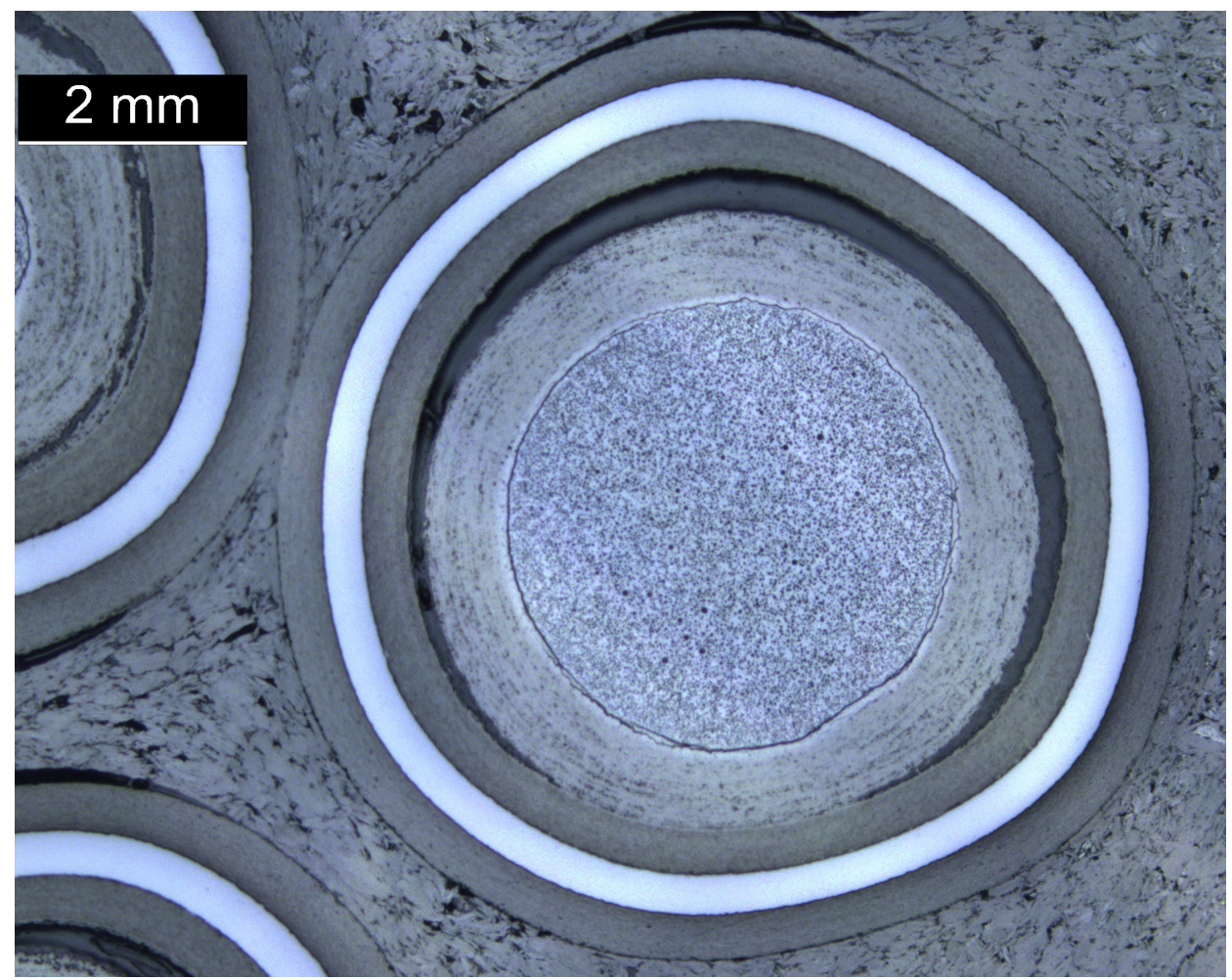

Figure 48. Driver particle from Compact 5-2 (TAVA $1047^{\circ} \mathrm{C}$ ), cross-section 3. Image also shown in Figure 19. 


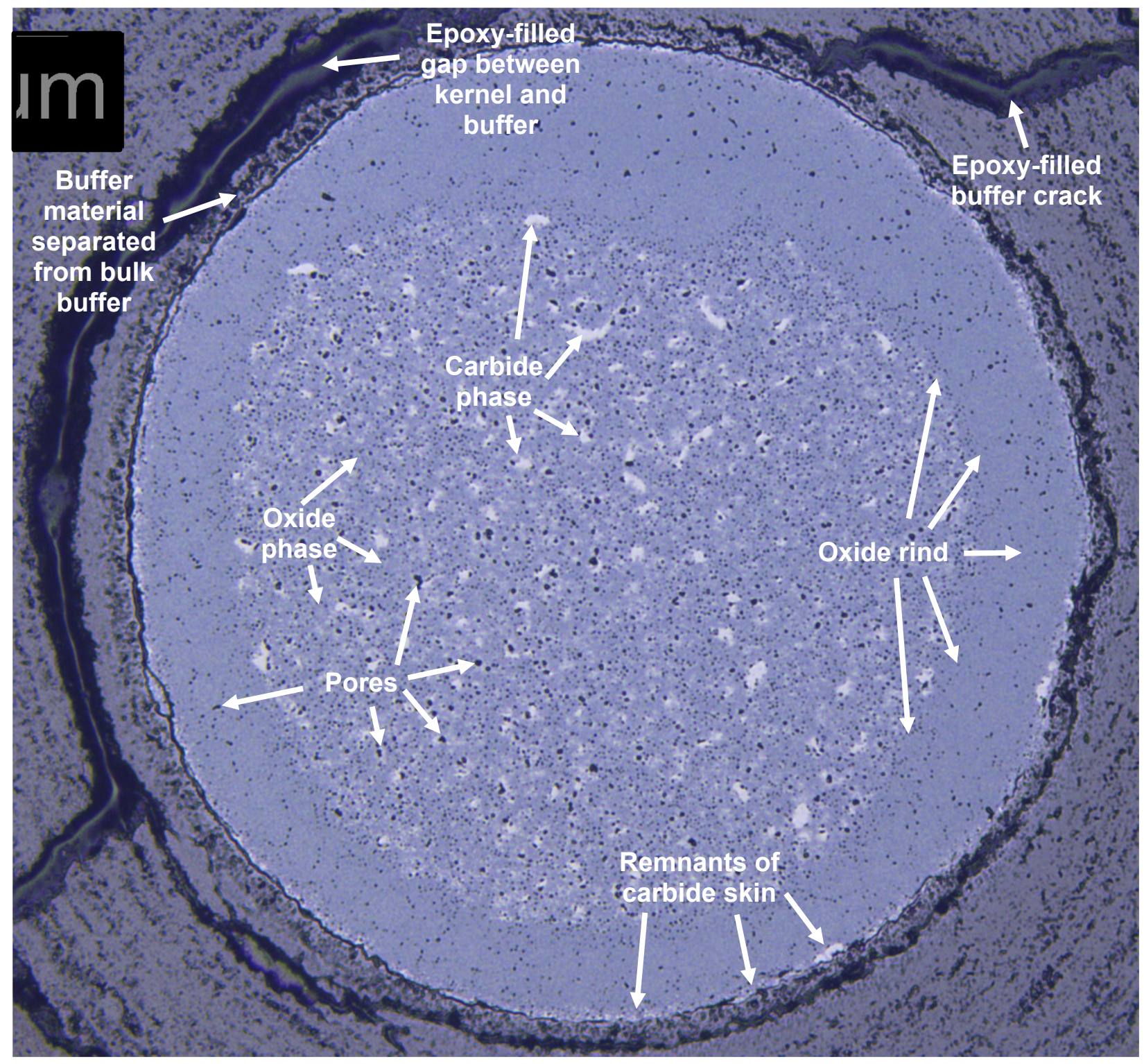

Figure 49. Driver particle from Compact $12-2$ (TAVA $872^{\circ} \mathrm{C}$ ), cross-section 1. Image enlarged from Figure 38. 


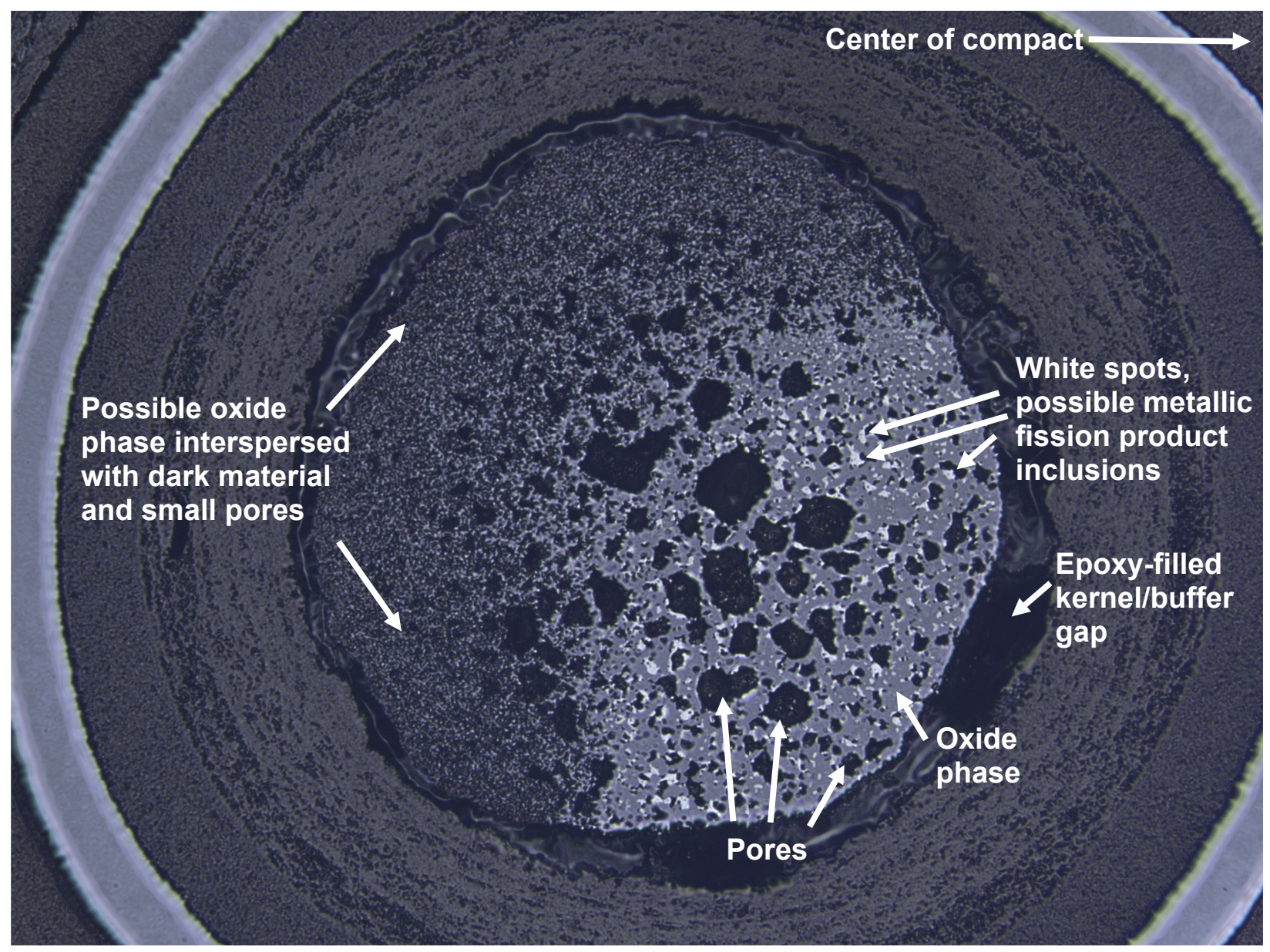

Figure 50. Optical micrograph of driver particle from the second cross-section of Compact 7-2. Particle was highlighted by the second-from-left-most red dot in the center micrograph in Figure 20. 


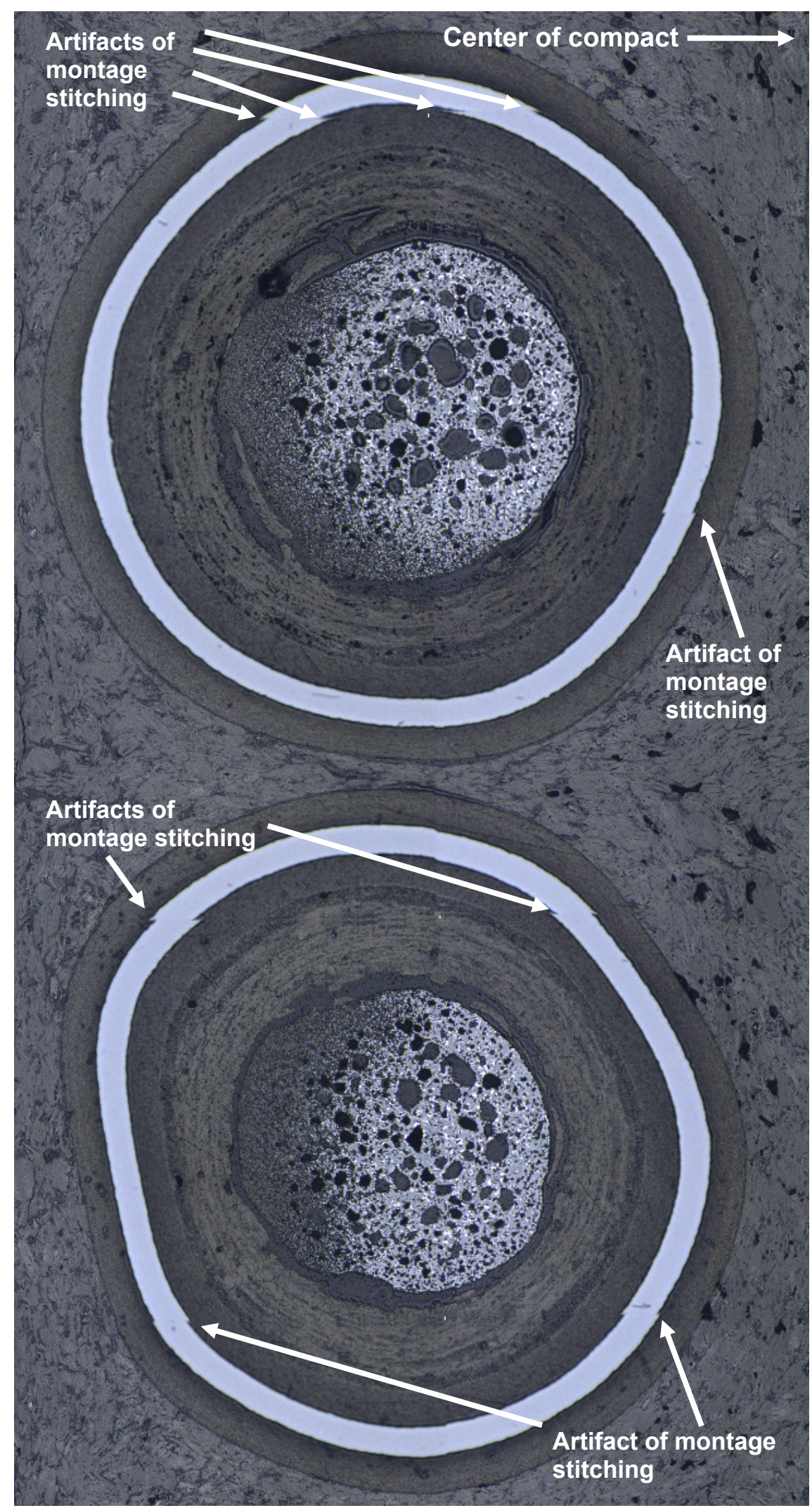

Figure 51. Montage of optical micrographs of driver particles from Compact 7-3, cross-section 3. These particles were highlighted in Region B in Figure 27. 


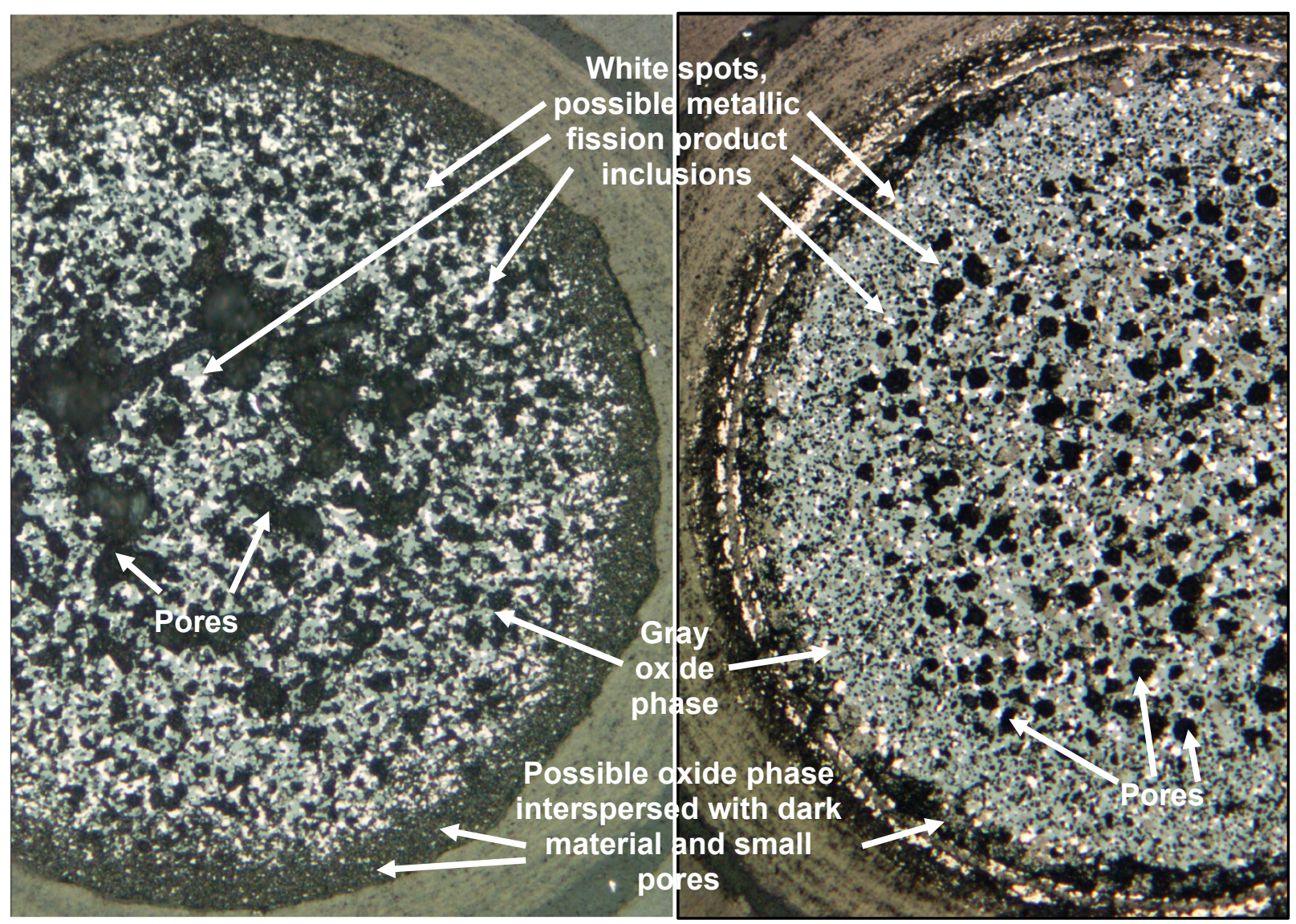

Figure 52. Particle 212-RS08 from $1800^{\circ} \mathrm{C}$-safety tested AGR-2 UCO Compact 2-1-2 (left) (Hunn et al. 2019b). Particle 642-RS27 from $1800^{\circ} \mathrm{C}$-safety tested AGR-2 UCO Compact 6-4-3 (right) (Hunn et al. 2019a).

\subsubsection{Compact Matrix}

Occasional gaps between the compact matrix and the driver particle OPyC were observed in the cross-sections of all the compacts (see Figure 53 through Figure 56). Only some of the particles in a cross-section contained these gaps. The most common places to observe matrix/OPyC gaps were in the narrow spaces between particles (see Figure 53 and Figure 55). It is possible some matrix material was lost via grinding before backpotting epoxy could stabilize the matrix at the matrix/OPyC interface; however, given the smoothness of most of the matrix/OPyC gaps, it is likely that the gaps are primarily due to the irradiation-induced movement of the graphitic matrix material away from the OPyC surface. There appeared to be fewer matrix/OPyC gaps in the Compact 7-2 cross-sections, and when gaps were present in Compact 7-2, they were narrower than in the other compacts. This may be a consequence of the higher irradiation temperature in Compact 7-2. The apparent thickness of the gaps is generally greater the farther from the particle midplane the cross-section is. Figure 56 shows a micrograph of a particle from the first polished cross-section of Compact 12-2. Here the particle OPyC has barely been exposed, the matrix/OPyC gap is fairly wide compared to those in Figure 54 and Figure 55, and the gap extends around more than half of the exposed particle circumference. 


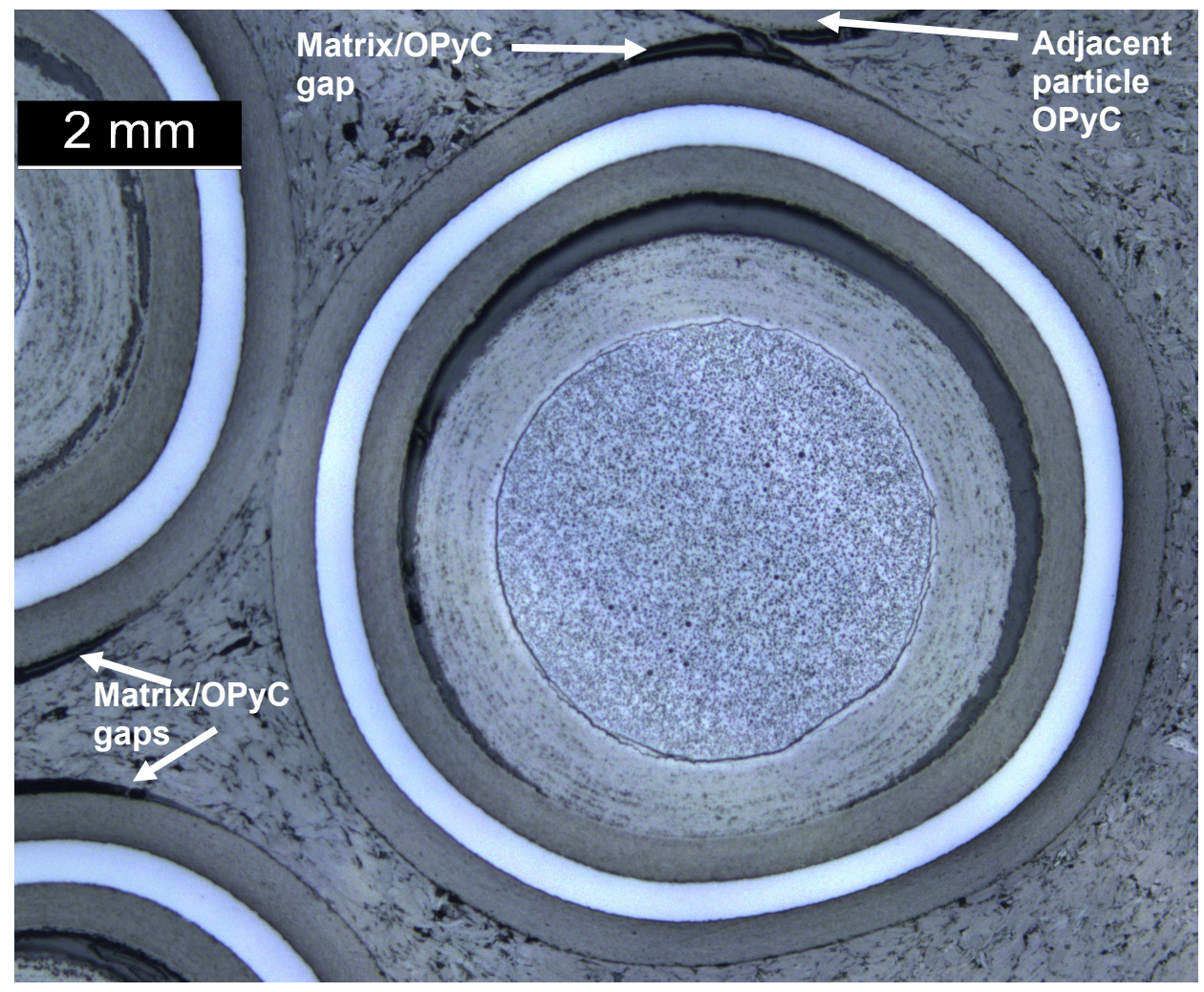

Figure 53. Driver particle from Compact 5-2 (TAVA $1047^{\circ} \mathrm{C}$ ), cross-section 3. Image also shown in Figure 19 and Figure 48.

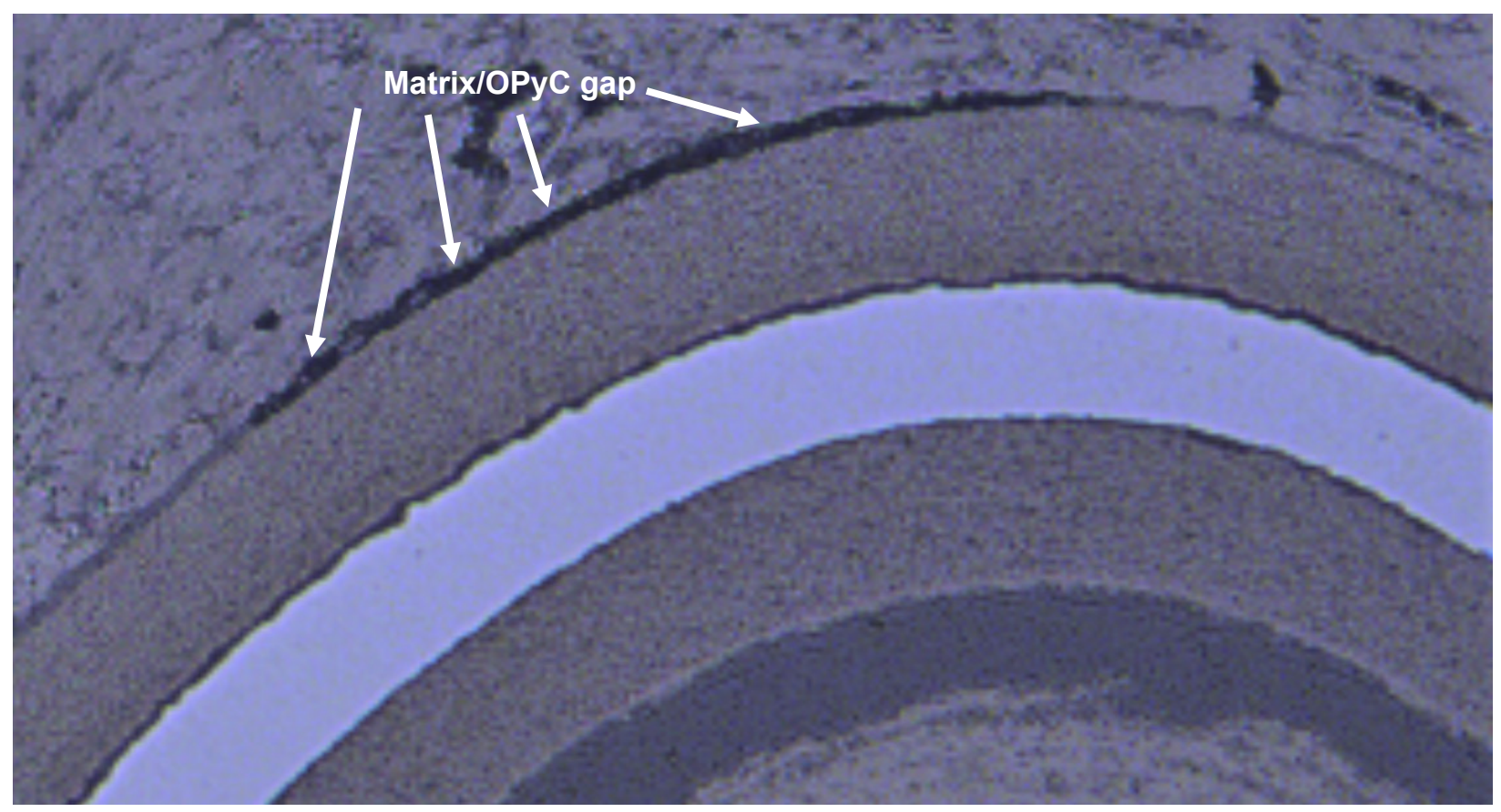

Figure 54. Image from the first cross-section from Compact 7-2 (MNT80A). 


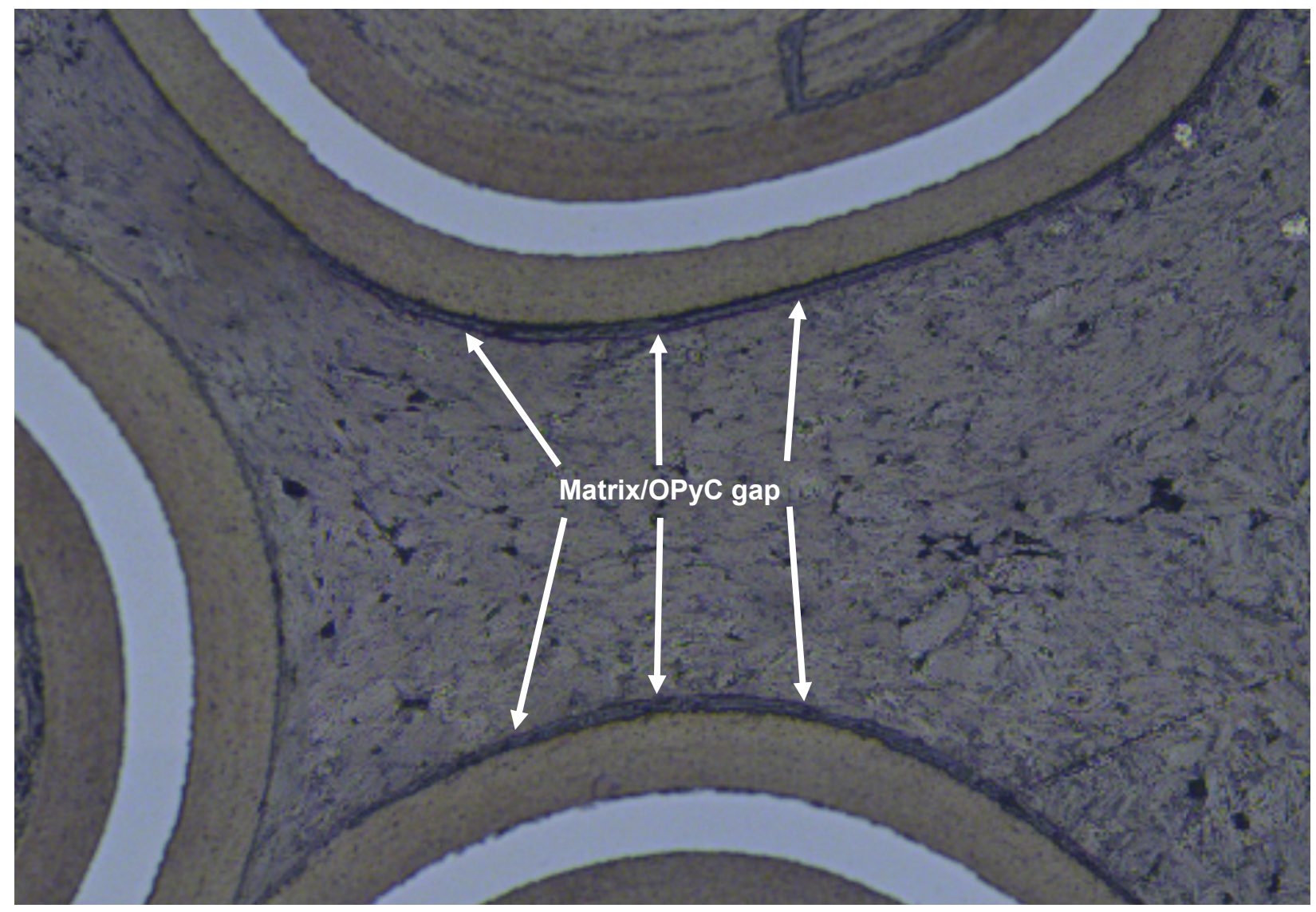

Figure 55. Montage of two images of the cross-section from the third polish of Compact 12-2 (MNT81A).

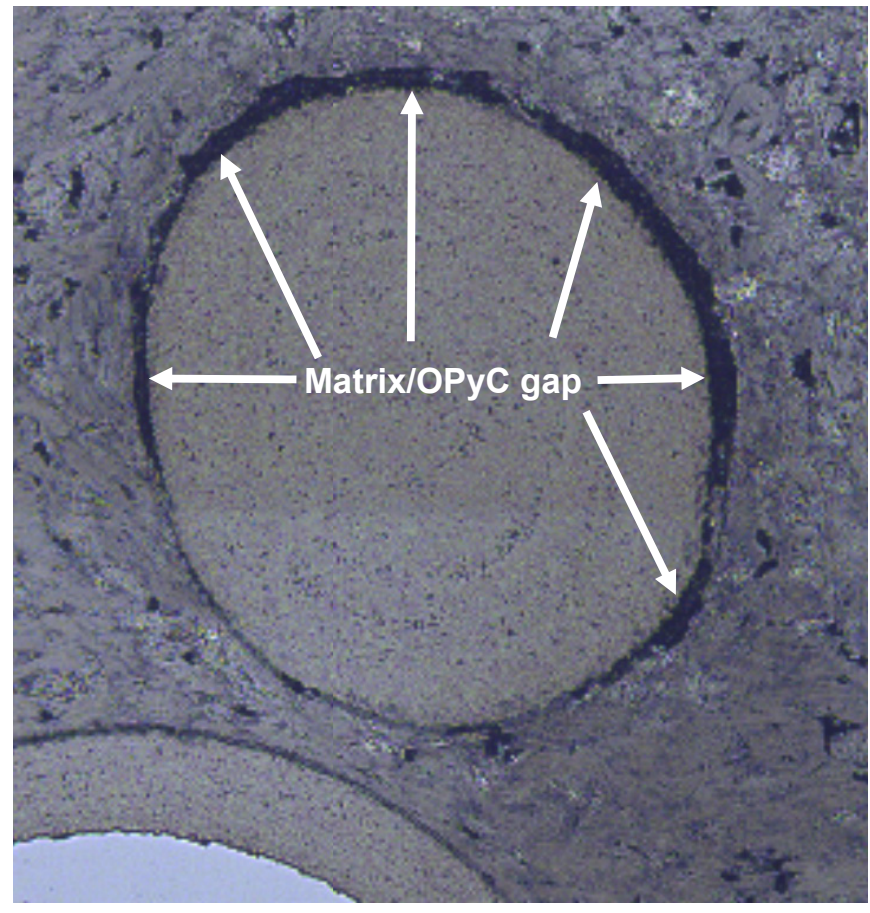

Figure 56. Montage of two images from the first cross-section of Compact 12-2 (MNT81A). OPyC barely exposed on particle. 


\section{CONCLUSIONS}

The following conclusions are made:

- The three AGR-3/4 compacts examined covered a relatively wide temperature range and featured both the hottest (Compact $7-2$ at $1375^{\circ} \mathrm{C}$ TAVA) and coldest/lowest-burnup compacts (Compact 12-2 at $872^{\circ} \mathrm{C}$ TAVA and $5.5 \%$ FIMA) to undergo PIE in the AGR program as of this writing.

- Not all of the DTF particles were observed, but of those observed, all had failed pyrocarbon coatings. It is highly likely that all DTF particles in these compacts were failed with breached pyrocarbon layers.

- Distinctly different DTF kernel and PyC morphologies believed to be related to the differences in irradiation temperature and/or burnup were observed.

- The morphology of the failed DTF pyrocarbon coatings varied with irradiation temperature. At the moderate temperature of Compact $5-2\left(1047^{\circ} \mathrm{C}\right.$ TAVA $)$ and the low-temperature of Compact $12-2\left(872^{\circ} \mathrm{C}\right)$, it appears that the DTF PyC fractured and folded in on itself due to irradiationinduced dimensional changes of the highly anisotropic PyC, and the kernel deformed to accommodate this PyC deformation.

- The extent of DTF kernel deformation to accommodate DTF PyC irradiation-induced buckling tended to be greater for the hotter irradiation temperature Compact 5-2 than for the cooler Compact 12-2.

- No remnants of the DTF PyC layer remained in the Compact $7-2\left(1375^{\circ} \mathrm{C}\right.$ TAVA $)$ cross-sections. The DTF PyC layer appears to have chemically reacted with the kernel material. The only material surrounding the Compact 7-2 DTF particles resembles the compact matrix material.

- With a low irradiation temperature and a low-burnup, Compact 12-2 DTF kernels retained sphericity more than Compact 5-2 DTF kernels. In both compacts, the kernels appear to have accommodated the pyrocarbon shards by deforming around the shards. Unlike the evenly distributed pores of Compact 5-2, the Compact 12-2 DTF kernel pores are located primarily in the region of the kernel that contained the UCO mixture prior to irradiation. The Compact 12-2 DTF kernels appear to still have the oxide rind around the periphery of the kernel with long, radial pores, and there are places where there is either increased porosity or remnants of the carbide skin around the outer perimeter of the oxide rind.

- Similar to AGR-1 and AGR-2 TRISO-coated particles, Compact 5-2 DTF kernels have small, round/spherical pores that are relatively evenly distributed. The carbide and oxide phases of the kernel are no longer distinguishable from one another as they were in the as-fabricated kernels. The moderate irradiation temperature enabled the kernel to deform to accommodate PyC shards to a greater extent than in the cooler Compact 12-2.

- In the Compact 7-2 DTF kernels, the $\mathrm{UC}_{2}$ and $\mathrm{UO}_{2}$ phases cannot be distinguished, and the porosity appears to be similar to the type of porosity observed in Compact 5-2 (i.e., spherical, evenly distributed, etc.)

- Some distinctly different TRISO-coated driver particle kernel morphologies were observed that are attributed to the differences in irradiation temperature and/or burnup.

- The TRISO particles in Compact 5-2 showed morphologies consistent with what has been observed previously in AGR-1 and AGR-2 PIE.

- The Compact 12-2 TRISO particles showed unique kernel morphologies with some features similar to what was observed in the Compact 12-2 DTF particles and in unirradiated particles. Due to the low irradiation temperature and burnup, these TRISO particles had clearly 
distinguishable oxide and carbide phases at the center of the kernel, an oxide rind surrounding this, and remnants of a carbide skin surrounding the oxide rind. The porosity in the TRISO kernels appeared to be less than in the DTF kernels, and the long radial pores in the oxide rind of the DTF particles was not evident in the TRISO particles.

- Many Compact 7-2 TRISO particles had kernels with sharp spatial gradients in morphology. This is the first such observation of a gradient in kernel morphology in the AGR program. The cool side of the kernel (away from the center of the compact) had a much darker appearance (like that of the buffer and pyrocarbon). There was some gray material resembling the $\mathrm{UO}_{2}$ phase interspersed with the dark material and small pores on this cool side. On the hotter side of the particle (the side facing the center of the compact), there is gray material that resembles the $\mathrm{UO}_{2}$ phase, large pores, and some sizable, irregularly-shaped white spots which are likely metallic fission product inclusions.

- Compact $7-2$ (TAVA $1375^{\circ} \mathrm{C}$, TA Peak $1417^{\circ} \mathrm{C}$ ) had the highest irradiation temperature of any AGR compact to undergo PIE as of this writing. The spatial gradient in the kernel morphology is believed to be caused by an unidentified thermochemical process requiring primarily a high average irradiation temperature and, secondarily, a spatial temperature gradient across the fuel particles.

- Comparing the AGR-3/4 Compact 7-2 kernels to as-irradiated and post-irradiation safety-tested kernels from the AGR-2 experiment indicates that there is a temperature/time threshold above which the morphologies seen on the cool side and hot side of Compact 7-2 kernels begins to occur. The hottest AGR-2 Compact examined had a TAVA irradiation temperature of $1216^{\circ} \mathrm{C}$ and no spatial gradients in kernel morphology were observed.

- For AGR-2 compacts with irradiation temperatures less than those of AGR-3/4 Capsule 7, some of the AGR-3/4 Compact 7-2 kernel morphologies can be generated in safety-tested particles $\left(\mathrm{T} \geq 1800^{\circ} \mathrm{C}\right)$ with azimuthal uniformity.

- In all three AGR-3/4 compacts examined, the TRISO coatings were consistent with observations of irradiated AGR-1 and AGR-2 particles.

- Occasional gaps between the OPyC and graphitic matrix material were observed in all compacts. Gaps were most often found in the small, matrix-filled spaces between adjacent particles. There is no evidence that the matrix/OPyC gaps degraded the OPyC in any way.

- Buffer morphologies in AGR-3/4 TRISO particles were similar to those observed in AGR-1 and AGR-2.

- The buffer fracture frequencies in AGR-2 and AGR-3/4 were plotted versus irradiation temperature and fluence. It was found that going to lower fluences and/or higher temperatures significantly reduced the buffer fracture frequency. Lower buffer fracture frequency was also observed at lower temperatures as long as the fluence was also significantly reduced. This is believed to be due to lower fluence, resulting in less irradiation-induced dimensional change (shrinkage) of the buffer, and higher temperature promoting enhanced creep relaxation of stresses within the buffer, leading to less buffer fracture. 


\section{REFERENCES}

Collin, B. P., 2015a, AGR-1 Irradiation Test Final As-Run Report, Idaho National Laboratory, INL/EXT10-18097, Rev. 3, January 2015.

Collin, B.P., 2015b, AGR-3/4 Irradiation Test Final As-Run Report, Idaho National Laboratory, INL/EXT-15-35550, Rev. 0, June 2015.

Collin, B.P., 2015c, AGR-3/4 Irradiation Experiment Test Plan, Idaho National Laboratory, PLN-3867, Rev. 1, May 2015.

Collin, B. P., 2018a, AGR-2 Irradiation Test Final As-Run Report, Idaho National Laboratory, INL/EXT14-32277, Rev. 4, February 2018.

Collin, B.P., 2018b, AGR-5/6/7 Irradiation Experiment Test Plan, Idaho National Laboratory, PLN-5245, Rev. 1, January 2018.

Collin, B.P., Demkowicz, P.A., Petti, D.A., Hawkes, G.L., Palmer, J., Pham, B.T., Scates, D.M., Sterbentz, J.W., 2018, "The AGR-3/4 fission product transport irradiation experiment," Nuclear Engineering and Design, Vol. 327, pp. 212-227.

Demkowicz, P.A., Hunn, J.D., Morris, R.N., van Rooyen, I., Gerczak, T., Harp, J.M., and Ploger, S.A., 2015, AGR-1 Post Irradiation Examination Final Report, Idaho National Laboratory, INL/EXT-1536407, Rev. 0, August 2015.

Demkowicz, P.A., Ploger, S.A., Winston, P.L., and Harp, J.M., 2016a, AGR-1 Compact 3-2-1 PostIrradiation Examination Results, Idaho National Laboratory, INL/EXT-15-36352, Rev. 0, November 2016.

Demkowicz, P.A., Ploger, S.A., Winston, P.L., and Harp, J.M., 2016b, AGR-1 Compact 1-3-1 PostIrradiation Examination Results, Idaho National Laboratory, INL/EXT-15-36365, Rev. 0, December 2016.

Demkowicz, P. A., 2017, AGR-3/4 Phase 2 Post-Irradiation Examination Plan, Idaho National Laboratory, PLN-5382, May 2017.

Derz, H., and Flossdorf, T., 1994, HFR-B1 Capsule 1, Ceramographic Examination of Coated-Particles in Fuel Rods, Progress Report No. 5, Subcontract No. 87X-SM415V, KFA-IWE-1/HZ-TN-37/94, Forschungszentrum Juelich (KFA), October 1994.

Hanson, D.L., 2006, HFR-B1 Final Summary Report, General Atomics, PC-000529, Rev. 0, Advanced Gas Reactor Fuel Development and Qualification Program, Project 30192, April 2006.

Hawkes, G., 2014a, AGR-1 Daily As-Run Thermal Analyses, Idaho National Laboratory, ECAR-9638, Rev. 4, September 2014.

Hawkes, G., 2014b, AGR-2 Daily As-Run Thermal Analyses, Idaho National Laboratory, ECAR-2476, Rev. 1, August 2014.

Hawkes, G., 2016, AGR-3/4 Daily As-Run Thermal Analyses, Idaho National Laboratory, ECAR-2807, Rev. 1, April 2016.

Hunn, J.D., Lowden, R.A., 2007, Data Compilation for AGR-3/4 Driver Fuel Coated Particle Composite LEU03-09T, Oak Ridge National Laboratory, ORNL/TM-2007/019, March 2007.

Hunn, J.D., Miller, J.H., 2009, Data Compilation for AGR-3/4 Designed-to-Fail (DTF) Fuel Particle Batch LEU04-02DTF, Oak Ridge National Laboratory, ORNL/TM-2008/193, October 2009.

Hunn, J., Trammell, M. P., Montgomery, F.C., 2011, Data Compilation for AGR-3/4 Designed-to-Fail (DTF) Fuel Compact Lot (LEU03-10TOP2/LEU03-07DTF-OP1)-Z, Oak Ridge National Laboratory, ORNL/TM-2011/124, 2011.

Hunn, J.D., Morris, R.N., Baldwin, C.A., Montgomery, F.C., Silva, G.W.C, Gerczak, T.J., 2013, AGR-1 Irradiated Compact 4-4-2 PIE Report: Evaluation of As-irradiated Fuel Performance with Leach Burn Leach, IMGA, Materialography, and X-ray Tomography, Oak Ridge National Laboratory, ORNL/TM-2013/236, September, 2013.

Hunn, J.D., Lowden, R.A., Miller, J.H., Jolly, B.C., Trammell, M.P., Kercher, A.K., Montgomery, F.C., and Silva, C.M., 2014, "Fabrication and Characterization of Driver Fuel Particles, Designed-to-Fail 
Fuel Particles, and Fuel Compacts for the US AGR-3/4 Irradiation Test," Nuclear Engineering and Design, Vol. 271, pp. 123-130.

Hunn, J.D., Baldwin, C.A., Gerczak, T.J., Montgomery, F.C., et al., 2016, "Detection and analysis of particles with failed SiC in AGR-1 fuel compacts," Nuclear Engineering and Design, Vol. 306, pp. $36-46$.

Hunn, J.D., Gerczak, T.J., Montgomery, F.C., Skitt, D.J., Baldwin, C.A., Helmreich, G.W., Eckhart, B.D., and Dyer, J.A., 2018a, AGR-2 As-Irradiated UCO Compact 5-4-2 PIE Report, Oak Ridge National Laboratory, ORNL/TM-2018/863, May 2018.

Hunn, J.D., Gerczak, T.J., Montgomery, F.C., Skitt, D.J., Baldwin, C.A., Helmreich, G.W., Eckhart, B.D., and Dyer, J.A., 2018b, AGR-2 Safety-Tested UCO Compact 6-4-2 PIE Report, Oak Ridge National Laboratory, ORNL/TM-2018/864, May 2018.

Hunn, J.D., Baldwin, C.A., Montgomery, F.C., Gerczak, T.J., Morris, R.N., Helmreich, G.W., Demkowicz, P.A., Harp, J.M., and Stempien, J.D., 2018c, "Initial Examination of Fuel Compacts and TRISO Particles from the US AGR-2 Irradiation Test," Nuclear Engineering and Design, Vol. 329, pp. 89-101.

Hunn, J.D., Gerczak, T.J., Morris, R.N., Montgomery, F.C., Skitt, D.J., Eckhart, B.D., and Burns, Z.M., 2019a, Safety Testing and Destructive Examination of AGR-2 UCO Compact 6-4-3, Oak Ridge National Laboratory, ORNL/TM-2019/1200, Rev. 0, June 2019.

Hunn, J.D., Gerczak, T.J., Morris, R.N., Montgomery, F.C., Skitt, D.J., Eckhart, B.D., and Burns, Z.M., 2019b, Safety Testing and Destructive Examination of AGR-2 UCO Compact 2-1-2, Oak Ridge National Laboratory, ORNL/TM-2019/1201, Rev. 0, June 2019.

Hunn, J.D., 2019c, Post-Irradiation and Post-Safety Test Examination of AGR-2 TRISO Performance, Presented at Gas-Cooled Reactor Fuels and Methods Program Review at Idaho National Laboratory, June 18-19, 2019.

Idaho National Laboratory, 2019, Technical Program Plan for INL Advanced Reactor Technologies Advanced Gas Reactor Fuel Development and Qualification Program, PLN-3636, Rev. 8, June 2019.

Kercher, A.K. and Hunn, J.D., 2006, "Results from ORNL Characterization of Nominal $350 \mu \mathrm{m}$ LEUCO Kernels (LEU03) from the BWXT G73V-20-69303 Composite", Oak Ridge National Laboratory, ORNL/TM-2006/552, October 2006.

Kercher, A.K., Jolly, B.C., Montgomery, F.C., Silva, G.W.C, and Hunn, J.D., 2011, "Data Compilation for AGR-3/4 Designed-to-Fail (DTF) Fuel Particle Batch LEU03-07DTF", Oak Ridge National Laboratory, ORNL/TM-2011/109, April 2011.

Morris, R.N., Hunn, J.D., Baldwin, C.A., Montgomery, F.C., et al., 2018, "Initial results from safety testing of US AGR-2 irradiation test fuel," Nuclear Engineering and Design, Vol. 329, pp. 124-133.

Ploger, S. A., Demkowicz, P.A., Hunn, J.D., and Kehn, J.S., 2012, Ceramographic Examinations of Irradiated AGR-1 Fuel Compacts, Idaho National Laboratory, INL/EXT-12-25301, September 2012.

Ploger, S. A., Demkowicz, P.A., Hunn, J.D., and Kehn, J.S., 2014, "Microscopic analysis of irradiated AGR-1 coated particle fuel compacts," Nuclear Engineering and Design, Vol. 271, pp. 221-230.

Rice, F.J., Stempien, J.D., Demkowicz, P.A., 2016, Ceramography of irradiated TRISO fuel from the AGR-2 experiment, Idaho National Laboratory, INL/EXT-16-39462, 2016.

Rice, F.J., Stempien, J.D., Demkowicz, P.A., 2018, "Ceramography of irradiated TRISO fuel from the AGR-2 experiment," Nuclear Engineering and Design, Vol. 329, pp. 73-81.

Schappel, D., Terrani, K., Power, J.J., Snead, L.L., and Wirth, B.D., 2018, "Modeling the performance of TRISO-based fully ceramic matrix (FCM) fuel in an LWR environment using BISON", Nuclear Engineering and Design, Vol. 335, pp. 116-127.

Stempien, J.D., Plummer, M.A., and Schulthess, J.L., 2019, Measurement of Kernel Swelling and Buffer Densification in Irradiated UCO and $U_{2}$ TRISO Fuel Particles from AGR-2, Idaho National Laboratory, INL/EXT-19-54502, Rev. 0, June 2019.

Sterbentz, J.W., 2013, JMOCUP As-Run Daily Depletion Calculation for the AGR-1 Experiment in ATR B-10 Position, Idaho National Laboratory, ECAR-958, Rev. 2, September 2013. 
Sterbentz, J.W., 2014, JMOCUP As-Run Daily Depletion Calculation for the AGR-2 Experiment in ATR B-12 Position, Idaho National Laboratory, ECAR-2066, Rev. 2, April 2014.

Sterbentz, J.W., 2015, JMOCUP As-Run Daily Physics Depletion Calculation for the AGR-3/4 TRISO Particle Experiment in ATR Northeast Flux Trap, Idaho National Laboratory, ECAR-2753, Rev. 1, July 2015. 


\section{Appendix A}

\section{A.1 Micrographs from AGR-3/4 Compact 5-2}

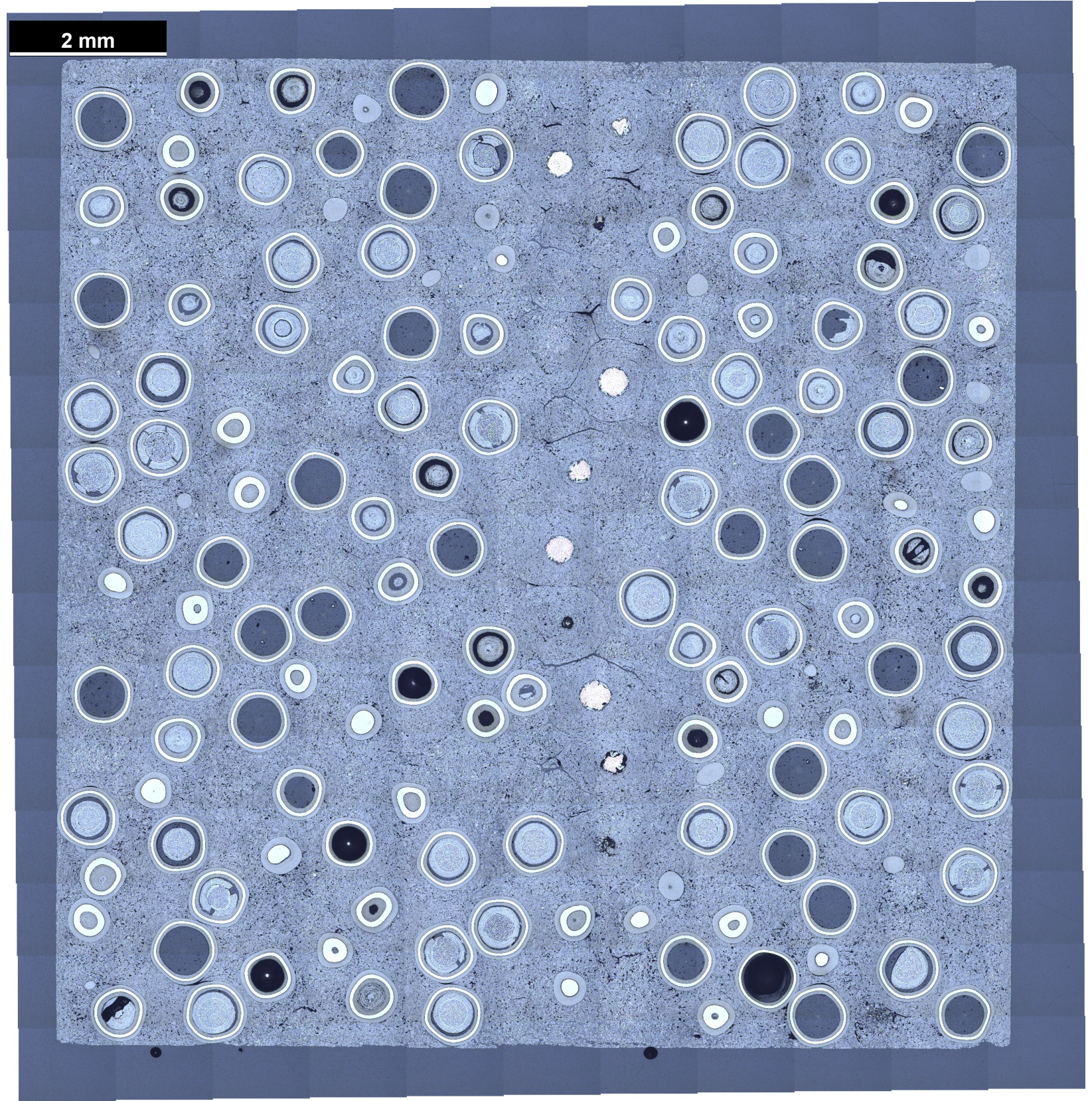

App. 1. Montage of micrographs of the first polished cross-section of AGR-3/4 Compact 5-2. 


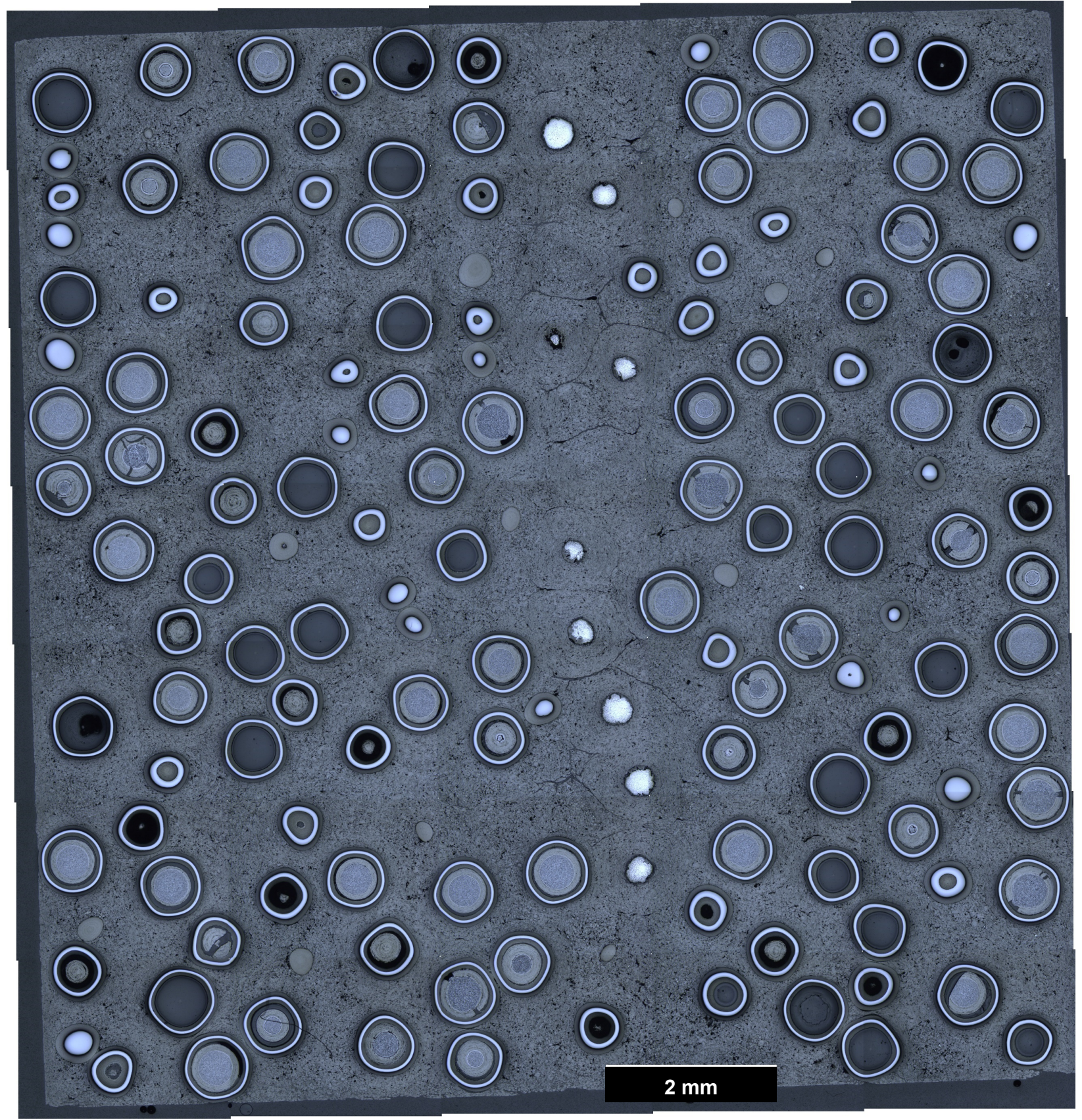

App. 2. Montage of multiple optical micrographs of the entire surface of the Compact 5-2 cross-section after the second polish. 


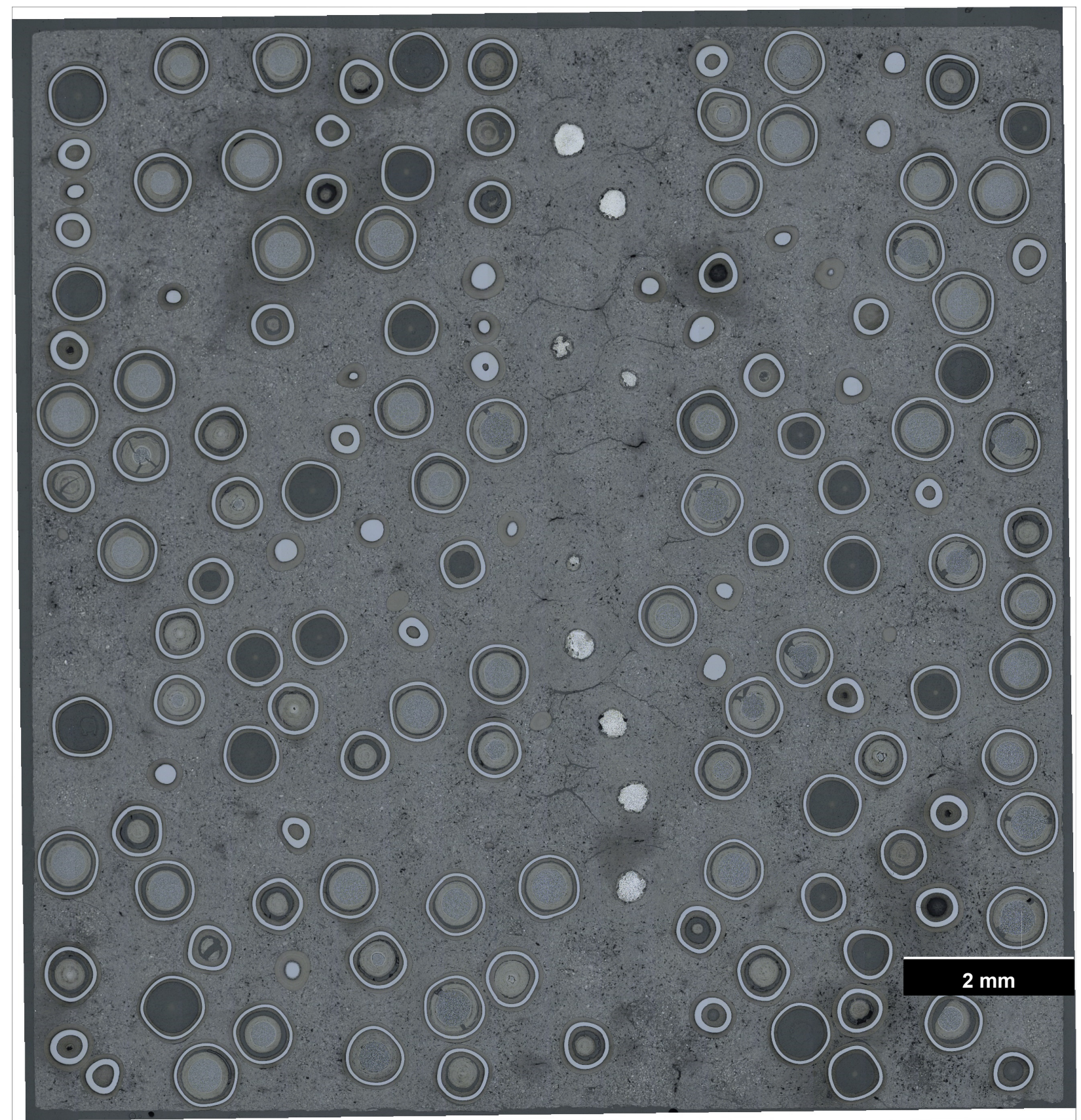

App. 3. Montage of multiple optical micrographs of the entire surface of the Compact 5-2 cross-section after the third polish. 


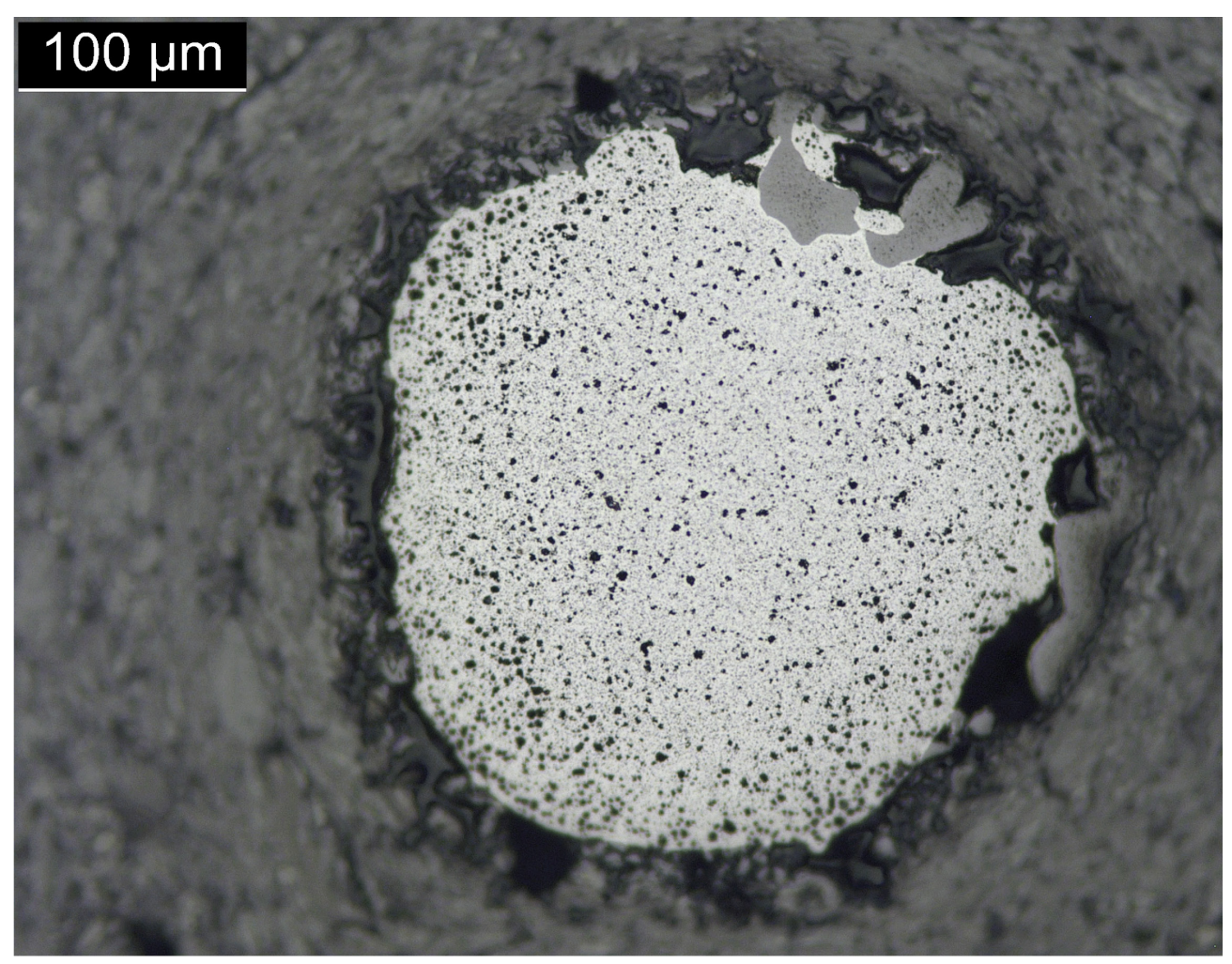

App. 4. Micrograph of DTF 3 from the third cross-section of Compact 5-2.

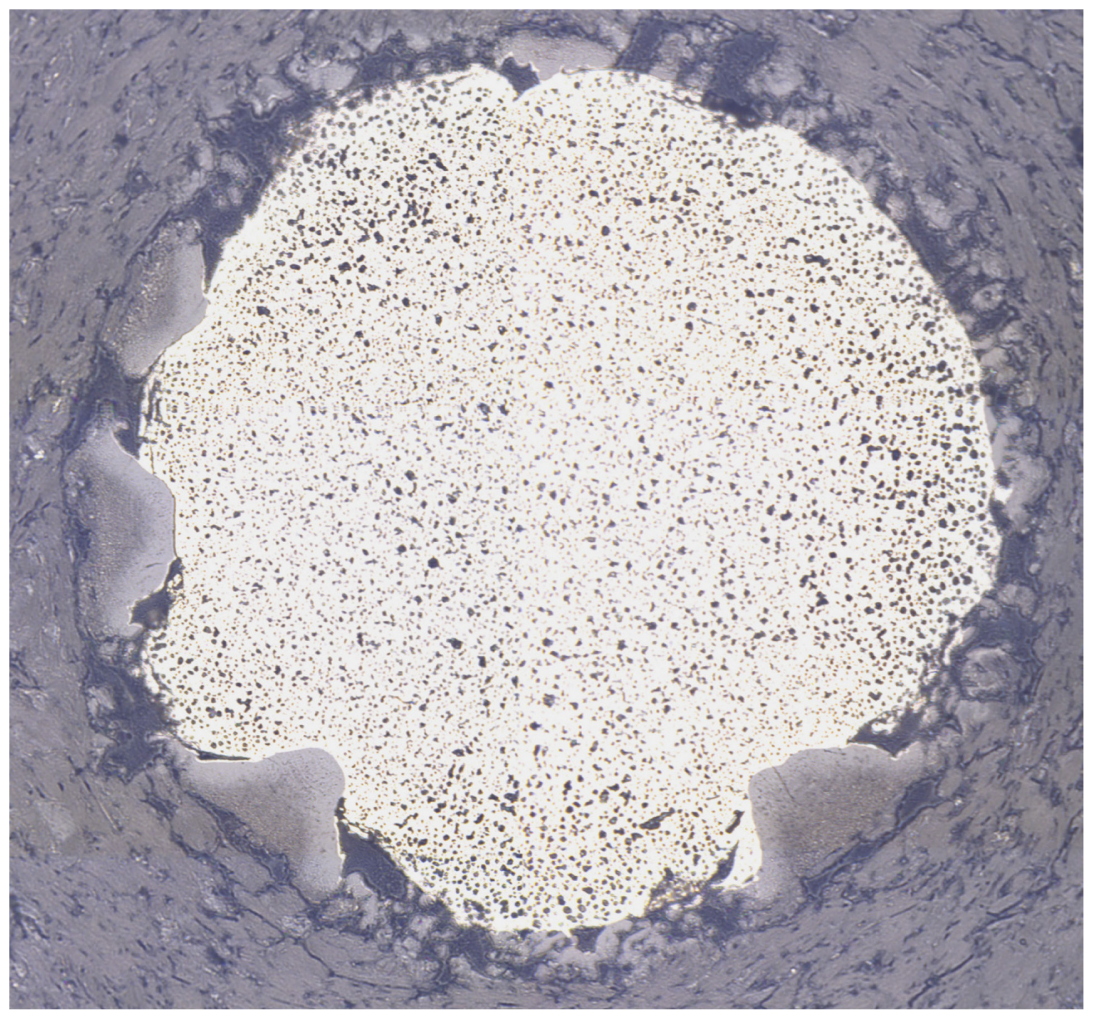

App. 5. Micrograph of DTF 5 from the first cross-section of Compact 5-2. 


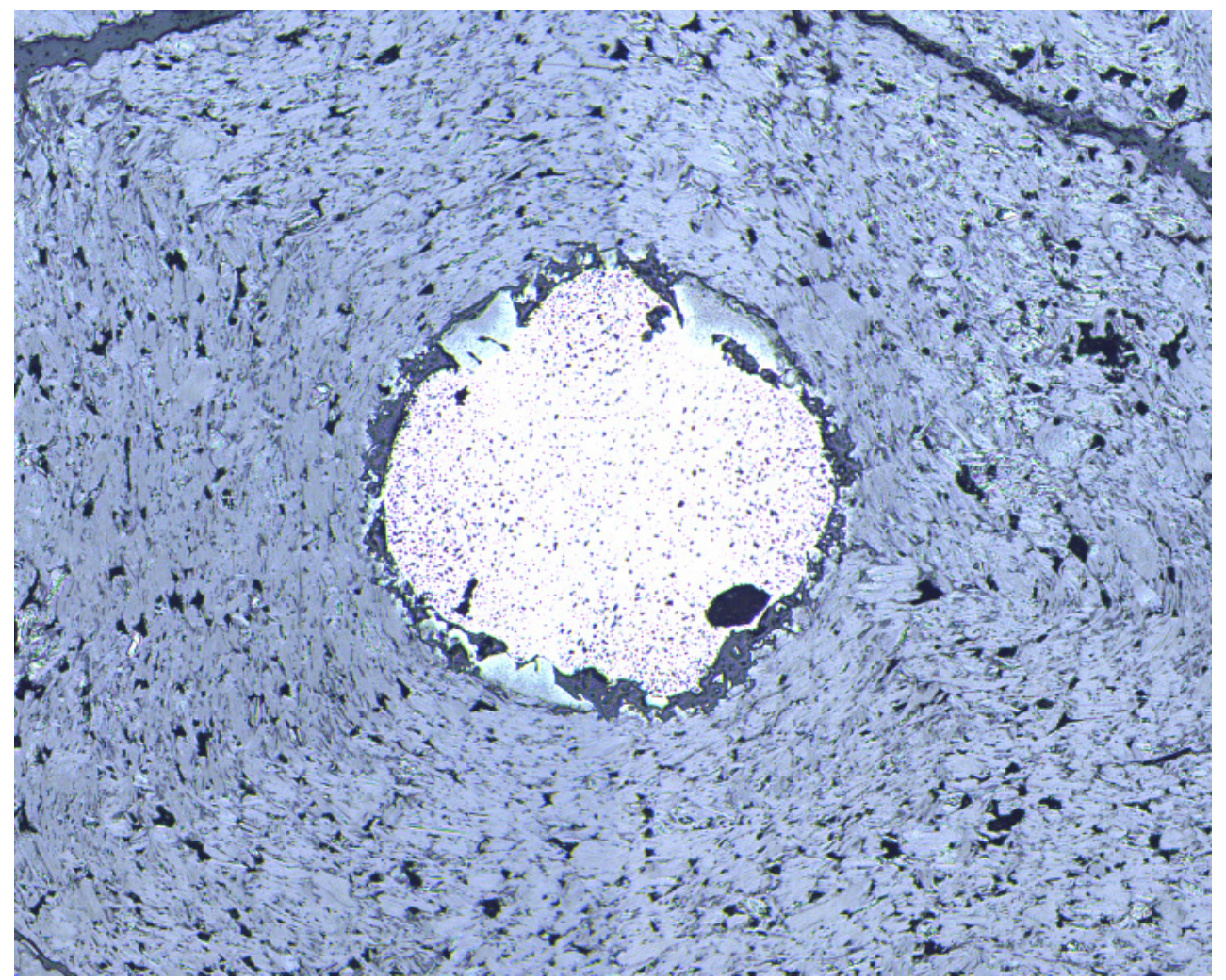

App. 6. Micrograph of DTF 9 from the first cross-section of AGR-3/4 Compact 5-2.

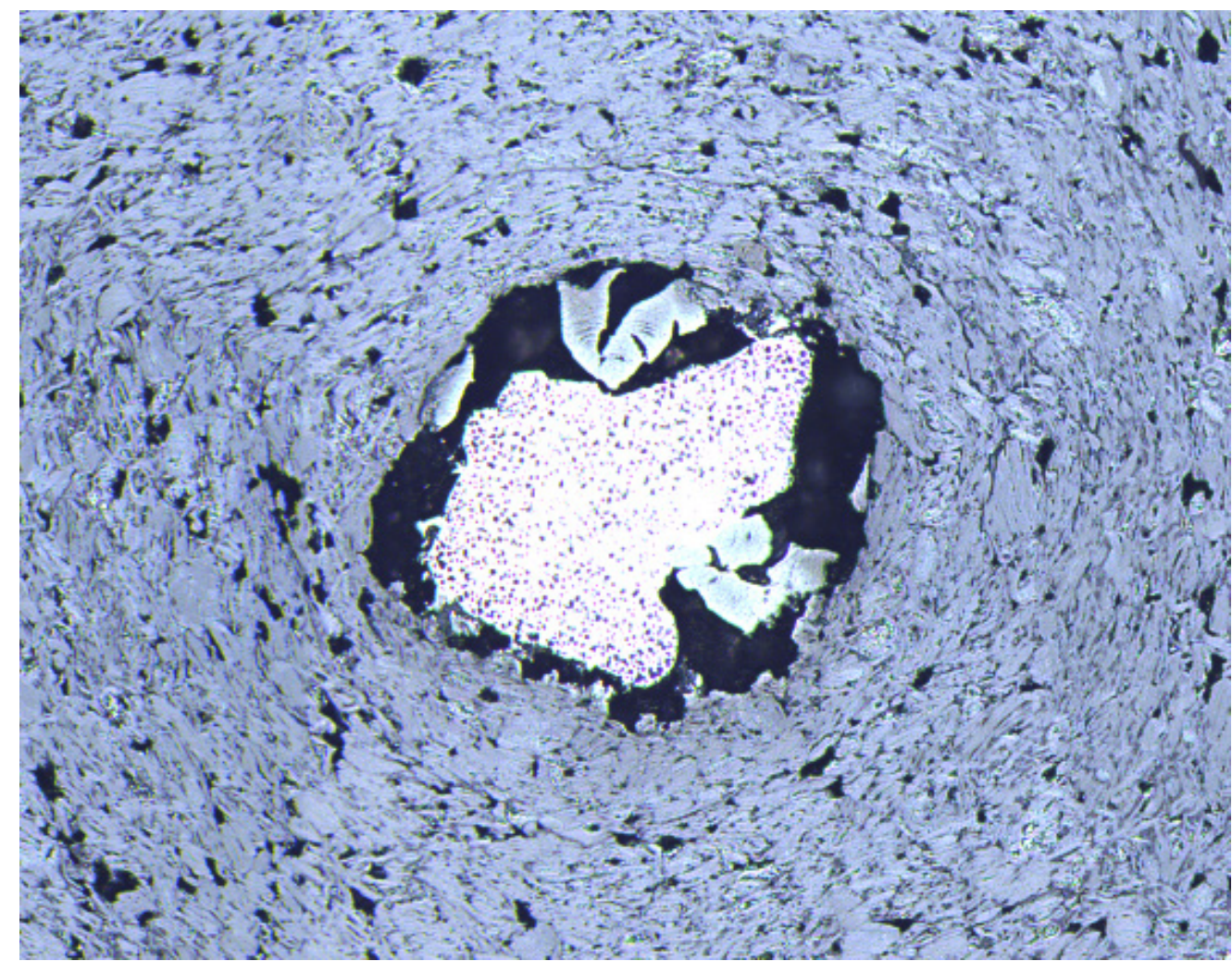

App. 7. Micrograph of DTF 10 from the first cross-section of AGR-3/4 Compact 5-2. 


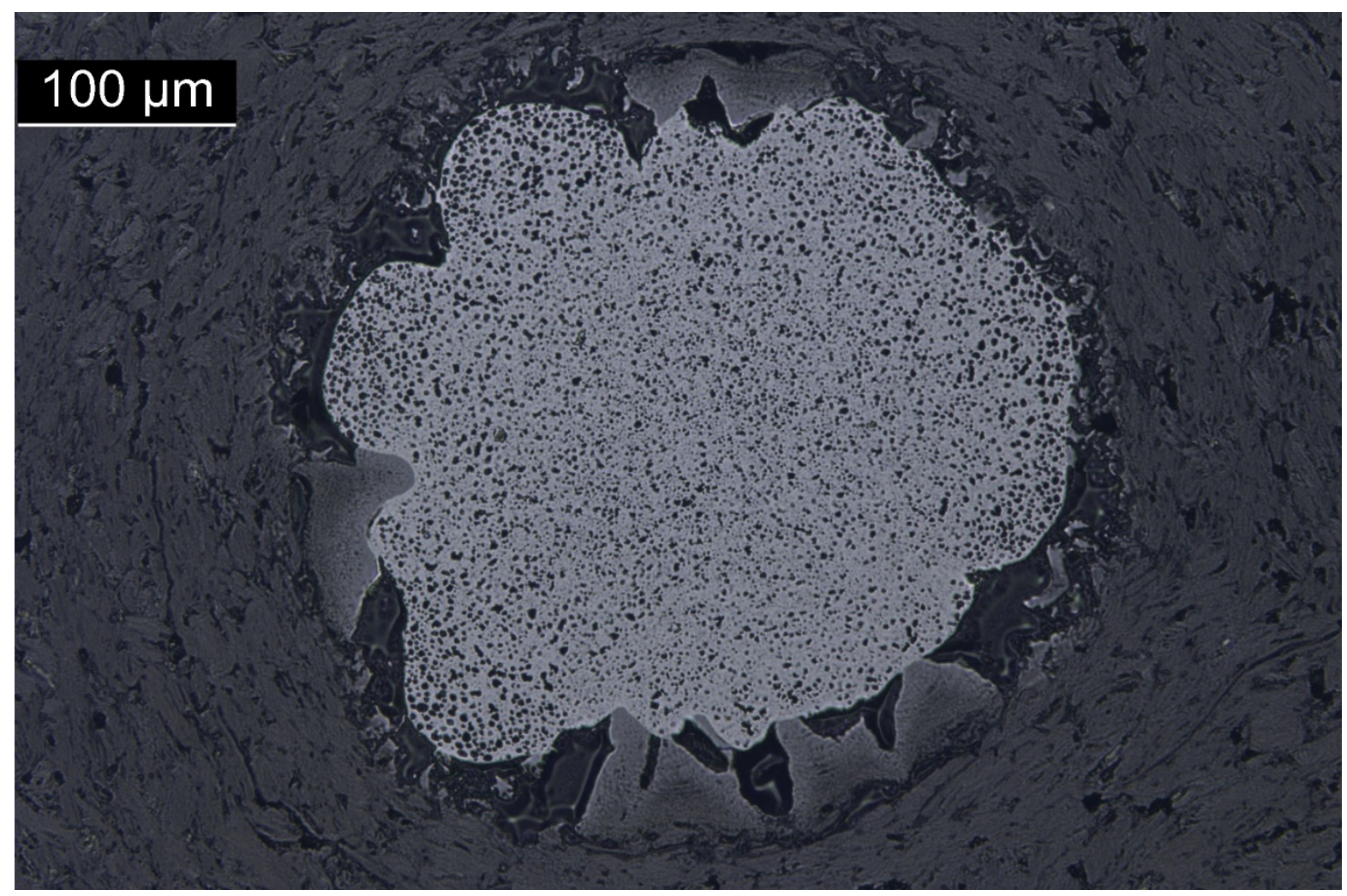

App. 8. Optical micrograph of DTF 10 from the second cross-section of Compact 5-2. 


\section{A.2 Micrographs from AGR-3/4 Compact 7-2}

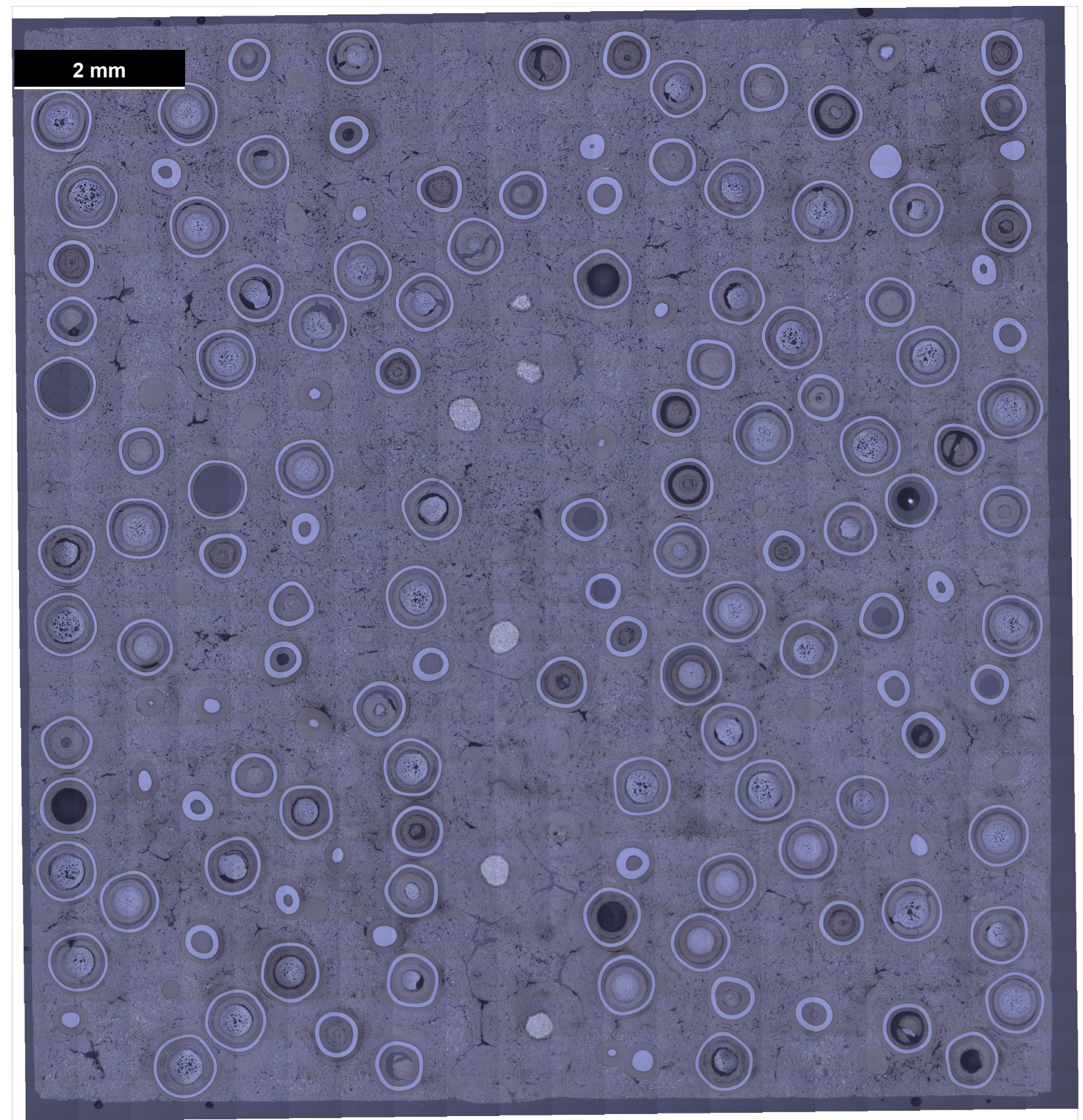

App. 9. Montage of optical micrographs from the first cross-section of Compact 7-2 (MNT80A). 


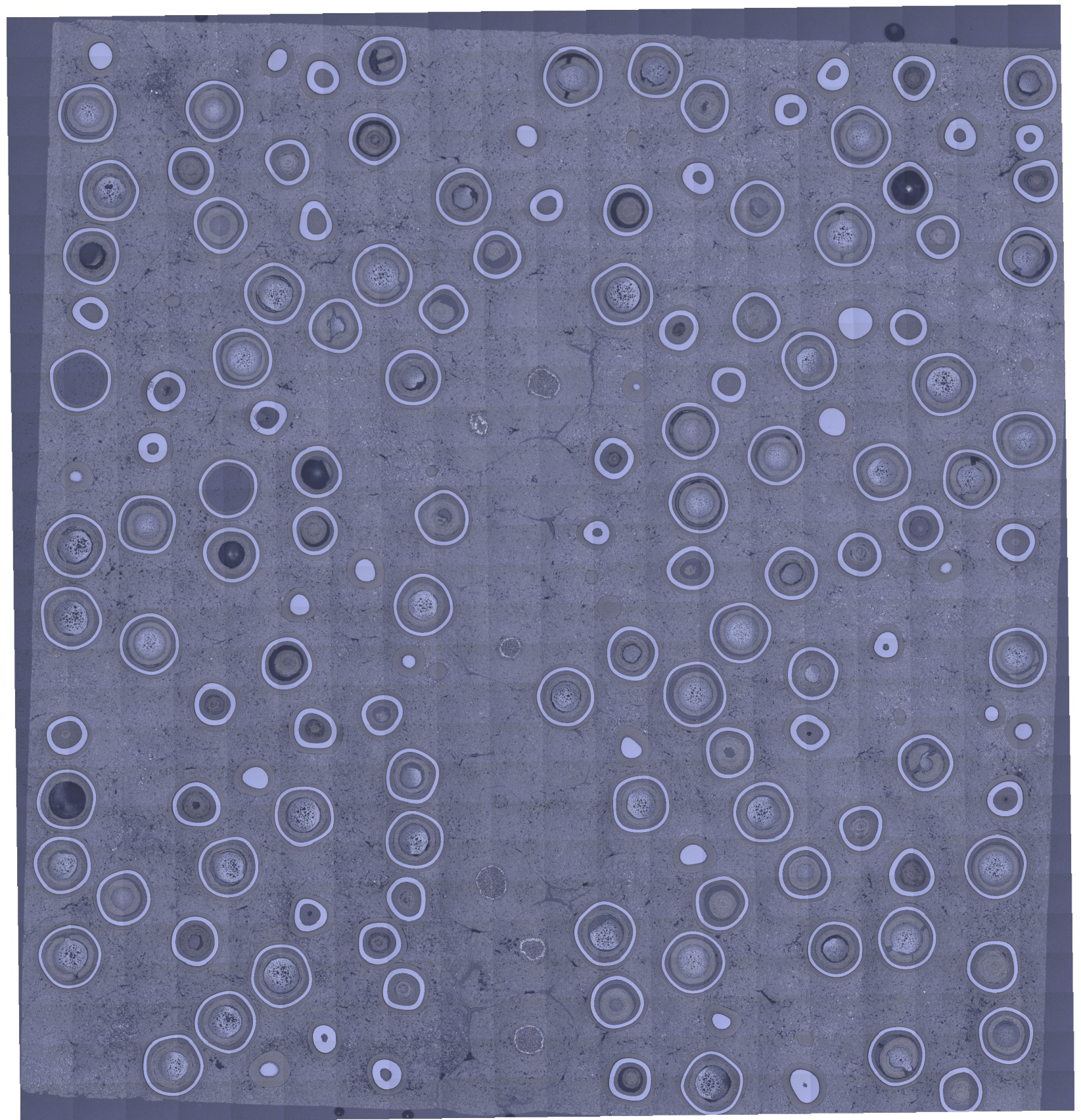

App. 10. Montage of optical micrographs from the second cross-section of Compact 7-2 (MNT80A). 


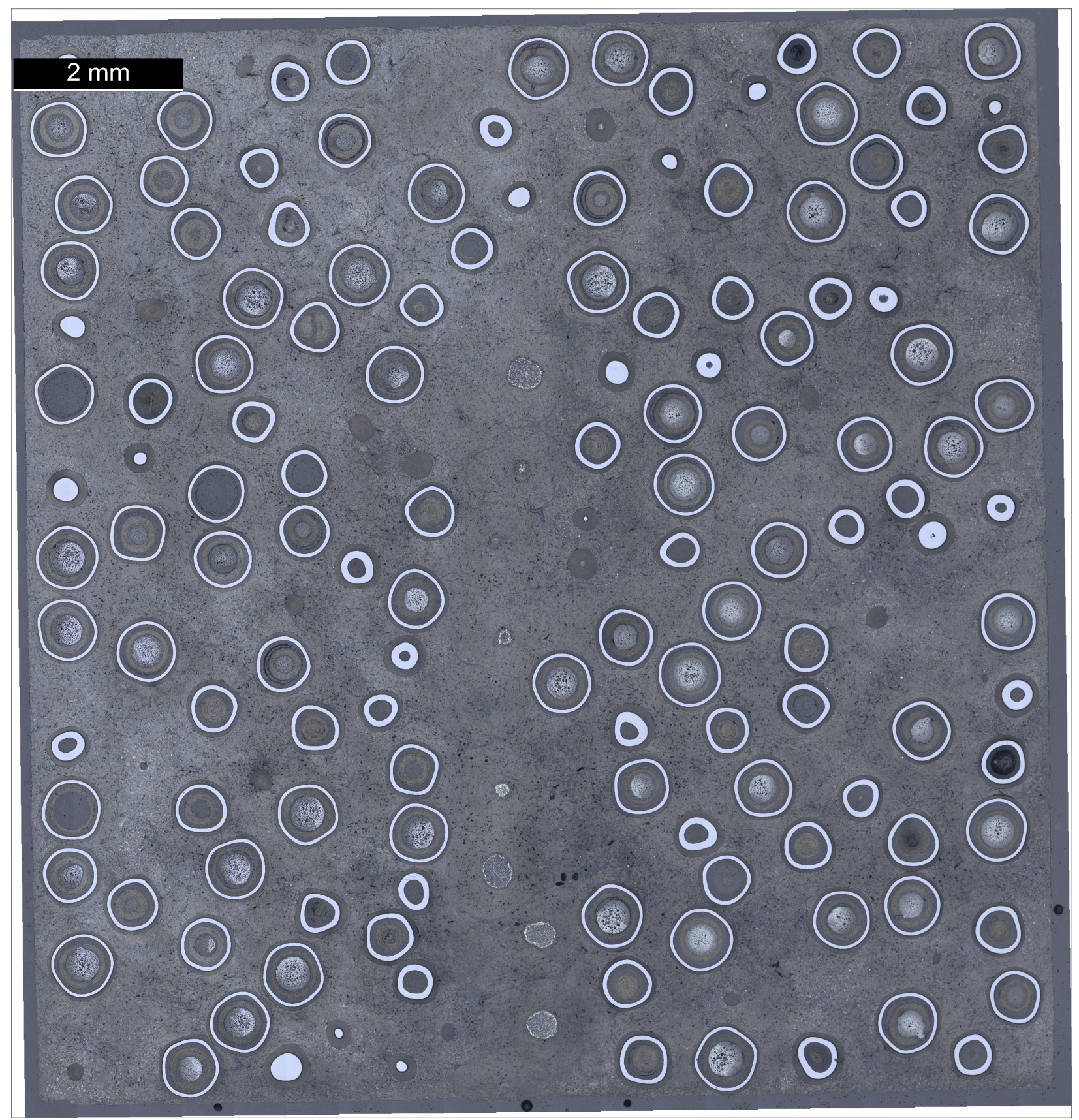

App. 11. Montage of optical micrographs from the third cross-section of Compact 7-2 (MNT80A). 


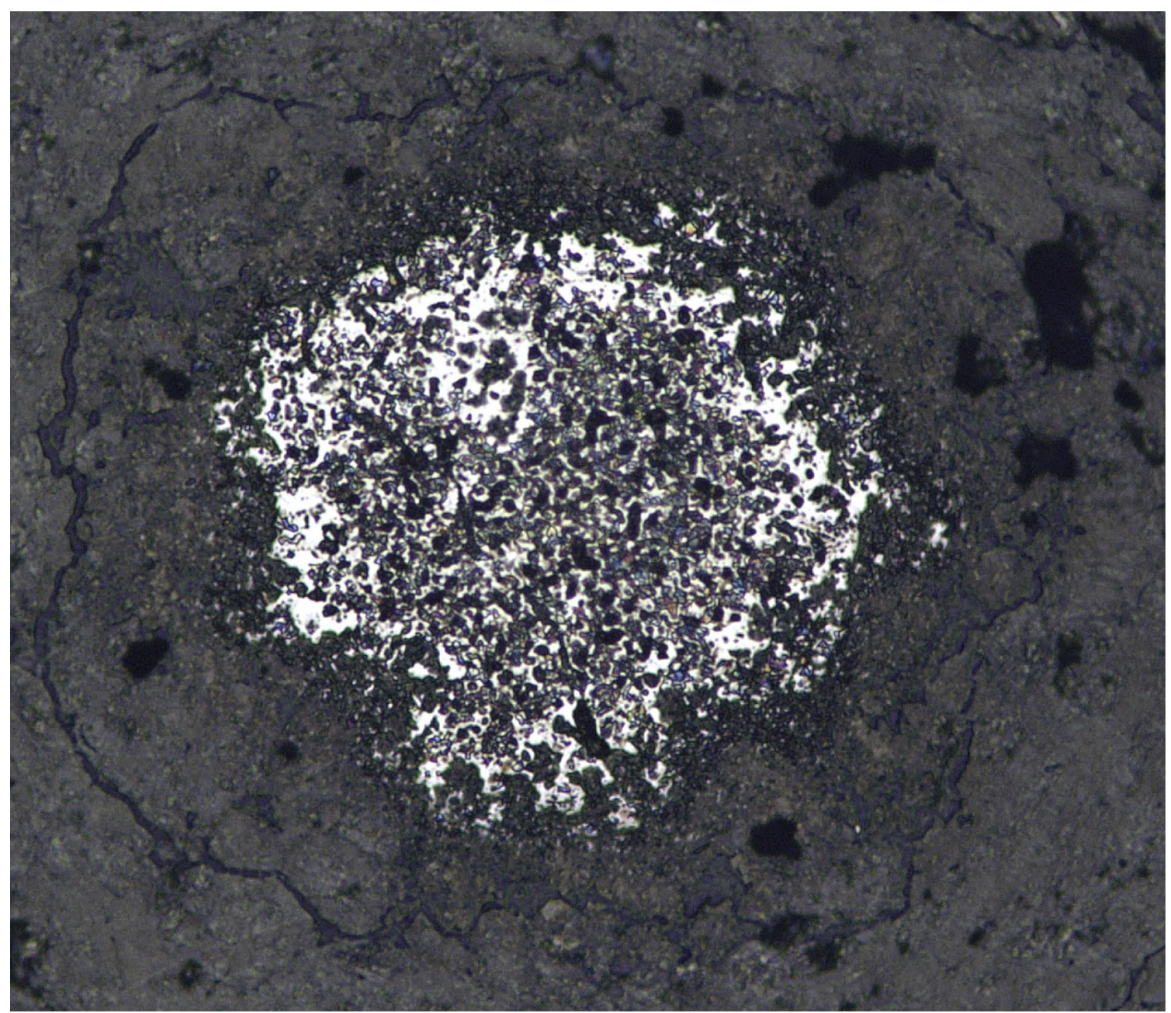

App. 12. Optical micrograph of DTF 7 from the third cross-section of Compact 7-2.

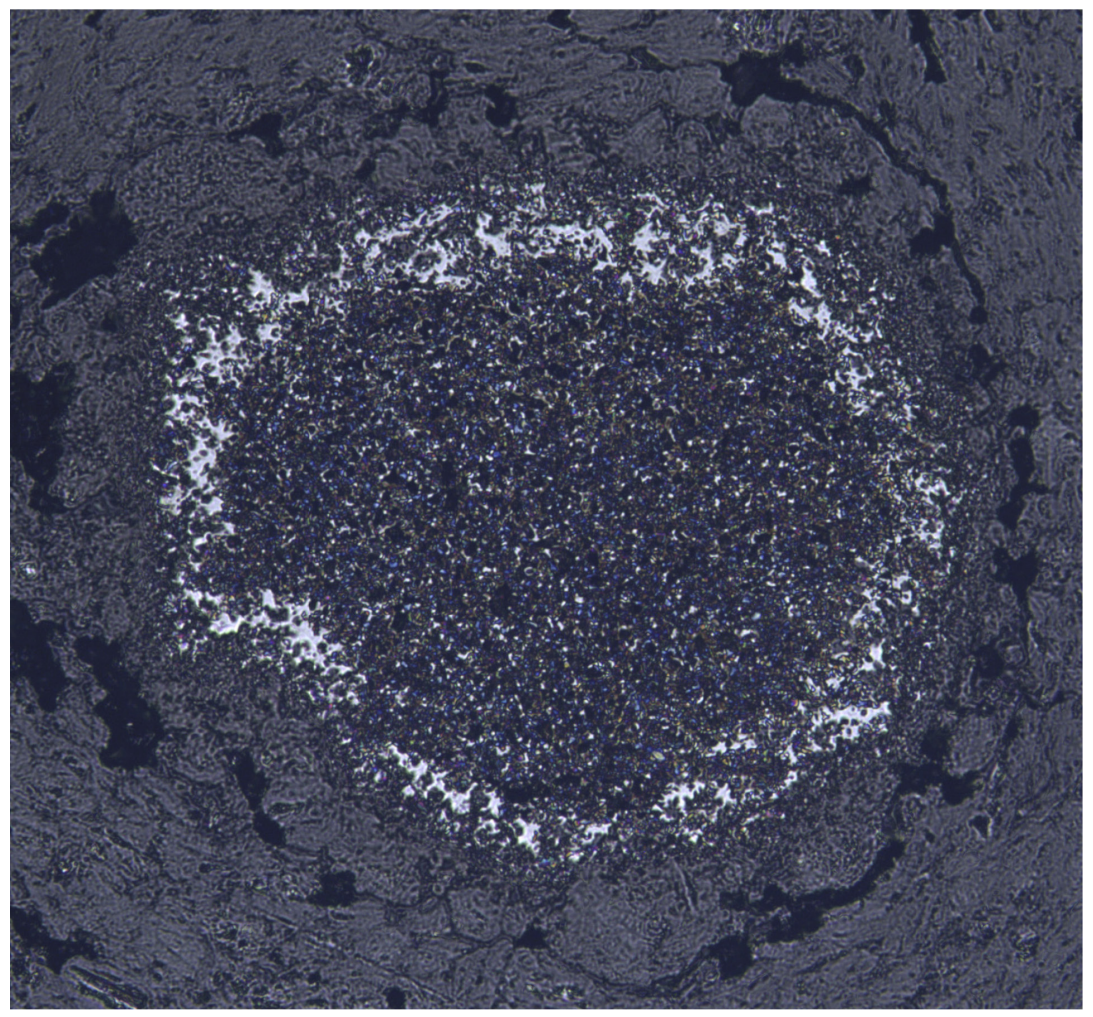

App. 13. Optical micrograph of DTF 9 from the second cross-section of Compact 7-2. 


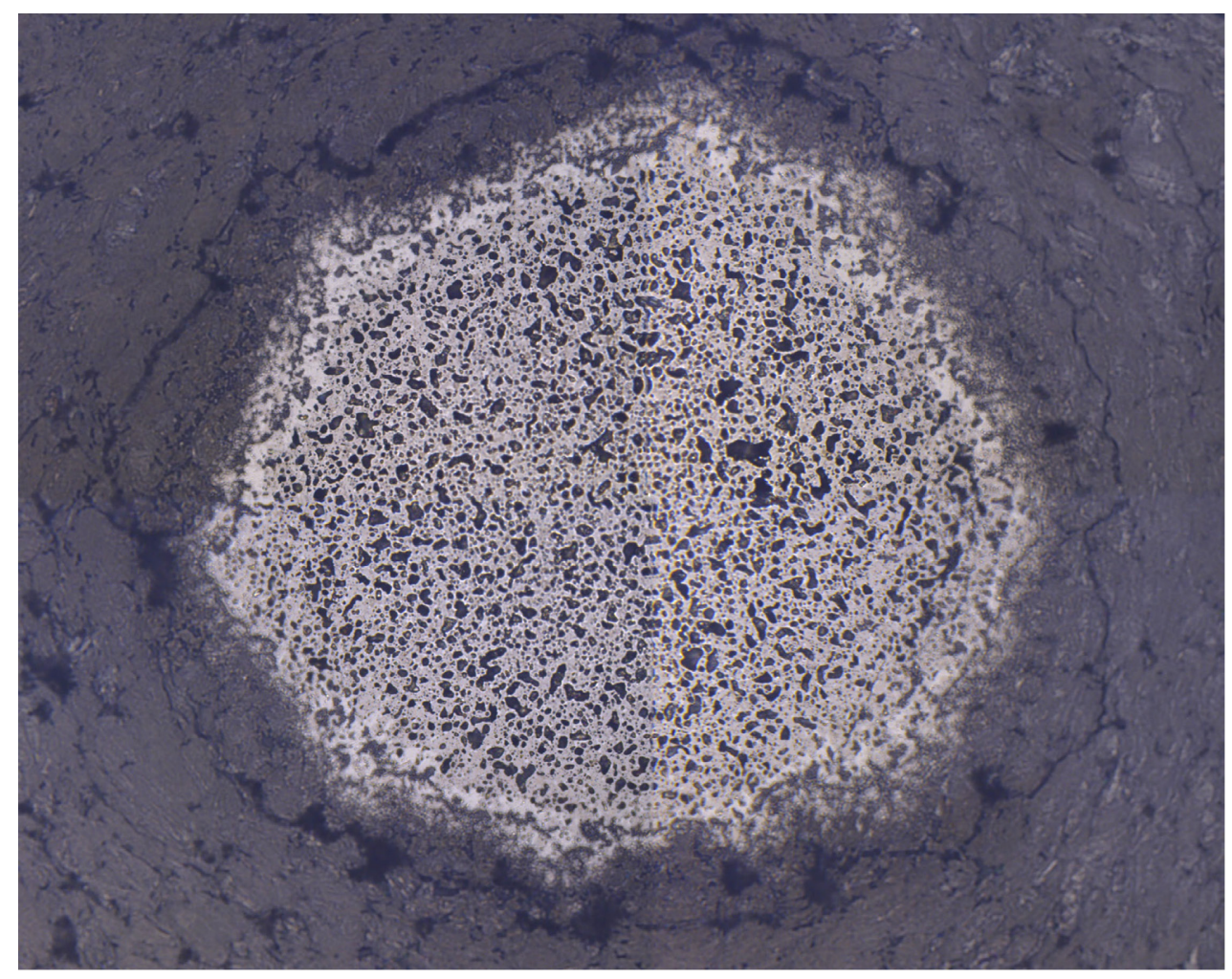

App. 14. Montage of two optical micrographs of DTF 10 from the first cross-section of Compact 7-2. 


\section{A.3 Micrographs from AGR-3/4 Compact 12-2}

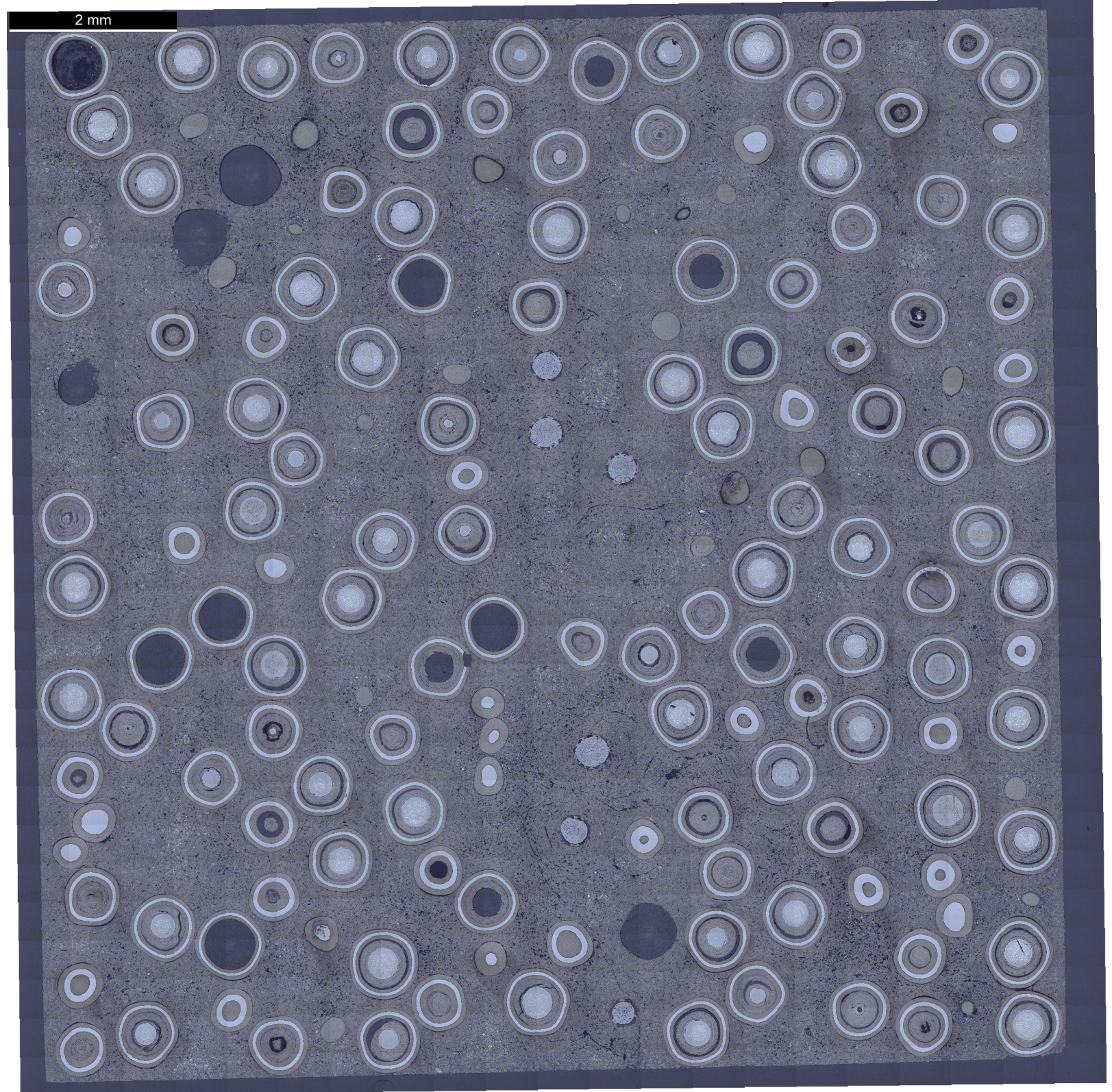

App. 15. Montage of optical micrographs of the first cross-section of Compact 12-2. 


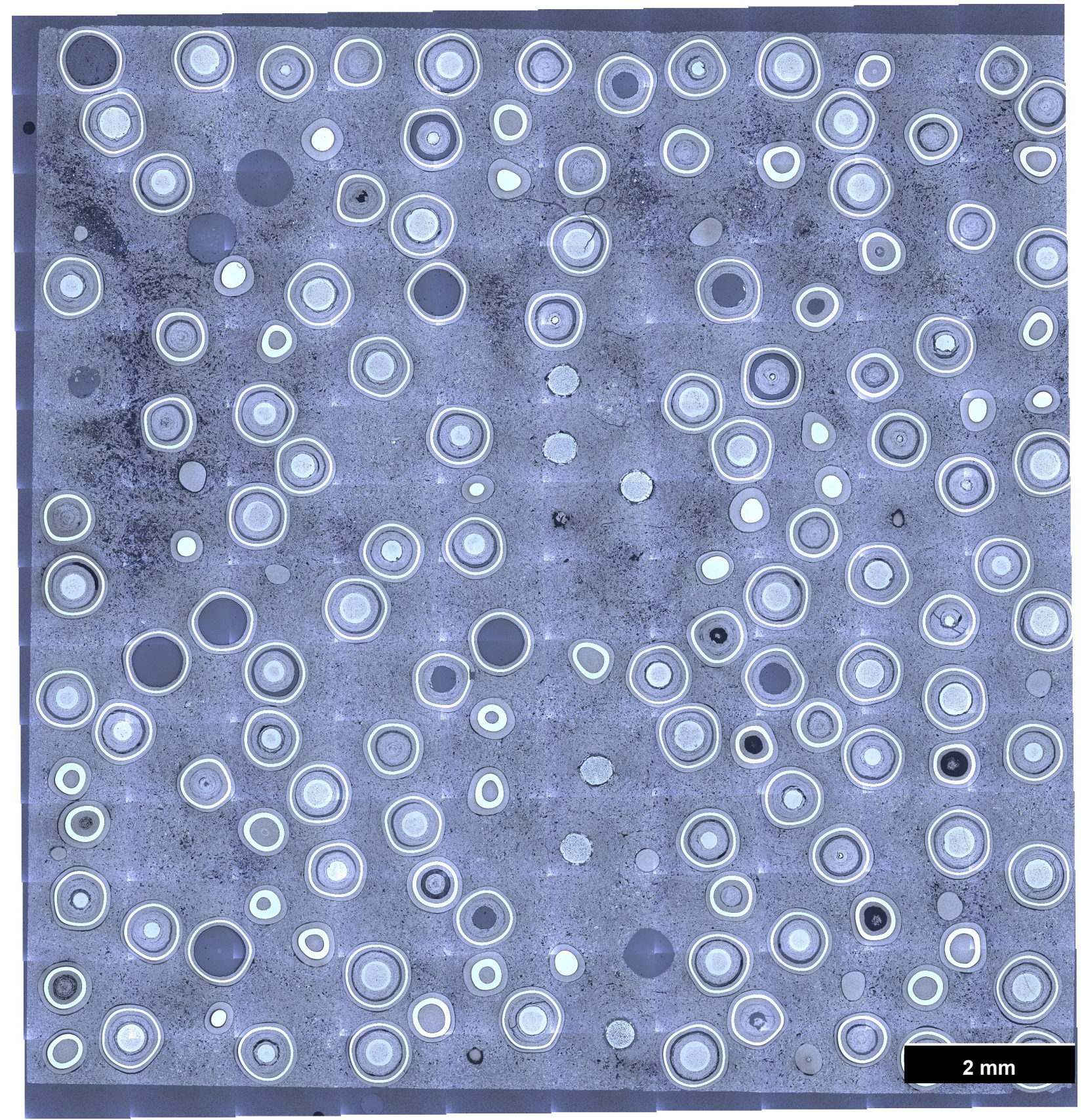

App. 16. Montage of optical micrographs of the second cross-section from Compact 12-2. 


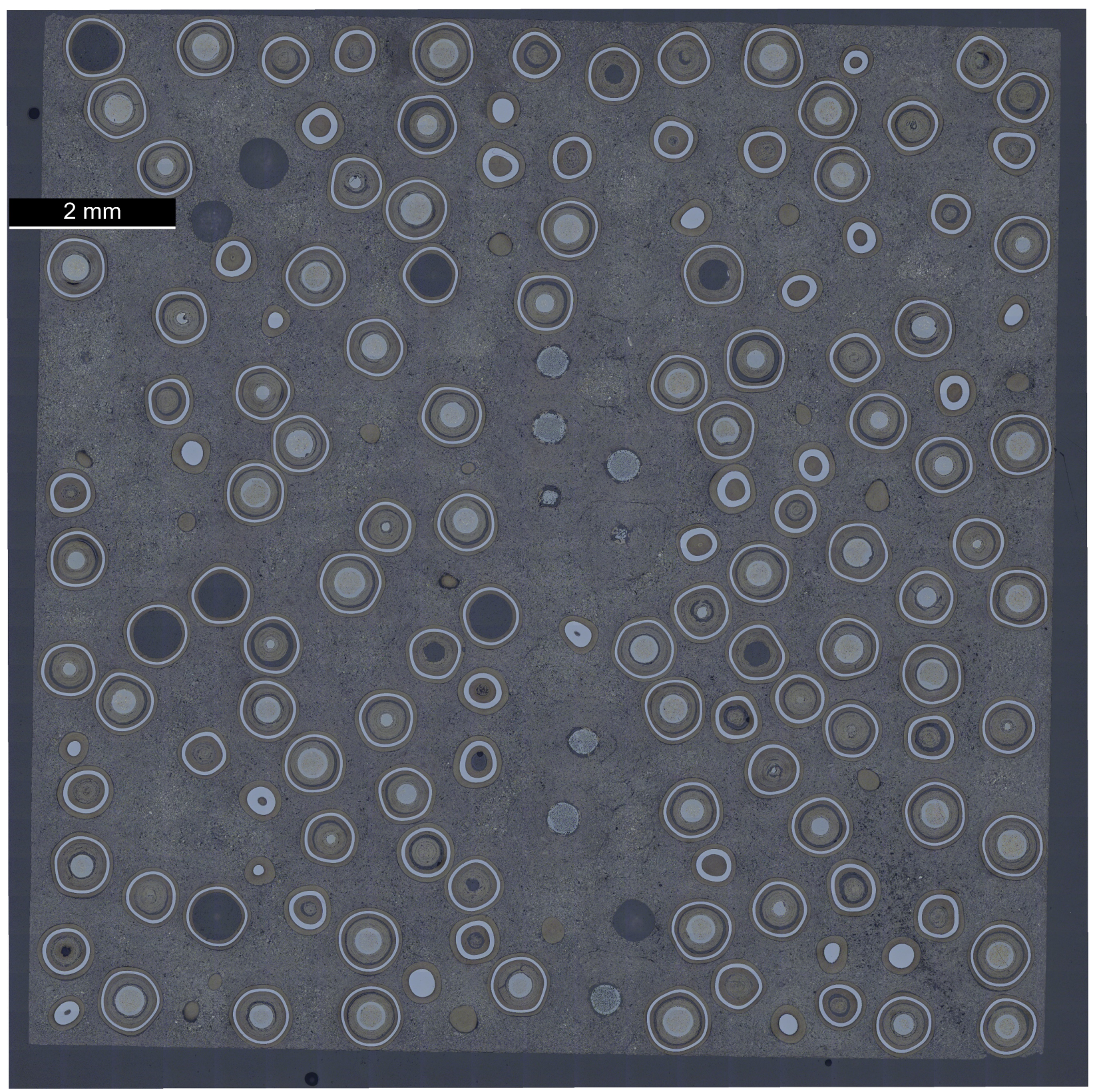

App. 17. Montage of optical micrographs of the third cross-section from Compact 12-2. 


\section{A.4 Buffer Fracture Frequencies for AGR-1 and AGR-2}

Table A. 1. AGR-1 compacts evaluated for buffer fracture frequency.

\begin{tabular}{|c|c|c|c|c|c|c|}
\hline Compact & $\begin{array}{c}\text { TAVA } \\
\text { Temp } \\
\left({ }^{\mathbf{C}} \mathbf{C}\right)\end{array}$ & $\begin{array}{c}\text { Fluence } \times \mathbf{1 0}^{\mathbf{2 5}} \\
\left(\mathbf{n} / \mathbf{m}^{\mathbf{2}} \mathbf{, ~ E}>\mathbf{0 . 1 8}\right. \\
\mathbf{M e V})\end{array}$ & $\begin{array}{c}\text { Burnup } \\
\mathbf{( \%} \text { FIMA) }\end{array}$ & $\begin{array}{c}\text { Buffer } \\
\text { Fracture } \\
\mathbf{( \% )}\end{array}$ & Reference 1 & Reference 2 \\
\hline $2-1-3$ & 988 & 3.77 & 18.4 & 23.3 & Ploger et al. 2014 & Ploger et al. 2012 \\
\hline $3-3-3$ & 1054 & 4.3 & 19 & 22.7 & Ploger et al. 2014 & Ploger et al. 2012 \\
\hline $4-1-3$ & 1075 & 4.2 & 19.3 & 13.4 & Ploger et al. 2014 & Ploger et al. 2012 \\
\hline $5-1-2$ & 1008 & 3.38 & 15.7 & 19.5 & Ploger et al. 2014 & Ploger et al. 2012 \\
\hline $6-3-3$ & 1106 & 2.7 & 13.5 & 34.8 & Ploger et al. 2014 & Ploger et al. 2012 \\
\hline $6-4-2$ & 1008 & 2.17 & 11.2 & 25.2 & Ploger et al. 2014 & Ploger et al. 2012 \\
\hline
\end{tabular}

Table A. 2. AGR-2 compacts with quantified buffer fracture frequency

\begin{tabular}{|c|c|c|c|c|c|c|c|}
\hline Compact & $\begin{array}{l}\text { Safety } \\
\text { Test } \\
\text { Temp } \\
\left({ }^{\circ} \mathrm{C}\right)\end{array}$ & $\begin{array}{l}\text { TAVA } \\
\text { Temp } \\
\left({ }^{\circ} \mathbf{C}\right)\end{array}$ & $\begin{array}{c}\text { Fluence } \times \\
10^{25}\left(\mathbf{n} / \mathbf{m}^{2},\right. \\
\mathrm{E}>\mathbf{0 . 1 8} \\
\mathrm{MeV})\end{array}$ & $\begin{array}{c}\text { Burnup } \\
\text { (\% FIMA) }\end{array}$ & $\begin{array}{c}\text { Buffer } \\
\text { Fracture } \\
(\%)\end{array}$ & Reference 1 & Reference 2 \\
\hline $2-1-3$ & $\mathrm{~N} / \mathrm{A}$ & 1194 & 2.88 & 10.95 & 18.7 & Rice et al. 2018 & Rice et al. 2016 \\
\hline $2-2-1$ & N/A & 1287 & 3.35 & 12.47 & 0.0 & Hunn 2019c & $\mathrm{N} / \mathrm{A}$ \\
\hline $2-2-3$ & $\mathrm{~N} / \mathrm{A}$ & 1261 & 3.00 & 10.8 & 1.4 & Hunn et al. 2018c & Hunn 2019c \\
\hline $2-3-1$ & 1600 & 1296 & 3.42 & 12.63 & 0.0 & Hunn 2019c & N/A \\
\hline $2-3-2$ & 1800 & 1296 & 3.46 & 12.62 & 2.7 & Hunn 2019c & N/A \\
\hline $2-4-3$ & $\mathrm{~N} / \mathrm{A}$ & 1216 & 3.08 & 11.52 & 1.9 & Rice et al. 2018 & Rice et al. 2016 \\
\hline $5-1-3$ & $\mathrm{~N} / \mathrm{A}$ & 1177 & 3.03 & 11.09 & 38.7 & Rice et al. 2018 & Rice et al. 2016 \\
\hline $5-2-3$ & N/A & 1108 & 3.00 & 10.4 & 86.4 & Hunn et al. 2018c & Hunn 2019c \\
\hline $5-3-3$ & N/A & 1093 & 2.90 & 10.1 & 86.0 & Hunn 2019c & N/A \\
\hline $5-4-2$ & N/A & 1071 & 3.14 & 12.03 & 77.1 & Hunn et al. 2018a & Hunn 2019c \\
\hline $6-2-3$ & $\mathrm{~N} / \mathrm{A}$ & 1095 & 2.30 & 8.22 & 15.9 & Hunn 2019c & $\mathrm{N} / \mathrm{A}$ \\
\hline $6-3-3$ & N/A & 1060 & 2.10 & 7.50 & 0.0 & Hunn 2019c & N/A \\
\hline $6-4-2$ & 1600 & 894 & 2.21 & 9.26 & 27.1 & Hunn et al. $2018 \mathrm{~b}$ & Hunn 2019c \\
\hline
\end{tabular}

